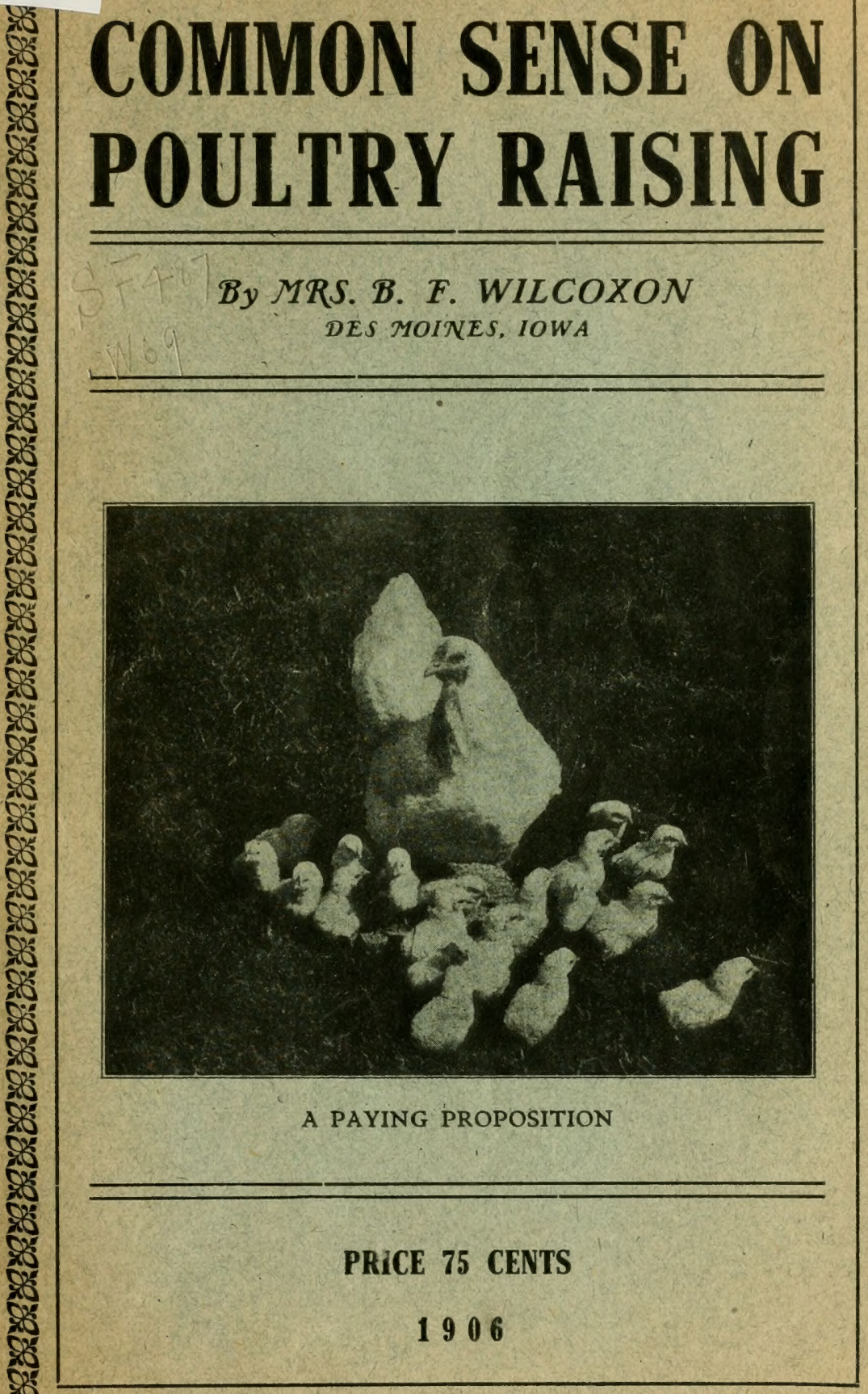


-

Copyright 1906

By Mrs. B. F. WILCOXON. 


\section{Common Sense}

\section{on Poultry \\ Raising}

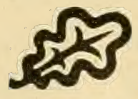

A Practical Treatise on Egg and Poultry Produc= tion-A Guide to Profits in Poultry

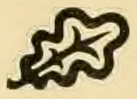

BY MRS. B. F. WILCOXON

PRICE 75 CENTS 


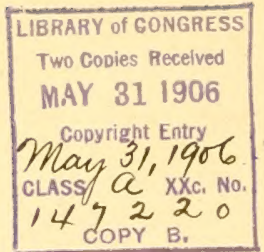

\section{Table of Contents.}

Characteristics of the Poultryman.

Poultry Talks with the Farmer.

Women as Poultry Keepers.

The Poultrymens' Opportunity.

Keeping One Variety.

How to Improve the Flock.

Cheap Poultry Houses and Yards.

Fall, Winter and Summer Care of Poultry.

Process of Moulting.

FOOd ANd Care.

Raising Ducks.

Management of the Incubator and Brooder.

Pian for Brooder House.

Poultry Diseases and Insect Pests

Notes by the Way.

$\therefore \vdots$

Caponizing.

Breeds. 


\section{INTRODUCTORY}

To answer the numerous questions fully and comprehensively that come up concerning the subject of poultry keeping, and other items pertaining thereto, would require a good sized book, and even then would probably not meet the conditions under which all would be placed. I thought perhaps I could give my readers some helpful ideas upon the subject of poultry raising even if not complete information. In order to succeed in poultry keeping, we must serve an apprenticeship, the same as in other lines of business. It is not something that I or any one else can tell you except to a very limited extent, and even then if you lack experience yourself, you cannot discriminate between that which is good and suitable to your conditions, and that which is not. Take as an example, the kind and number of houses. It would be impossible for one unacquainted with locality and surroundings, to say what would be the most desirable size and style of houses to build, knowing nothing of the lay of the land, the cheapest procurable building material, the breed of fowl to be kept, whether of the large combed varieties or small, whether for eggs, meat or exhibition, and whether to be kept yarded or on free range, and the amount of money to be appropriated for building purposes. Let us stop and consider the varying propositions contained in the above, and the amount of time and thought that would necessarily have to be expended to place the matter before you in a manner that would assist you in forming correct conclusions of your own; let us remember that this is only one of the subjects of many which confront the poultryman. You will realize the magnitude of the task before me. The best advice I can give on the subject is " go slow," and the old familiar adage, "Look before you leap." You will no doubt find many pleasures as well as some vexations and some losses, even on the whole profitable, and that as a general rule the profits will be in proportion to the intelligent care given, and to the careful consideration of seemingly unimportant details. Experience is the best and only genuine school. Old breeders can only give the beginner pointers to work by. There is no royal road to poultry culture. There can be no fixed method of feeding or breeding fowls. Success comes from right methods, and these methods must be learned in the school of common sense application.

Wishing you success in your poultry operations, I remain,

$$
\text { Yours truly, }
$$

Ft. Des Moines Poultry Farm,

MRS. B. F. WILCOXON. Des Moines, Iowa.

April 1st, 1906. 


\section{Characteristics of the Poultryman}

In the poultry business many obstacles arise from time to time that almost cause one to seek other vocations in life. There is just as much hard work in it, both mentally and physically, as in any mercantile business. Mentally in trying to solve the problem why every egg did not hatch, why some chicks die in the shell, and how and what to feed to obtain the best results. Physically in keeping the poultry houses clean, feeding and watering the stock.

No season is without its cares, but at certain times lack of eare is most disastrous. Houses should be cleaned at all seasons. Warm weather increases the degree of filth, and with it lice and mites appear. If those who have made a success in the poultry business would tell of the failures which led to their present position there would be fewer people going into the business one year and dropping out the next. If they had known what to expect, the probability is a less number would start, and those who would, would more than likely make a success of it. As it is, most people get an idea that the poultry business is all sunshine. This is all right until after they have made a trial, then it is altogether different. I have seen enough to convince me that it is not all sunshine. I do not say this to discourage any one intending to enter the poultry field, but rather to encourage and point out the difficulties that are sure to present themselves. Poultry is not hard to raise if you only use common sense. There is no success without great labor, and no one should go into the poultry business unless willing to work. There is no occupation that requires more nerve and ability to look after all the "little details" than the poultry business. There are poultry raisers on all sides who get into careless, "slip-shod" habits of management which result in nothing but failure. One must exereise "eternal vigilance", and study the life and habits of fowls. Yards and houses are as bare as use can make them.' The feed given in winter is corn for breakfast, dinner and supper. This is thrown on the bare ground, with ice water to drink. Under such eircumstances poultry go to roost in a half frozen condition, shiver through the night, and the next day the owner wonders why he did not get eggs when the hens had all the corn they wanted. A knowledge of chemistry and seience goes well in the poultry yard. We should have faith in our business and ability, work with eyes open, strive for a purpose. If any man who has been at all successful in any stock line would only stop to think that should the same energy and thought be devoted to the poultry business that is given to any other class of live stock the profits can not help but be satisfactory. A man whose ehickens are found on the warm side of a barbed wire fence is the one who swears that poultry does not pay. "Is there money in poultry keeping?"' is a question that is often asked. One person was known to reply that there was because he had put it there and had never been able to get it back again. But I can say that I know there is money in poultry because I have gotten money out of it. Keep an account. A person who cannot go to that much trouble seldom succeeds in anything. Keep an account of all poultry expenses, so you can tell how much profit there is in it. 


\section{Poultry Talks With the Farmer}

The cost of raising poultry is small when compared with the high prices they command. For the small amount of money required I know of no other legitimate business that will bring quicker and better returns than poultry. It is a sure business when one understands it, because you can generally control the conditions which assure success. There is money in poultry and will be for years to come. The fact that many fail to make a "go of it" is what makes it profitable.

The demand for poultry is greater than the supply, and so long as this is the case the careful, hard working man or woman will reap the results, while the indifferent will fail. The conditions and circumstances surrounding different persons make it impossible for any one to lay down fixed rules that would be a sure guide to those who seek success; every one must work out his or her own salvation. There are thousands of poultry keepers in the United States, no two of whom possess the same degree of skill. I have a way of my own. It may not come up to what a great many of you have experienced. Nevertheless I get good results and that is what we are all after. One of the few trades in which the demand for skilled labor is in excess of the supply is that of the poultryman. To keep the hens in laying condition is the aim of every poultry raiser during the winter months when a full egg basket means so much. The hen that lays eggs that are worth from twenty-five to thirty-five cents per dozen is the hen to breed from, rather than the hen that lays eggs that are worth only twelve to fifteen cents per dozen.

The strain must be back of the flock. It is possible by selection, careful breeding and scientific feeding to double the number of eggs which the hen will lay. Give the hen the right treatment and she will repay every kindness if she is the right kind. Feed for eggs. If she does not respond sell her and get the right kind.

No other problem in our poultry experience has been so difficult of solving as how to feed. There are two things necessary to produce large quantities of eggs. First, proper food and eare; second, a strong constitution, one which will enable the fowls to digest and assimilate a large amount of food. The moulting season of the hen is about as good an indication of her vigorous constitution as ean be found. If she moults in a short time and scarcely stops laying at all she is worthy of being selected as the mother of a great nation and can be safely bred from. If she takes a long time to moult, is " off her feed," she is weak, and the sooner you get rid of her the better. In feeding for egg production a valuable lesson may be learned from nature. If we notice fowls that receive the least eare and attention laying most of their eggs in the spring time, notice the conditions surrounding these fowls; the weather is warm, they have plenty of green food, more or less grain, insects, plenty of exereise and fresh air. Endeavor to make it spring time all the year round. Provide a warm place, not warm by artificial heat, but made as warm as possible. Give the poultry proper proportion of green food, such as vegetables, grain and meat (milk in various forms will take the place of meat), grit, fresh air and plenty of exercise. A great many make a mistake in feeding too much corn. Get a chemical analysis of the egg and various foods, study them with an eye to the demands of your flock and cost. This will keep you figuring a day or two perhaps. Judgment is a good thing to mix the food with. Chickens should be made to work for every grain they get. To make them do this throw it in a deep litter. Chickens, like people, do not thrive on a perpetual diet of food the year round. If those who fail to get eggs will try the above bill of fare they will be amply paid for their trouble.

Laying hens in winter require extra care and attention. Where a great many people fail is in not properly protecting their fowls from sudden changes of the temperature. Weather conditions are very change- 
able. It is not the extreme cold weather that checks egg production, but the sudden changes which in nine cases out of ten may be avoided by keeping the hens in their houses when the thermometer gets to zero and lower.

There is a large demand for choice breeding stock at good prices, and those who have carefully bred breeding birds, which have been properly mated and advertised, are able to sell all the eggs they can spare at profitable figures. The poultry business is not one which ean easily be overdone, for only those stay in it who have the natural qualifications for it and have grit enough to stick to it along the right lines until they win out.

It is evident that exercise is the only method to develop muscle, and make a strong, healthy chick. Without these qualities you cannot grow chicks well developed at a period in their existence that will pay the most revenue for the time and money expended.

See that the breeding males get extra feeding. It is some trouble to look after our breeders properly, but it is more trouble to throw out unhatched eggs and dig graves for dead chicks.

No brooder is big enough to care for more than fifty chicks except for a short time. That is as many as should be in one flock, no matter how large the space. Twenty-five in a flock is just one hundred per cent better for the chicks than fifty, but the best plan sometimes costs too much. Use good sense and strike a reasonable average that is compatible with conditions.

Many a brood of promising chicks is drowned in a drenching rain. The loss from this cause each season is very great. Provide shelter for the youngsters.

With modern methods there is absolutely no reason why the hatehing and rearing of chicks should not be continued during the entire year, eare being taken to use strong, fertile eggs for hatching.

\section{Women as Poultry Keepers}

As woman is ever the home-maker, it is upon her that ordinarily devolves the responsibility as well as much of the actual work of poultry keeping. Our cities contain thousands of women who would fain contribute something to the family support, but are unable to do so. To such, a removal to the country and the founding there of a little home with a big poultry yard may present itself as the simple solution of a serious problem.

An instance or two coming under the writer's own observation will be of value upon this point. One woman who devotes a few odd moments each day to some three dozen hens shut up in a very small enclosure elears $\$ 80$ in pin money annually. Another raised 700 chicks from 25 hens in one season and sold $\$ 375$ worth of eggs during the same period. In the following August, September and October she sold $\$ 600$ worth of stock, keeping about 150 of her best hens for the next breeding season. In the months of January, February and March she sold $\$ 421.75$ worth of fowls. A Missouri farmer's wife has elothed and fed herself, her husband and three children for thirty-five years by means of her poultry and cows, and this with common stock only. At the commencement of their married life the hens and cow were the only estate of herself and husband not covered by a mortgage. "When I bought that eighty acres of hazel brush and scrub oak," her husband is wont to say, "If I had been sold out under the hammer my ereditors would not have realized one per cent upon what I owed them, and but for the wife, the cow and the chickens I never could have paid for this little farm,"

Coming to the practical question of how much ground would be required for a poultry yard of modest dimensions and the cost of stocking 
it, one may begin with a lot 50 by 100 feet, make the buildings for it out of boxes, or lath and tar-paper tents, and stock it with two dozen common, one-of-a-kind hens at an expense of $\$ 6$. For one who knows nothing at all about chickens it is best to begin with common stock. After the experience gained with these during the first season the best are none too good. With enough capital to do so and some experience it is just as well to begin with the best. But at the very outset the novice not only has formed no valid opinion as to the relative value of the various breeds of poultry. but is generally in the dark as to the most reliable sources of supply. In buying eggs of a recognized breed it is well to remember that the cheapest at the outset are by no means always so in the end. It pays to deal with reputable poultry raisers. Subseribe for some of the leading poultry journals, but do not believe all that you read, acting only upon the advice which common sense tells you is practical. Note who are the advertisers and who are the exhibitors. Get acquainted with the breeders. Note whether the exhibitor at a poultry show is a breeder or merely a dealer, one who buys and sells, but knows nothing about the successful breeding and rearing of the stock he exhibits. To make a success of poultry raising you must get before the public; you must exhibit; and you must advertise. All this is expensive, but it pays and pays well. When you have succeeded in establishing yourself in this way you may begin to consider whether you care to become a fancier.

Women are generally more successful than men because they are aceustomed to occupy themselves with little things and know the importance of patience and perseverance. In a certain district conveniently located to one of our large cities, the farmers' wives make more money on eggs and chickens than their husbands do from the cultivation of the soil.

Women are always glad to do something toward the support of the family, but the trouble is that in retired districts they have so little experience in the ways of the world that they are unable to form practical plans and to execute them unaided, and it is generally extremely difficult to persuade their husbands and fathers to co-operate with them. For it must be understood that the profits above referred to cannot be realized unless some special preparation be made for the accommodation of farm poultry. The head of the family must attend to the marketing, provide all necessary supplies, etc.

We therefore urge upon men to start their wives and daughters in the business by furnishing them with the means and help required in such an undertaking. Furnish them with a good poultry periodical, and success can be assured, while work on the farm will not be retarded, and an income will be derived from a new field of stock raising.

\section{The Poultrymens' Opportunity}

Into the business life of every owner of hens come at times chances to increase the profits. The wide-a-wake man is on the out-look for these opportunities and takes advantage of them. The man who plods along year after year, feeding as his father did, selling just as he did twenty years ago, keeping the same grade of birds, may get a dollar a year profit per hen.

Is there progress in poultry keeping? Read the market reports. Look at the advertisements in our pages today as compared with those of five years ago. What was said three years ago about dry mashes? Did you hear of dry chick foods ten years ago? Was the thoroughbred bird so largely in demand on the poultry farm of your childhood days? How did the winter prices of eggs in the last five years of the nineteenth century compare with those of the first five years of this? 
The poultry keeper of today must keep his eyes wide open to make the most of the times in which he lives. He must know something of feeding values of the various articles that can be used in his rations, that he may intelligently buy as prices change from season to season. He should understand the limits of his birds so that in his efforts to increase the egg yield he does not injure his birds for breeding. He must know much about the various breeds as suited to meet his market demands.

The man who would do all this cannot lean entirely upon the knowledge gained by past experience, cannot accept as true all the teachings of past issues of poultry journals, nor get all his enthusiasm from « single farmer's institute a year. The poultryman who is making the most out of his birds, the man who is known outside of his town, the breeder who is improving his stock each year, is the one who changes his flans to meet the demands that come up year by year.

This up-to-date poultryman is a reader of good poultry literature, files his magazines month by month for easy reference, keeps in touch with market needs and prices. We try in our pages to stimulate our readers to better work and more intelligent handling of birds, that they may make the most of the birds they own and reap the largest harvest. Prices of eggs are advancing take the year through, the demand for thoroughbred birds never was greater, the feeding value of grains and meat never more varied.

Take time to consider these things that you may make the most of the opportunity at your very door.

\section{Keeping One Variety}

In commencing to breed fowls, start with one variety only. Purchase the best fowls your purse will allow. When you have thoroughly mastered the business of keeping a few at a profit, and have the time, room and money to branch out farther, and want more yards or more fowls, increase the number of the same breed you have, if you like them and intend to stick to them. So long as you breed fowls, stick to one variety.

With one breed the expense is not only reduced but the profit is greater. And if the breeder is so situated that his fowls ean have plenty of range, the work of caring for a thousand fowls of one breed is not so much as caring for one hundred fowls of eight or ten varieties. This I know from experience. Fowls of different varieties kept in separate runs require much attention, especially in the breeding season, and the person who thinks there is not much labor attached has only to try the experiment.

\section{Holv to Improve the Flock}

The promiscuous buying of birds here and there, of various breeders and families, even if choice specimens are so secured, and breeding them together without a knowledge of the ins and outs of their ancestors, more often leads to disappointment and disgust than to satisfaction and a desire to continue in the business.

We would advise any of our readers who are about to start in thoroughbred poultry raising to start right or if they have already started to stop and begin over if the results have been disappointing. By all means purchase reliable stock of breeders who ean give satisfactory assurance of the quality of the stock to be purchased. Start in a small way, even if only one pair or trio ean be selected and purchased that are good. Breed each female separately, which can be done easily by using 
a pedigree or trap nest box. Keep each hen's eggs separately, set and hateh them separately, mark the chicks therefrom, and then watch the results. If a certain hen lays more, eggs than the other, of course she is more productive; if her chicks average better in quality than the other she is the better breeder. The following season, if her stock is remarkably good and it is thought best to continue breeding from her, mate her to one of the best last year's cockerels, and hateh her eggs separately and mark her chicks. For another yard select two or three of her pullets of the first year, secure a male to mate them from a reliable breeder, and be sure you get size, shape and color in him, such as you want, keep the eggs from these pullets separate and mark their ehicks. By this start you have two families of birds to breed from and are ready to do some "line breeding," at the same time you will know just what your stock is doing for you, and altogether the start has not been an expensive one. In your first purchase, if possible, buy of a line-breeder and ask him to make the proper mating, and be willing to pay him his price for good birds. Such a course will be money and time saved at the start, and your pleasure and profit will come to you much sooner.

The beginner must not expect a large average of high-class stock at the outset, but he should content himself with a small percentage of such at the beginning, increasing it each year as he becomes familiar with the quality of his stock and the care which he may give them in both mating and care. To illustrate what may be expected, let us say: Once we were examining some good young birds belonging to a young breeder, which he had reared that season from his own stock. He had also secured a setting of choice eggs from a breeder he procured his stock from originally, and had two chicks, a cockerel and pullet cooped by themselves, saying: "These are the best from that setting of eggs, now can I mate that cockerel with my stock?', On examining him we found him so defective in color, that we replied, much to his surprise, "He is worth only what he will bring for a broiler," which was the ease. He was absolutely worse than useless as a breeder of fine stock. We relate this to illustrate the difficulty in producing choice specimens, anil if the owner does not study and learn what constitutes a choice breeding bird, even though his first year with stock mated by one who knows how proves good, he is liable to ruin the stock of the second year by mating to something of little value, as this man would probably have done had it not happened that the bird's defects were pointed out to him. For such and like reasons it is better to buy stock line-bred and when new blood is wanted, buy again of the same man, first explaining to him what results were the outcome of the first purchase.

\section{PURE BREEDS FOR UTILITY.}

In some unexplained way there has been an opinion permitted to become quite general that breeders of poultry who are breeding for utility purposes have but little use for pure bred fowls. This idea or belef has become so well grounded in some localities that very intelligent people will have nothing but the fowl of mixed breeding for their purposes. All poultry breeders want health, vigor and constitution, and to this end many believe it ean be obtained only in the common or mongrel fowl. At the same time these breeders wish to try to breed fowls of the makeup of one of the pure breeds for other qualifications. They want the hardiness of the common fowl and the makeup of the best pure bred fowl obtainable for their particular purpose, whatever that may be. The'y want them to be pretty much of the same color, and in selecting those for the market they will not take any that fill their ideal for breeding purposes. Some of them go far enough to work for a betterment in shape or laying qualities and in view of all these peculiarities they are not willing to ac- 
cept a breed that already has them to a marked degree for fear they will lose the one important qualification of constitution.

We have watched the efforts of the fancier and fail to see where it is necessary to injure any of the meat or egg qualities by selecting for fancy points. A great many of them lose sight of these utility points in making selections, but they do not all agree in this method of selection. Egg production is one of the chief and practical qualities of the pure bred fowl. It is as susceptible to proficiency as to any other desired trait. The most essential elements of the fowl that will meet the greatest demand must be endowed with practicability. It is a mistaken idea that constitution is gained by exposing fowls to rigorous weather, enduring them to inclement weather and compelling them to get their feed wherever and whenever it happens to come in sight, giving them plenty of opportunity to hustle for it.

It was our pleasure recently to watch the unloading of some poultry by some poultry breeders. In conversation with a couple of them I learned that one person obtained one cent more per pound for his poultry than another. After they had gone away the buyer was asked why he paid more for one lot of fowls than the other. He said that the lot that brought the best price were all of one kind (one of the well known breeds) and would dress out better and sell for more when dressed. He was asked if it was because they were all of one color or plumage that made them valuable. To this he answered that it was the feather and color that indieated the breed and that shape and meat were indicated by the knowledge he had of that breed.

The utility of poultry can be had in various channels, each being followed by the use of pure bred fowls. There was a time when cross-bred fowls were supposed to be quite the thing and some still adhere to this belief, but by a better development of the pure bred, it has been fully demonstrated that it is quite as profitable to keep for ntility purposes. A great many are interested in the fancy side of the poultry business, but the vast majority of those who keep fowls are working for more practical results than exhibition points. There is always more or less fascination to the business of breeding poultry, whether it be by the fancier for the showroom or by the farmer for market. To the latter the more profits he can make out of the business the greater the fascination, and to the fancier the more fine points the better he likes the business. Raising choice table poultry and producing eggs or breeding high scoring fowls will always find advocates, and any of these three branches can be made to yield a handsome return. The all purpose fowl is today nearer a pure bred fowl that it was a decade ago. Utility, as applied to poultry, means that kind from which the best results may be obtained, usually measured in dollars and cents if not dollars and sense.

\section{THE FANCY AS A CALIING.}

No one need fear of the fancy being overdone. The "short-term" fancier and the demand.for good birds by those starting in the business will keep up an active demand for high class stock for many years to come. The small per cent or really high class exhibition birds from the average mating will also help keep the market alive. From five to ten per cent of the best matings produce top birds. Fifty per cent of any variety or breed should be sold for table use or kept for market eggs. Line breeding, a closer following of pedigrees and severe selection will improve these averages in any breeder's yards. The fancy presents as much of an opening today as the breeding of any class of pure bred stock. It can be entered more cheaply, and for the man of real ability as a student of breeding, the returns will come sooner than in any other field. Hard work with the hands and good head work, will put the 
breeder to the fore early. There are many men who are putting the best they have in themselves into the business of poultry breeding; and they are making names for honesty and success. Stand up for the fancy and the business in general! There is room at the top, and applied manhood can get there. The fancy is a recognized calling and many glory in it.

\section{CULIING.}

"Culling" means: To separate, select, to pick out (Webster). The poultry raiser's culling should begin with the birds that are to furnish the eggs from which the future chicks are to come. First remove every bird that is not vigorous. Do this with absolutely no regard to the score or the egg record of the individual. Only vigorous breeding stock will then remain. This healthy, vigorous flock should again be culled.

Is the Standard of Perfection in view? If so, every bird which shows its probable inability to throw chicks of standard merit should be removed, or if allowed to remain its eggs should not be used for hatching.

We can now pass on to the eggs. The eggs should be eulled. Avoid for hatching purposes every egg that in size, shape, color, strength and texture of shell does not conform to your standard for a market egg, no matter how good the bird that laid it appears to be. For the best results the eggs should be culled again. When it is possible and practicable to do so, avoid for hatching purposes every egg that was laid by a bird whose laying ability has not been up to a fairly high standard, and every egg laid by a bird that was not in the best of breeding condition at the time the egg was laid, even if she appeared to be all right when the breeding pen was made up.

This strict culling will result in the use for hatching of good eggs from good hens only. It is not so much time that it takes as courage. It does take courage, lots of it, and some time. After the eggs have been set, under hens or in the incubator, they should be culled again. As soon as they can be surely distinguished by testing, cull out all infertile eggs, and if the "know how" has been learned, cull out all those in which the germs have died, or have not developed as they should.

The eggs should hatch in twenty-one days. A strict ruling would require that all eggs not hatched by that time be destroyed. "Let your own discretion be your tutor." The chicks that hatched in due time should be culled-if they need it. Cull out every chick that is deformed, erippled, and those which "don't look or act right." 'They are no good. If the previous culling, as outlined above, has been thorough, there may not be much more culling to do; but, as the chicks grow and thrive under good feeding and care, watch closely for a chance to cull again. "Get. the habit" of culling. It would make a splendid fad, with an effect upon the poultry business that it will be safer for me to leave to your imagination than attempt to describe.

Cull from now on, as the chance presents itself, until the circle is completed and you arrive at the breeding pen again. Cull out those that do not appear right and those that do not perform right. A little flock well culled, like "a little farm well tilled," will be a greater source of satisfaction and profit than larger operations run hit or miss, without careful attention to details and constant culling.

\section{IINE BREEDING.}

It is the ambition of most fanciers to form a strain of their own, which can be relied on to breed something approaching what is mated up 
for, so that if in building the foundation of the strain you are not exceedingly careful in your selection of stock birds, a number of years may be wasted in making attempts to do the impossible.

Therefore be sure that you get your foundation from the very best strain of your chosen variety, and from the man himself that originated it. I for one, never had mueh faith in those who advertise birds from Mr. So and So's strain. They may be very honest individuals, and men who are anxious to give good value for money received; but does it not strike you that if you are commencing a strain of your own that it would be much safer to trade with a man who relied upon himself, his own birds, his own way of matiug and his own reputation, than with one whose only claim to laving a good breeding yen is, that they have heren hought from some other individual better known than himself.

To form a strain of your own it is necessary to make up your mind as to the value of the birds in your yards, if they are worth while keeping or not, and to choose from them such birds as measure up to the Standard. Don't try to lay a good foundation of inferior birds, with the expectation of being able to breed up, with care and attention to a winning Standard.

It is hard work enough, and takes all your skill and knowledge of the breed to turn out winners when you have the best blood obtainable, but with inferior stock it is well nigh impossible. Man does not live long enough to complete such a task. Good blood in skillful hands will always be found the cheapest. With it, one may have disappointments; without it, expect nothing else.

By this I do not mean that a breeding yard of 100 point specimens are needed, for such don't exist, nor the prize winners at some leading show for they are generally birds that we call good all round specimens, with perhaps no particular faults, and yet perhaps with no particular point in which they excel. Such birds are not the best birds to breed from, a bird that in some few points, or even in one point almost reaches perfection though it may be only mediocre in others, is far more satisfactory for stock birds when judiciously mated on the principle of compensation.

This method of breeding, eall it strain breeding, line breeding, or inbreeding, whatever you please, is the only way of breeding from which good results may be expected.

It may take several years to perfect even one point, but to the true fancier this makes the pleasure of breeding to see his desire slowly, perhaps, but surely fulfilled.

In making up your first year's breeding pen do not expect a great deal, if the rhicks shuw some improvement he satisfied. The second year with the old hens run one of the cockerels you have bred, selecting the one that looks as near like his sire, and as perfect as possible, in those points, in which the hens lack. Then mate the cock to his best pullets, selecting them, of course, with due regard to the method of compensation. From these pens you may expect something that is a little nearer perfection.

Then prery yar in mating wp strietly avold bringing in any cross

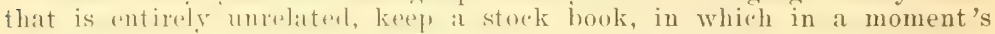
time you can find out the relative quality and quantity of the biood in your strain, and so be guided in the selection of inmates for your breeding yards, it will then be many years before fresh blood is needed, but if on the contrary fresh cock birds are frequently introduced the breeder never knows what he is doing.

Line breeding is the only method, using only the principles of compensation, that will intensify the power of the present to stamp its own likeness on its progeny, and to strongly hold in eheck the tendency to throw back.

If this method is adhered to, each season will develop fresh beauties, and consequently less defects, until little by little some of the stock will finally gatin the ultimatum of our fancier's hopes and aspirations by 
achieving for him the honor of the blue ribbon in some of our leading exhibitions.

Not the result of money, but of your skill and patience, for to win a prize with a bought bird is nothing, but to create a new strain better than all your predecessors is to be of some real value to the fraternity, and a genuine fancier.

\section{THE BREEDING YARD.}

That the "Breeding Yard" is the poultry fanciers stock in trade we are all of us ready to admit; withont it we might raise poultry, but at the same time any definite improvement, in fancy points, utility qualities, or both, would be very difficult of attainment, if not an absolute impossibility.

That this is not well known is seen from what is generally called a Breeding Yard. With very many poultry breeders the breeding yard simply means a half or a whole dozen fowls, containing one male in the flock, the birds may be the result of one or more settings of eggs purchased from some breeder the spring before, and as a good price was paid for the eggs, the birds must out of necessity be all there is to be desired, that is, thus very many reason.

Now if nothing else were wanted than a flock of pure bred birds no one could find fault with their reasoning, and we are positively sure that this is all the multitude desire, and all the trouble it cares to take in the matter of raising pure bred poultry. That year after year, eggs from such yards are shipped all over the country, as eggs coming from fancy stock, and as far as it only means from stock breeding true to color, and breed characteristies this also is all right, and mostly gives general satisfaction, where not a great deal of money is expended in the purchase of the eggs. But if this method is employed, with the idea that this is breeding fancy fowls, then such reasoning is very much at fault, as this is all that the market poulterer is doing, he uses pure bred stock, as well as the fancier, with this one exception, that he does not sell his eggs at fancy prices, to do this much more eare and selection is necessary, and because of this a breeding yard is necessary, not the kind of a yard as above mentioned, which simply amounts to the raising of pure bred poultry, but a breeding yard, and all that it includes.

In the jargon of the Fancier, breeding yard, stands for improvement, how often in conversation with a fellow fancier, we have heard him say, "I have one of the finest matings you ever saw," or "I wish you could see my breeding yards.', What does he mean by this? That he has selected a very few of his very best birds, with some notable improvement in view when he made his selection, and this is what is to be understood by breeding yard, a few fowls put together by an experienced breeder, or by an amateur, Standard in hand, that the output from these few selected birds, may have in greater perfection, what their progenitors were deficient in. This is the sole purpose always, and nothing but improvement.

We have heard quite frequently about "The unattainable Standard," but there is nothing in it unattainable, it is true that we have all of us our discouragements, but they come to every breeder worthy the name, and who sets before himself a high ideal, which, is always a difficult task to reach, but not by any means unattainable.

"The unattainable Standard?" Well even if it were unattainable, we shall have the satisfaction, that we did our best to measure up to it, and to do one's best, is all any man can do, and where it is done with an appreciation, of just what is wanted, success will finally result and the needed improvement will be realized. In breeding we cannot have everything nor try to obtain everything, at the same time, for if we do we shall most certainly fail. 
It is a comparatively easy matter to keep a flock of average quality up to the average, but when we go beyond the average, the trouble, work, and yes, the pleasure begins.

Our ideal is before us, we know what improvement we want to make, but certain strongly developed points are necessary, in fact we cannot make the desired improvement without them. We have a large flock, for instance, and from it we proceed to select our breeding yard, the flock looks handsome, never saw a better one, and the work of selection is begun.

One fowl after another is picked up and examined very minutely, and as we proceed, the flock grows less and less valuable.

Here is one bird which has the desired improvement in perfection, but it is so bad in some other respects, that little as our amateur knows about breeding, he knows that it would be madness to use it.

Here is another bird, all that could be desired, but in the particular point wanted it is lacking. And so we keep on, and out of every 200 forwls we have a few that come up to our ideal of the desired point for which we are going to breed, and we almost hate to look at the larger half of the flock good as it was a little while ago.

But the end is not yet, for the next day, after another examination, we find still more that will not muster, and as day after day, our selected bixds become fewer, and fewer, but at the same time better and better, we find ourselves, quite often in those two or three pens, and it is with almost a heartache, that we pick up another bird, think it over, reason with ourselves against better knowledge, drop her on the floor, back again in an hour, how queer it is, but that bird is the first one our eye falls on, we pick her up again, look her over once more, heave a sigh, and then carry her out to the other discarded ones. At feeding times, we linger for a while among the few selected birds, what beauties they are. Next pen containing the birds that we cannot use for breeders, and as we open the door, there stands in front of us the bird set aside in the morning, how she looms up magnificently in that pen, we repent, pick her up again, almost fondle her, and finally put her back again among the selected few.

But that bird is making us uneasy, she goes to bed with us, and in the morning is our first thought, we again weigh the consequences of our last night's doings, go out to the pen and take her out again, to be gone forever. Have you ever had such an experience? If so, you know in part what it is to select a breeding yard, but when done, you will have a few birds anyhow, left, from which improvement may be expected, and what is really worth bearing the name of a breeding yard.

\section{BREEDING STOCK.}

There are several reasons for a shortage and the high price of fresh eggs during the winter months. Improper breeding of stock, improper feeding and care in bringing stock to maturity, improper housing and improper feeding to produce the required results.

By improper stock, I mean hens that have no record of being an eggproducing strain. I venture to say that 90 per cent of the farmers who are raising poultry for eggs do not know how many eggs his bens are laying in the year. He does not know which hen is laying fifty eggs, or which one is producing one hundred and fifty in a year, and yet he continues to breed from the whole flock, a mistake too often made. If some attention was paid to the flock, he would soon note the birds that are his best layers. If he would then breed from his best layers, he would soon have a laying strain. The egg-producing hen is the active bird. She is the one that is inclined to be nervous and continually moving about. Invariably when in laying condition she can be noted by the 
brightness of the face and red comb. These are the birds from which to breed.

An experiment has been carried on in the state of Maine to show what can be done by careful selection and feeding to produce eggs. ' $1 \mathrm{ne}$ experiment was started some years ago, with 1,000 hens. A record was kept of the amount of eggs laid by each hen during the year. The best hens were bred from the following year and a record kept of the offspring. This was continued until one hen had a record of 281 eggs to her credit for a year; another 260 , several 240 , and a goodly number a record of 200 and over.

It has been estimated that the cost of feed per hen for a year is from 75 eents to $\$ 1.00$. Now then, if you keep a record of how many eggs each hen lays during the year, you could soon determine which were the money makers and which the spongers. With eggs at an average of 15 cents per dozen throughout the year, the hen would have to lay from five to six dozen to pay for the feed consumed. Now, if your hens are not yielding more than this amount, you are losing money in keeping them, and the sooner you get rid of them the better.

\section{HOW MANY HENS.}

How many hens may be kept with one male bird is a question often asked. That depends on the season, the breed, and the range. An active bird of the Leghorn or Minorea breed can take care of more hens than the heavy Cochins and Brahmas. During the early spring if the weather is cold, and especially if high winds prevail, the males are less attentive to their harem than during fine weather. As few people plan for large numbers of very early chicks, it is better to give the male bird fewer hens than he might care for and insure fertility. It is possible, however, to give, so few hens to a vigorous male that he annoys the hens unnecessarily. In this case the best method is to either give him more hens, or leave him with the hens but a part of the day. Many a trio of fancy chickens has been overmated and their owners disappointed with infertile eggs when if the male had been with the birds but part of the day the eggs would have been well fertilized and hatchable. When the weather is fine and the fowls in the pink of condition one vigorous male will take care of a very large flock.

How many hens can be put with a male bird with profit, is a question which ean only be answered by one familiar with the birds. From five to twenty, depending on the bird and range.

\section{KEEPING 1,000 HENS.}

The average cost of feeding a hen for a year-one dollar-would make the outlay or expenditure for food one thousand dollars per year. If the hens each produced one hundred and twenty-five eggs, and these eggs sold for a cent and a half apiece, there would be eighty-seven cents made on each hen. If these hens could be so handled as to produce one hundred and fifty eggs each per year, there would be one dollar and twenty-four cents made on each hen. If these same hens could be induced to lay one hundred and sixty eggs per year, you would have a profit of almost one dollar and a half from each hen. Therein lies the secret of success in keeping hens for producing eggs for market. We read so much of the hens that produce two hundred eggs each. We know for fact that there have been many hens that have prostuced two hundred eggs and over; but there have been few instances where large flocks of thousands have been kept that have exceeded very much the average of one hundred and thirty eggs per hen. 
It is within the possibilities to have large flocks of hens that will produce on an average of one hundred and fifty to one hundred and sixty eggs per hen, and we know of some poultrymen who can handle large flocks and do better than this; but when speaking of the probabilities of the market egg business, we must give the average and not the exception to the rule. Anyone that can gain over one hundred and twenty-five eggs from each hen per year, is a good manager, and can make more money than a living from a thousand hens; but you must be up and doing and caring for them as they should be cared for, if you expect to make a profit.

\section{THE KIND OF HENS.}

The breed of fowls for the farm is not of as much importance as is the way they have been bred. In the majority of cases hens are kept principally for the eggs they will produce, and it is important that the poultry kept be the product of hens which have been earefully and systematically bred for layers. It is hardly necessary to say that pure bred poultry is so far ahead of the mixed fowls for egg production that there is no comparison, but many are not aware of the fact that some pure bred fowls are worth four or five times as much for layers as are sume others equally as pure blooded, but which have not been specially aelected and bred for prolific layers. As one man of considerable experiencé wrote me the other day, "A poor man would get rich with one kind, while a rich man would get poor with the others.' So the imporianit point in selecting the breed for the farm is to select the breed you like best, and buy the stock from a breeder of that variety, who is breeding each year from his best laying hens and improving his strain in egg production. If eggs alone are desired the smaller non-sitting breeds will probably be preferred, but where eggs and dressed poultry are both desired some of the general purpose breeds will do best.

\section{Cheap Poultry Houses and Yards}

It seems a characteristic of many of our successful poultry plants that their beginnings were not attender with magnificence, the original buildings were not fine examples of poultry architecture, the owner did not even deem them fit to illustrate his first annual catalogue. But these plants have developed into our now successful poultry farms. In the yards of many a fancier with a national reputation you can find houses of a type that have never been portrayed in our poultry journals as admirable, these houses are frequently 'make-overs' from some unused building or some old pieces of scrap lumber thrown together and made habitable by liberal use of tar paper and rags. Yet these houses sufficed to shelter the fowls placed therein and what the breeder lacked in comfortable quarters he made up in painstaking eare.

As time passed and profit was made many of these houses were aband. oned or reconstructed, but some were left and on almost cvery poultry farm are still in use standing to prove that expensive houses and fixtures are not requisites of a good beginning in poultry culture.

Nowhere do we find as up-to-date, well-constructed, even elegant poultry houses as on the abandoned plant, where money was apparently not lacking when the original buildings were erected. Poultry houses are so frequently portrayed with elaborate descriptions of the roosts, nesting boxes, feed troughs, and grit and beef scrap receptacles that one may forget that a house is only so much room enclosed with tight walls; only so much space protected from elements. Economy is usually attended with inconvenience, the person desiring to build cheap poultry houses 
must expect to do without poultry house luxuries. Our best styles of houses consider the comfort of both the fowls and the attendants but our cheap houses consicler that of the fowls only and leave that of the attendants to take care of itself.

All this is not inteuded to argue that poor houses are superior to good ones but it is offered to show that beginnings need not be elegant or even apparently auspicions.

The beginner will probably find the most economical way to house his first acquisition of fowls in some old unused building which will likely require some corrections such as filling up to make dry, some additional window to make it more light and a wholesale stopping of cracks to make it warmer. A leanto of the barn can be made with little trouble into an excellent poultry house especially if it happens to be on the South side, an old shed will make a good house and even old hog houses have been converted into poultry houses affording good accommodations.

If one has no old buildings that can be converted to his use and is compelled to erect new houses he has the piano box house with all its possibilities and the dry goods box house. Two piano boxes will make a house six by ten feet in size that when covered outside with Paroid or Flinkote roofing paper and inside with tar paper makes a very comfortable house which will keep the combs of the Mediterranean breed from freezing even in the coldest weather. This house need not cost over $\$ 5.00$. A single piano box with open front and hooded top and roof covered with heavy roofing paper makes an ideal colony house for thirty young chicks of frying size, and can be built for $\$ 5.00$. A dry goods box house is made in any size to fit the length of the boards when taken from the boxes, for dry goods boxes unlike piano boxes should be torn apart before using in the construction of a house. The boxes can usuallv be obtained very cheaply.

Old lumber left from some other building, torn from some old decrept house or purchased from the wrecking company can be made into the best kind of a house if the poultryman is willing to go to the necessary work that is required to prepare odd sized material and does not possess too much vanity to be content with a house that appears to have been made for use rather than for appearance.

The apex house is one of the most comfortable from the standpoint of the fowls and can be made very cheaply, it affords more floor space for the material used than any other house. The attendant, however, is liable to bump his head against the sloping rafters many times a day. This house is constructed in the form of a letter A making the wall serve as a roof also, the best height is eight feet and the wiith twelve feet. The length should not be over twelve feet when made on these dimensions. The rafters will be ten feet in length, the sheeting may be made up of odd sized material, the ridge of the roof should run north and south, there should be a window in the south, east and west and a door on the north. The roof may be either shingled or papered and when papered on the inside with tar paper makes a surprisingly warm house capable of accommodating a breeding pen or fifteen laying hens.

The economy of the apex house lies in the fact that it may be built of ord material and requires so little lumber for its capacity, a house of the dimensions given above can be built for $\$ 10.00$ even when the lumber must be purchased and the cost is much less when second-hand material is used.

Prepared roofing paner for the outside and tar paper for the inside are important elements in cheap poultry house construction; the former enables one to do away with the high priced shingle roof and by using both the former and the latter, warm houses are possible without double walls.

By building houses low the cost can be considerably lessened although at the sacrifice of convenience. A very popular form of house with many fanciers is made as follows: Height in front five feet, in back four feet, 
length six feet, width four feet, the material used is one by twelve inches pine in nine foot lengths. It is papered with tar paper and roofed with Pariod or Flinkote. These houses are used in winter for small breeding pens, and in summer as colony houses for young chicks. They are supplied with a large low placed window which is removed in the latter case. The cost of this house is about five dollars. It is readily moved from place to place, but is inconvenient for the attendant. Inconvenience, however, as stated before, is the price that the poultry man must pay for cheap houses.

A house that can be built for a much less cost than the above and the same time may be made much larger and capable of accommodating many more chickens is the straw covered house. This house consists simply of a frame of any size or shape that the builder may desire, that side of the house intended to be the front should be made tight and fitted with a door and window, then straw direct from the thresher may be turned on the frame work until it is covered. The top should be dressed off so as to shed water and the straw about the sides arranged tightly up against the frame. A sheet of oiled muslin may be used instead of the solid front, in fact, if the house is made deep enough (fifteen to twenty-five feet) the front may be done away with entirely and in a heavily covered house of this kind it will be comfortably warm in the back even in the coldest Winter weather. It should be made to face the south if possible, the roosts should be placed in the back farthest from the open end.

If one wishes to build accommodations for many fowls he will find the continuous house economical from the fact that one side of each compartment is saved every time an extra room is constructed.

The simplest styles of continuous houses are cheapest and also the best. The single slope roof is the easiest made and requires less cutting of the material. A house eight feet in the front and five feet in the back and twelve feet wide with solid partitions every twelve feet makes a very good house. Each compartment will hold comfortably a breeding pen of ten birds or a laying pen of fifteen. This house may be built single walled if it is well papered inside and the cost is less by using roofing paper instead of shingles.

\section{HOUSES AND YARDS.}

The house and yard room for the poultry ought to receive more attention than it does on the average farm. Houses should face the south and be high enough to permit the attendant standing up comfortably inside while doing the work. They should not be built more th in twelve feet wide from north to south, and whatever length is necessary to accommodate the fowls to be kept. If buildings are wider than that, the sunlight will not penetrate to the north wall, and the buildings will be damp and musty, and not a healthy place for hens. A building twelve by twenty-four feet would house a flock of forty or fifty hens if the entire floor space was utilized for a feeding floor. The roosts could be placed in the north part of one end of the building with droppings board underneath to catch the droppings and high enough up from the floor to allow the entire floor space for scratehing, this should be about two and a half or three feet. Then by boarding up the roosting place at the ends and arranging a curtain of common sheeting to drop down to enclose the front on extreme cold nights you have a very comfortable as well as a very convenient poultry. house. The nests, water jars, grit boxes and other internal arrangements ran he arranged along the walls, up out of the way of the litter and dirt. Two common sized windows in the south front would furnish plenty of light for a building of this size, but it might be a good plan to have a door or two also in the south front, to throw open on nice sunshiny days in winter, thus converting the build- 
ing into an open front scratching shed. If a small pen was added on to one end of such a building for fattening pen for cockerels and a place to keep over a few of the best hens for breeders it would make an ideal house for a farmer's flock.

Where the hens ean be given free range all summer, the yard room is not of so much consideration, but on most farms there are certain seasons when the hens must be kept in, and a good sized yard then with a little extra care in feeding, will well repay any expense incurred. Two rolls of four foot poultry netting will make a yard about one hundred and thirty-five feet long and as wide as the length of the building, running south from the house, and would give the flock ample room for good results in egg production any time during the growing season, and in the spring it would be an elegant park for the use of a small pen of the best hens with their male escort, to furnish the eggs for hatching purposes.

The colony house is getting to be generally recognized as one of the essential facilities to successful poultry keeping. All up-to-date poultrymen use them, and from the almost exclusive use made of them in summer time for young chicks, it is a wonder that more of the farmers and farmers' wives would not fall into line. Just let me say right here that it is the latter we should strive to enlighten on poultry topies more than anyone else, if we would have the poultry industry of our land keep abreast with all other industries.

The colony house is a cheaply constructed out-door house for the growing chicks during the Summer time. It is all nonsense to think of housing chicks during the Summer in a house that is used for Wintering old fowls. Why? It is too close and hot. It has not ventilation enough and old and young fowls should not be allowed to run together. The young and growing chicks should be kept separate from their older kin and to this end should be provided with separate quarters. The colony house is a solution to this problem. It is not always necessary to buy lumber and make it specially. Very often boxes or packing cases can be obtained that can be easily converted into such. A piano case, if roofed with tar paper, bottomed or otherwise fixed so as to keep out the rain, is just as good as the best. Of course, it can be altered to suit requirements.

It serves all purposes, and is easily constructed. It is three feet wide and four feet deep, and three feet and half in front with about a foot pitch in the roof, which is battened to keep out the rain. There is a screen and a window in front; the latter can be fitted in by buttons or taken out at will, when necessary. There is also a door on the left side and a separate bottom. Now what are the advantages of all of these? First, let me say that this style of colony house is good for either cool, damp or hot weather. It can be adjusted to suit all kinds of weather. In the early Spring when some days are cool and damp, the window in front will be found necessary if the house faces the south, which it should. It will admit sunshine and warmth to the mother hen and her flock within. On such days the window should always be kept in place and the door closed. Then it will be Summerlike and dry within when it is the reverse without. The chicks need not get wet. They can be fed and watered within, where there is plenty of room for a dozen chicks and a hen to seratch and run about. The bottom, or floor, should be covered with nice, dry sand, which will not only furnish the chicks with grit, but will keep the apartment within clean and wholesome if they are cleaned out regularly. As the days get warmer in the Spring, during the daytime the little door can be opened and a slat door placed in position. This will keep the mother hen within, while the chicks get out between the slats and scratch about on mother earth and nibble the tender blades of grass and pick up many an insect or worm. When night comes, the slat door can be removed and the permanent door closed and all is $O$. $K$. for the night. There is no fear of their getting wet or cold. Nothing in the 
shape of a dog, cat, rat, mink or weasel can euter to disturb their peaceful slumbers, or take their life. 'Their owner can also sleep just as soundly as they do, for he knows they are safe. I said it had a separate bottom. The top and bottom are not nailed together. They are two separate pieces. By making them thus it is necessary to clean it. The change can be done quicker and better and easier. All that is necessary is to have one extra house and on days when you wish to clean out you can have the spare colony house clean to start with. Change the flock in the next one to it and then clean the used one and so on until all are cleaned, when the last one will be empty. This one will be the first one used in the next shift on the next eleaning day. Another good advantage gained by having the top and bottom in separate pieces is for the detection of lice. Lice like to lurk in cracks, especially in joints in the floor. To detect if lice be present with this style of colony house all that is neecssary is to raise the top part and look around the floor or the bottom part of the top that fits on the same. If none be seen here you can conclude that none are present. If they are seen there you can apply the necessary remedy to get rid of the same. What is a good and effective way of getting rid of the pest? For colony houses I spray with a solution of carbolic acid. I get the crude carbolie acid-from the wholesale druggist and dissolve it in water aud spray with a spray pump, in every crack where the lice lurk. This will not only kill all the lice and destroy all eggs, but it is a good disinfectaut as well. After spraying, which should be done on a nice warm sunny day, allow the whole to dry before putting into use again. Sprinkle a nice layer of dry sand on the floor again, and all is sweet, clean, free from lice and ready for occupation again.

In hot weather this style of colony house will be found just as good as it will in the cool or damp days of the spring. The window in front can easily be removed for it is only kept in place by buttons, a screen of fine mesh (one-half inch is what I use) is tacked on permanently, and is either in or out. This allows the chicks to get plenty of air at night for now the mother hen is no longer needed to brood over the flock, and she has been taken away and the flock have full possession of the quarters. Because the little chicks have heen raised in this house from their earliest ilays, they will always seek shelter there at night, all through the Summer. Every night at dark, after all the chicks are in, the doors should be shut and fastened. Not being a very early riser myself at all times, I leave a little feed ready for them, which they will make good use of when daylight comes, for chickens are invariably early risers and are not contented if their wants have not been attended to. No matter how much they may want to get out they have their appetites partially satisfied anyway. I find it is not good to let them out too early, for then the grass is wet.

As for the placing of the colony houses it is not necessary to say that although placed in the sun themselves it is a good thing to put them near a shady place, where the chicks tan find shelter on the hot, sweltering days of July and August. To place the colony houses in the sunlight and facing the south is a good thing for two reasons. First, on cold days when the chicks are confined, they will be kept warm within. Secondly, sunlight is always a good preventative to disease and destructive to germs which find no support before its strong rays. It will be seen in the pictures a berry patch is to the rear of my colonies. Here the chicks when not feeding in the daytime seek shelter. At certain times every day I feed or cause them to be fed under a tree which stands near by. They then run out from under the berry bushes, feed, and then run back and lie down until they are hungry again. Within the berry patch are their drinking fountains, the water in which is kept cool by the sharle of the bushes.

By means of raising my chicks, I have provided them with the best possible shelter in all kinds of weather. I encourage them not to roam or forge about. I find that they grow quicker and do better and are always safer when kept as I keep mine. I never lose any of my chicks 
by hawks, dogs, cats, rats, minks, weasels or anything else for the simple reason that I have provided against such. The reason why so many lose their chickens by any of the foregoing is that they have not been provided against. It is an easy thing for them to do it, and does not take much time. To have such colony houses makes the labor of raising ehicks easy and besides ensures their safety and comfort at all times. A colony house the size I have stated is large enough for a dozen chicks from earliest Spring till latest Fall, when they should be placed in their Winter quarters. This should not be until the snow falls. Before this time of the year the window in front should have been placed in position, which will serve to keep it warm within at night.

\section{HOUSING AND COOPING.}

The housing of both old and young stock on a poultry plant is one of the most important points of consideration, from a standpoint of either the health or profitableness of the flock. Roomy, airy, storm and rat proof coops for the young stock is absolutely essential to the successful raising of a fine bunch of youngsters, that will make money for their keeper. Overerowding of the growing stock in filthy, poorly ventilated coops is one of the causes of poor success on many farms. And coops which do not protect the chickens from driving storms and the nightly raids of rats and skunks will usually have very few occupants in the fall, when the young stock are ready to be placed in their winter quarters. Many of the failures in getting eggs in the fall and winter months from the hens, are due more to neglect in regard to this matter of housing the laying stock than in anything else. The young stock that has been properly cared for on the range during the summer cannot stand close housing in their winter quarters in the fall and early winter months. Doors and windows should be protected with inch mesh wire netting so they ean be left open to give the hens fresh air night and day, in mild weather, whenever there is not danger of its getting cold enough to freeze their combs. The laying stock must be protected from sudden changes in temperature or feeding; this is imperative, to the best results in egg production, no matter what other rules may be disregarded. And even the chill resulting from giving real cold water to the fayers in winter will have a strong tendency to retard laying. For best results the water should have the chill taken off. Every little detail which adds to the comfort of the hens is important in obtaining the maximum amount of winter eggs. 


\section{QUARTERS FOR YOUNG STOCK.}

Have you ever tried the raising of chickens in new brooders or new houses? Did you ever notice that the best egg yields were in new buildings or places where birds had never before been kept? In such quarters lice and red-mites have not been introduced and hence play a very small part in the stunting of the chick or in reducing the egg yield.

It takes so short a time to build a small house, and chicks do so well in clean buildings, that we advise every one of our readers to put up a louse six to ten feet for brooding purposes. This will give room for two brooders, or five mother hens, and do for house room for a flock of seventy chicks until the cockerels are old enough to be sold. If the front of the house is largely wire netting it will care for thirty pullets until cold weather, and house a breeding of ten birds through the winter months. Do not make the house too high. Seven feet in front, four in rear, with shed roof, makes a house handy to use. One window of two sashes will give light enough, and this can be arranged to swing as a door. Have a wire netting covered frame to fill the window opening to use on pleasant days.

Have the house so made as to be wind and wet proof on ends, back and roof. Admit all sunshine and air through the front. Better have a board floor this spring, as the ground is cold and no good grading can be done before May. If you will make this house on runners, a horse can be used to move it to some field later in the spring and bring it back near the barn in late fall. A house like this fills many needs and if used for growing chicks this coming season will nearly pay its cost in a smaller death loss of the young flock.

\section{LET IN THE FRESH AIR.}

If the windows of your poultry building are still in place take them out at once. Let the hot air out, allow the cool breeze of night to replace the stuffy atmosphere of the house. The birds will be more comfortable, give larger profits, if you will give them a better ehance for pure air. If the windows are on hinges, swing them in and out of the way. If put in the old fashioned way, take them out for the next three months and where necessary cover the openings with netting. If your poultry building has a high stud, with low set windows, see if you cannot make some opening so that the heat of the top may escape more easily. Sometimes a high door in the ends of the building can be put in so that the breeze may blow from end to end of the houses. The sun heated house is over hot at noon, but this need not continue all night. Plan to make your poultry more comfortable from this time till late autumn.

Why not pattern from nature, as to her method of rearing and caring for her young birds and animals. Is the food for young birds cooked, mixed with cayenne pepper, or fed in mashes in a sloppy condition, from which arises bowel trouble and general debility? Why then is it so with our young chicks? The old-time worn method of mixing cornmeal to the consistency of gruel is out of date.

Use millet seed, cracked wheat, cracked corn, dry bread broken fine for dry part, and lettuce or finely chopped cabbage for green food. Grit of the proper size should be available, and above all things have an abundance of fresh water. Quarters shonld be absolutely free from vermin and serupulously clean. A grass range from which they may obtain bugs, worms and plenty of exercise is of the utmost importance. Have a good dry place for them to get in at night and when it rains.

Plan for laying house, $12 \times 48$, $5 \mathrm{ft}$. in back, $7 \mathrm{ft}$. in front, roof sloping part one way, this house will accommodate 125 hens; divided off into 3 


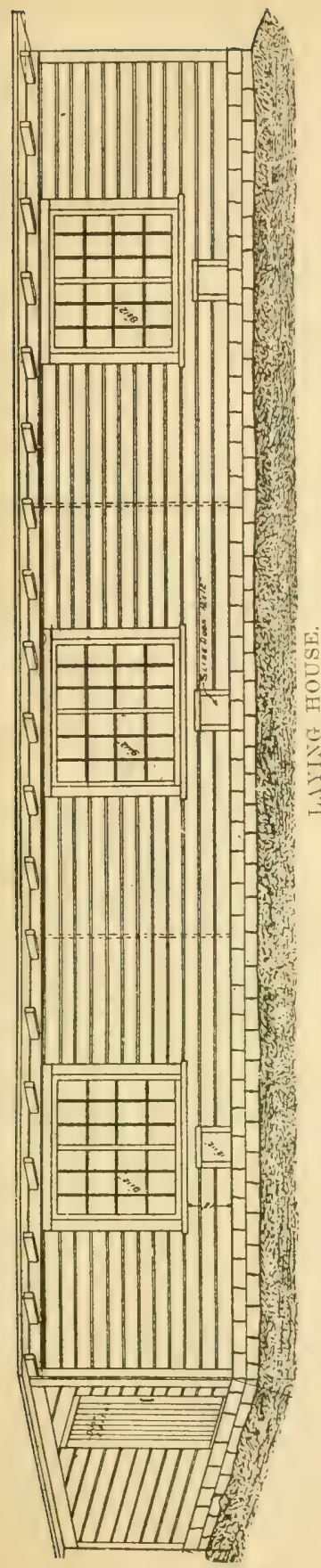

different pens each pen 16x12. But you must use dropping boards with a trough 1ft. wide and Ift. deep and to be as long as the dropping boards or roosts, to be put under where the drop boards are hinged; so as you raise the roosts the droppings will fall into the trough, therefore you always have a clean house. The dropping boards that the roosts set on must be hinged to the side of the building $2 \mathrm{ft}$. from the ground. Make the dropping board out of $1 / 2$ inch lumber so it will be light to raise and lower, using a pulley and rope to raise and lower the roosts, or a $2 \times 4$ hinged to the outside dropping boards and use that to raise and lower, which I find to be handier than a rope and pulley. This house should have a window $30 \times 36$ to every $16 \mathrm{ft}$ of house; placed on the south side with the lower sill of window, $21 \%$ feet from the ground, and hinged from the bottom so as to let them down on inside during warm weather and place wire netting over the window on the outside. Use $2 \times 6$, stand on edge for sills that go around on outside of house and use same for inner sills, put a cross sill to every $8 \mathrm{ft}$. of house. In a house $48 \mathrm{ft}$. long it would take 5 cross sills besides the 2 outside sills. After the sills are in position, we are now raady to set the studdings; the end studding can be first placed, setting them 2ft. apart, leaving a $3 \mathrm{ft}$. 8 inch space for door wherever you may desire. The studdings should be of $2 \times 4$ with $2 \times 4$ for plates. Rafters $2 \times 4$, placed $2 \mathrm{ft}$. apart. Now you are ready for siding; first place tar paper for lining on the studding outside, then your siding over that. Use $1 \times 6$ drop siding for sides and ends, driving it as close together as you can, then use 2 ply asphalt felt, readymade roofing and you have a good laying house except the ventilator. Cut a 6 inch hole in top of roof in center of building, using a 6 inch stove pipe; let it come within 6 inches of ground inside; extending above roof $3 \mathrm{ft}$. Material for this house will cost $\$ 125.00$.

HOUSES MUST. BE KEPT DRY.

And how to keep them dry is the next problem, as the first time the thermometer drops below zero the inside of the houses will be covered with a white frost. We have found the best way to remove this is to build a loft two or three feet above the roosts and cover with about six inches of straw or hay. This adds greatly to the warmth of the house and absorbs the moisture. Loft should not have tight floor; use enough boards to keep litter from falling down, and this litter should be removed in summer. 


\section{MAKE CONDITIONS FAVORABLE.}

As a practical farmer and poultryman, I take it that every farmer should have as much pride in his poultry as in any other stock upon his premises, and bestow upon it the necessary attention to produce from it best results. With most, the days of eross breeds or no breeds in cattle, horses, logs, and sheep have passed, and they have properly eguipped themselves for the successful rearing of the pure breeds. The same attention should be given the poultry house and its oceupants.

The farmer should be the successful poultryman. His surroundings are such that he has every advantage over the villager or his city cousin, who attempts to rear chickens in the confinement of a city lot, and who must proeure all of his feed by purchase, and if his eggs are sold on the open market in many instances the balance is on the wrong side of the ledger.

Now any business to be successful must yield an income above the cost of conducting it. Our city cousins do succeed and purchase every ounce of feed given their fowls, thereby teaching our rural friends a lesson in economies. If they can and do succeed, should not the farmer be pre-eminently the suceessful poulterer? Let us look at the conditions by which he is surrounded-ample range for large flocks, an abundance of feed at the cost of production, grain, grass, grit, and the meat that is so much talked of is easily supplied by milk, sweet or sour, and an abundance of cottage cheese.

The farmer that is not successful with poultry has no one to blame but himself, and perhaps has failed to see that he need not send his egg money to some far away advertiser for a patent egg producing food, but simply make intelligent use of what he has at hand.

\section{Fall, Winter and Summer Care of Poultry}

The fall months relieve the poultry-raiser of many cares and close observations. The chicks do not require the eare and close attention that they need earlier in the season. Incubators and brooders are cleaned and stored away until another season, but there are a great many things that must have our undivided attention.

The pullets that we expect for winter layers must be kept growing and in good health. We should see that they are not over crowded. The fall of the year is the worst time for roup. It is generally brought on by letting the cold wind strike the fowls or by letting them roost in damp houses. Damp weather is a breeder of the disease. An afflicted bird shonld be separated from the rest of the flock, as roup spreads rapidly. Drinking vessels should be kept clean. Put a few drops of carbolic acid in them so that disease will not make such ready inroads on them. Have poultry house in a dry spot; kept dry, clean and well ventilated. Slacked lime ought to be sprinkled on the floor to absorb moisture. With proper care roup can he prevented. It is a difficult disease to cure when it once makes its attack. Begin in time and depend upon the preventive and not the enre.

It is important to push the pullets, because if they begin to lay during the fall before winter sets in they will keep on laying; should they not lay before winter begins they will not lay at all until spring, but will begin early. Liberal feeding assists in overcoming some of the difficulties. Cull out all inferior stock and select only early, strong, active pullets. One must have an intelligent interest in the care and feeding of fowls to get best results.

Green food and a constant supply of animal food are essentials that must be present to obtain a large number of eggs. One pound of cut bone for a dozen hens once a day, which should not cost over a cent a 
pound, will produce more eggs than five times as much grain because the cut bone is complete in egg making substances, while the grain is largely deficient in many respects. The cost of a bone cutter soon comes back to the poultryman in the increased egg yield of his flock. The fall eggs are now advancing in price and will continue to do so. Do not feed too much fresh meat and bone; remember a hen would have to run a long way to catch enough bugs to supply two ounces of fresh meat; cut bone lessens the grain bill, cheapens cost of food and gives larger profits on fowls and eggs. Following my bill of fare, I shall double egg yields in two weeks, and this refers to egg flocks, not to breeding yards of fancy birds. These are handled differently, as they are not pushed for eggs. The egg yield during the fall months is generally not one-half what it might be, and you can get the results I do. You will be pleased with the inereased profit for a very little extra labor.

\section{WINTER CHICKENS.}

Chicks can endure cold weather better than extreme heat. Disease, lice and mites always come with summer months. The expense of feeding is no greater in winter. Profits can be realized from broods hatched in November, December and January. The winter hatches do not grow as fast as the spring hatches, but a heavier coat of feathers are grown. They feather out fast in winter months and are more solid and compact and are just the right size to sell in April and May when prices are at the highest point. For winter chicks select the larger breeds. One winter I raised 500 in a vacant room in the house. I could almost see them grow. I took 500 from the incubator and only lost 3 out of the whole lot. I kept them in the room until they were feathered out. It was a care, but it paid. When they were less than two pounds I sold them for 60 cents each. Broiler raising is a specialty in poultry work and returns good profits to those who are successful. The one who has his own fowls can make sure of the fertility of the eggs used. I raise 3,000 anci 4,000 chickens every year and find the per cent of mortality small in the winter months and early spring. The cost of hatching broiler chicks in January and February is no greater than that of May and June. The latter are marketable in July and August when the market is glutted. 'Ine April and May returns are from 35 to 50 cents per pound, 60 to 80 cents per chicken which cost about 25 cents to raise, a very good profit. On the other hand the August price shows but a small margin of profit with a lower per cent of hatches and a larger per cent of mortality. The secret of profit from broiler raising is to produce high elass broilers that will bring top prices at the smallest cost, with rapid growth. Eggs averaging high in fertility and produced by stock that is strong and vigorous make the battle half won at the start. The business is not only good now, but will be even better in the future as the wild game disappears. Much of the prairie chicken and quail served in fashionable hotels are nothing more nor less than common guinea hens and pigeons. When a knowledge of this fact becomes more common the domestic hen will be more popular and her products consequently higher in price.

\section{POINTS ON THE FLOCK IN WINTER.}

No class of poultry is more readily subject to colds than laying pullets in a badly ventilated house.

Another frequent mistake is to stock up laying houses with pullets of free range and then not pay enough attention to exercise and a supply of green stuff or its equivalent. 
Hens fattened on a corn diet are a failure as layers, and, laying, give us eggs that do not hatch well.

We would name as the cheapest foods that could be fed to produce large numbers of winter eggs, cut or chopped clover hay, green cut bones and wheat.

Oyster shells and grit, the very best grade of each, are also comparatively cheap, considering the extra results from a regular supply of same steadily before the hens.

Some hens lay well only when what might be termed "fat." Few or no hens lay well when "lean," which teaches us that most eggs come from hens well nourished and in good condition.

Bulky food is of great advantage to poultry, as it serves to assist digestion and promotes health. That poultry which is confined and has to live on grains alone is condemned to what might be called a living death.

The gain in eggs when meat is supplied will come easily. 'Two extra eggs a week from each hen would pay the bill; would pay for a decent grade of fresh green bones, or first class meat, or beef scraps, and no other should be fed.

With grain, especially corn and oats, at high prices, the matter of cost in feeding is a vital one. As a ration for laying hens wheat is today the cheapest grain. But no grain should be fed alone, at least not for any length of time.

There is no sense in supplying ventilation on a windy night, as few poultry houses are so built that there will not be a great plenty without. Still, with a tight house such as laying hens should have, ventilation is of utmost importance.

This is a form of bad management very frequent with amateurs and careless people and explains what they cannot understand: why they cannot keep their pullets at shelling. out eggs all winter. Fresh air is cheap. Then supply it to your laying stock.

Laying condition seems to heat their blood and the change from a warm, foul house to the frosty, sharp outdoor air of midwinter is too much for them and a cold is the result. Then pullets get out of laying condition and it may be weeks before they are laying again.

Lean meat, or its equivalent in insect life, is one of the essentials of egg production. If meat in some form was supplied daily, there would be sufficient eggs secured, over and above the number that would be obtained without the use of meat, to not only pay for the meat, but to increase the profits.

Warmth being a condition favorable to egg production, we must build accordingly for our laying hens. Warmth attained by crowding the house or by total absence of ventilation is worse than no warmth at all. Protection from the bitter and piercing winds and frosts of winter is mostly to be aimed at.

Bran, a by-product of flour, is also a very palatable poultry feed, in this way, however, in providing bulk. Cut clover will take the place of bran. I consider a mash three parts cut clover, one part bran, three parts middlings, one part finely ground oats, with the addition of some meat meal, about right for laying hens.

Clover hay should be fed in form of a mash, and middlings, ground oats, linseed oil meal and bran added. Green cut bone should be fresh, clean-smelling stuff only, should be fed in very small quantities, well scattered and daily. Wheat should be fed in litter only or where poultry run over fields, then over as wide an area as they will range.

On the range the pullets have been accustomed to a large amount of exercise and a great variety of food, and taking them from the above in 
the fall when laying or just at laying, confining them and feeding them mostly grain is not ealculated to push them right as to laying. The opposite happens, and the splendid harvest of eggs in prospect vanishes.

Middlings are sometimes known as "shipstuff,", "shorts," "seconds," "dark flour," ete. As millers endeavor to have the flour for family use as white as possible, they bolt very closely, the result being the middlings are separated apart from the flour. The middlings contain a great proportion of the very best of the wheat for feeding purposes to laying hens, while the larger portion of the flour is starch.

\section{THE SUMIMER CHICKENS.}

If you have been successful in getting out a large number of early chicks and desire to continue hatching during the summer you must arrange to keep the late chicks entirely separate from the early ones. If all are allowed to run together the early ones, which are by this time of good size, will trample over and crowd back the late chicks, with the result that the Iatter do not get the amount of feed necessary to force their growth. Then, too, the raiser who has a large number of early chicks generasy loses interest as warm weather approaches and does not look after the welfare of the lats broods as carefully as he did those that hatched early in the season. When this is the case late chicks are of but little value.

Suppose you desire to hatch during the summer in the hopes of having enough stock to supply all demands. You should care for the late hatch as carefully as you did the first little ones you took from the nest or incubator. When the December and January shows are on and many of your early cockerels are beginning to look a little coarsè and the early pullets have lost some of their grace and beauty on account of having commenced to lay, you go to your flock of summer hatched chicks and pick out your cockerels and pullets that will carry off the ribbons. This has been proved many times.

Every year there are a great many people who buy a setting or two of eggs and the chicks they get from these are the only ones they raise. Many times these people, who do not have incubators, are not able to obtain setting hens untıl late in the season, hence they must hatch their chicks during the summer months or go without. Now, there is no good reason why this class of poultry raisers shonld not buy one or two settings of eggs and get their chicks out during June and Tuly. It is folly to discourage, them. Not having any other young chickens to care for, they will naturally take a great deal of interest and give their summer hatched chicks the care they will require to bring them out in fine shape.

\section{Shade and Water.}

The absence of shade and the neglect to provide fresh water during the hot months will cause great suffering among fowls. The humane poultryman will not neglect these two important items. The water pail should make the rounds as frequently as the feed pail, and in very hot weather fresh water is more important than the mid-day meal.

An ideal range upon which to rear young stock would be an orchard or lot covered with small trees or brush having a living spring near by, with pastures, meadow land or grain field adjacent and over which the chicks might have free range.

With such a location the hen man is on "easy street" in many respects, as it will only be necessary for him to feed regularly and protect the flock from their natural enemies, which are very likely to abound in 
such a location. Not all of us, however, can have such a range "made to order," consequently deficiences must be provided for artificially. A substitute may be arranged by driving four stakes in the ground and covering over the top with limbs or boughs cut from trees or pieces of old boards, hay or straw may be used for covering. These sheds may be low, and need not be more than three feet from the ground, requiring very little work to make them, and no expensive materials; have plenty of them so that the chicks will not be obliged to erowd together when trying to escape the hot sun.

In the production of fine exhibition fowls, shade and plenty of it is a necessity, as all white fowls and many partly-colored ones will become "brassy" or faded if allowed in strong sunlight. Many of the winners at Madison Square and other large Eastern shows are said to have been raised entirely in the slade, and there is no question but that the fancier who is planning for a long string of premiums will greatly improve his chances for the same by giving due attention to the matter of shade for the growing chicks and adult fowls as well; under such treatment the plumage will retain all its natural brightness, and the fowls will present a much neater and cleaner appearance than if allowed to become faded and dingy.

\section{Process of Moulting}

With the older fowls beginning to look ragged, and loose feathers becoming plentiful in the houses and runs, the poultry yard will be less attractive than at any other time of the year. The egg basket will show a considerable falling off, many of the hens having ceased to lay. But to make poultry profitable, the birds should have plenty of care and attention bestowed upon them, so as to get them through the strain of molting as soon and with as little damage as possible. Fowls that have their liberty and are well fed usually go through this period without much difficulty. Those that pass the night in warm houses will generally begin to molt sooner than those that roost in cool, open outhouses or on trees. Special care should be taken that the birds have aceess to shelter during rainy days. A thorough soaking when they are nearly bare of feathers is apt to result in an attack of roup, or cause a chill, the effects of which will last for many months. Fowls that are confined to small runs should have plenty of green food, lettuce that is running to seed being as good as anything. Some Epsom salts will be found beneficial twice a week, as much as will make the drinking water taste slightly. A little flour of sulphur mixed with the soft food and given in the proportion of a teaspoonful to every three fowls two or three times a week on dry days will help the new feathers to grow. It is of no use to place a piece of stick sulphur in the drinking vessel, as some people do, for sulphur is insoluble in water,

'The cock should always be separated from the hens while the molting is in process. They will do well in small quarters, if kept elean, fed well and allowed some grit. Exhibition baskets are used by some fanciers to keep the cock birds in at this time, a run of a couple of hours during the day being all the liberty they have. Small and warm surroundings such as these promote and quicken the molt, which is a longer business for the cocks than the hens, owing to the time the sickle and other tail feathers require to grow.

Any birds that are likely to be required for show purposes must be kept out of hot sunshine, or they will become tinged and sunburnt. Old hens that are to be got rid of and which are intended to be killed for the table should be disposed of just as they begin to shed their feathers. It is not always easy to tell from the appearance of a hen, as she runs 
about, whether she has begun to molt or not. Some hens -will stop laying and will hardly eat anything for a few days and yet not shed any feathers, till they suddenly appear most bare. They will lose flesh rapidly during the interval after they have lost their appetite. If a visit is paid to the roost, those that are still laying will be found with full crops, while those that have stopped laying will have but little food in them. No great mistake, therefore, can be made if those hens that are on the perch at that time with empty crops are selected for killing. "The poultry house should be kept clean or the accumulation of loose feathers in the corners will tend to the increase of insect vermin.

The molting of the fowls is usually from June to November, sometimes extending well into winter. The molting season is not the same with all hens, nor does a single hen begin at the same period every year, but usually a month sooner or a month later. The hens that begin to molt early are those that finish their molting early, and are ready for laying before winter commences. Having completed their growth of feathers, they are in excellent condition for doing service, but should the process of molting extend into winter, the hens that have not yet finished by November will probably not lay until spring, consequently the matter of molting is one which all who are interested in fowls must deeply consider.

The molting process requires three months, and as the production of feathers requires a large proportion of nitrogen and mineral elements it becomes necessary to supply the fowls with something more than grain and grass. Carbonaceous food exclusively is detrimental, as the hen is inconvenienced by the fat stored on the body rather than benefited thereby, and yet the majority of poultrymen feed liberally on grain to their molting hens, in the belief that such food is the best that can be given. The food should consist principally of ground meat, cut green bones that have a fair proportion of adhering meat, but all fat foods should be avoided. A bran mash, composed of bran and mashed potatoes, will provide an agreeable change, while ground bone, milk and a little sulphur in the food once a day will benefit them highly. All hens not molting by November will prove poor layers before Christmas, and if such hens are fat they should be disposed of. It is a well known fact that if a hen or pullet does not begin to lay before the cold weather sets in, she will perhaps not begin to lay before early in the spring, but if she starts to lay before the winter begins, she will continue to lay for a long time, or until she becomes broody.

Pullets hatched in spring will not begin to molt until the following year, as only the hens will molt in summer; but a pullet that was hatehed very early, about January or February, may molt, though the chances are that she will not do so until next year. Clean, dry quarters should be provided for the hens that are molting, and lice must be kept down, as the hens that are molting will quickly suceumb to lice, owing to the debilitating effects of the process. As to the males, they should have been sold off long before, as it does not pay to keep one that is molting unless such male possess some characteristics that are sought, and the sooner the males are sent to market the higher prices they will realize.

More diseases are generally contracted during the molting period than at any other time, and by the use of good, sound, stimulating food, pure water, plenty of room, and good clean quarters only can we pull through it with safety. The heavy strain upon the constitution of fowls in casting their feathers is much greater than one would suppose, and if the best of care is not adopted they become reduced in condition to such an extent that the liability to contract diseases is so alarming that they can scarcely escape it. The worst thing that can be done is to crowd too many in one roosting place at night, in badly ventilated and unclean quarters. Make everything clean first, and use disinfectants. The best disinfectant that has ever been tried is crude carbolic acid and coal oil, about one pint of the acid to one gallon of kerosene. Use this cleverly 
and do not be stingy with it Thoroughly paint the roosts and the dropping boards, or better still, the entire inside of the poultry house. Paint the roosts once or twice a week through the molting season. Feed good, sound grain and by no means the refuse of anything. Do not confine them to one variety of food, but different varieties; corn, wheat, oats, buckwheat, any good, sound grain relish, and occasionally a little sunflower seed, if procurable, and a meat ration once per week.

\section{Food and Care}

No matter what kind of food may be selected there is no combination suitable for all purposes. First, determine what you intend to do, and then feed accordingly. One should not feed as much protein to nonproducers as to layers, as the production of the egg demands that the hen should have food rich in protein. The sitting hens, males, and hens that show no inclination to begin laying, do not require as much protein, nor as much food, as the layers. It may also be added that the growing chick must be well supplied with foods rich in lime (such as bone), as well as with a suffieiency of protein, as growth is evidence that it is producing flesh and bone. The pullet also requires more protein than the matured hen, and there arrives a period when the matured birds will not demand as much food as when younger. No rules ean be formulated for feeding all kinds of fowls, as each flock differs from others. The poultryman must determine for himself which of his hens require special foods, as breeds, egg-production, ages and other conditions must be considered. Do not overlook the fact that each hen is an individual and that she has her likes and dislikes, being profitable or unproductive according to surroundings and circumstances.

Do not make the mistake of buying oyster shell for grit. This is not grit and will not take the place of grit. Both are necessary, but if you must do without one let it be oyster shells.

\section{COMFORT OF THE FOWLS.}

In nine cases out of ten, failure in the poultry business is due to carelessness on the part of the earetakers. How many people neglect giving their fowls sufficient water; have no regular hours for feeding them and keep them starving for hours in the morning, especially if the weather is stormy? Yet they expect the hens to lay the same as if they were well attended. One of the main causes of failure is lack of eleanliness in the hen house. Dirt breeds insects. If the hen house is infested with lice, give the house a thorough fumigating, and dust birds with insect powder or sulphur. Remove fowls. Buy a few pounds of brimstone, place it in a pot in the hen house and set fire to it. See that the erevices in house are all closed. After the house has been fumigated, clean, whitewash with lime, and pour some coal oil on the roosts occasionally as a precaution. Clean the hen house daily in winter and empty ashes on the floors. Grit in winter is indispensable. Ground bone or oyster shells should be liberally supplied. Vegetables, meat, oats, wheat and bran should be fed alternately. Give boiled potatoes for one meal a day. Plan for the comfort of the egg producers and use them so well that they just can't help laying. Keep only young active hens.

\section{Green Bone for Poultry.}

Green bone not only furnishes almost the exact material required 
for the egg, but it stimulates and arouses the digestive organs, rendering other kinds of food of greater value in the economy of egg production.

Green bone will certainly make hens lay. I have fed it for a long time and noted its effect. I have sometimes been obliged to discontinue its use and have always observed a falling off in the number of eggs laid. Green bone at a cent a pound is cheaper than grain and far more satisfying. Forms or preparations of animal food for hens put in a condition for keeping any length of time may contain all the elements necessary in a hen food, but they are not so easy to digest as the fresh article. Preserved foods are never so healthy as the fresh.

\section{How Much to Feed Fowls Is as Important as What to Feed.}

The only rule for feeding is the rule of appetite. Keep the appetite good. To do this is the fine art of feeding. It cannot be taught; it must be learned by practice. Fowls do not eat the same amount of food each day. Pullets not laying eat more than the same weight of old hens not laying. Some breeds eat more than others, all other conditions being equal.

Remember that the hen that is laying needs about twice as much feed as she would need if not laying. Like any other machine, she must be furnished with the material from which to manufacture her finished product-eggs.

All food and drink has to be brought up to the body temperature before it is absorbed or digested. Supply water as needed throughout the daytime. Empty dishes at night.

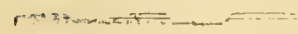

\section{Feeding Bran.}

One point in favor of bran is that it contains a much larger proportion of lime than any other cheap food derived from grain, and as the shells of eggs are composed of lime, it is essential that food rich in lime should be provided. It may be urged that the use of oyster shells will provide lime, but it will be found that it is the lime in the food that is most serviceable, because it is in a form that can be better digested and assimilated than carbonate of lime. Clover is certainly also rich in lime and when a mash of eut clover and bran is given to the fowls they will need no oyster shells or other mineral matter as a source from which to provide lime for the shells of eggs. But do not forget that in summer, however, the use of all kinds of food should be administered with judgt ment. If the hens have a free range, give no food at all as long as they are laying satisfactorily, but if they begin to fall off, let bran be a leading ingredient of the food supplied. In winter the bran and clover is even more essential, as the fowls can then not secure sufficient green food on the range.

\section{Green Food.}

Where fowls are kept in pens and yards throughout the year, it is always best to supply some green food. During the winter and early spring months mangel-wurzels, if properly kept, may be fed to good advantage. The fowls relish them, and they are easily prepared. As it is not difficult to grow from 10 to 20 tons of these roots per acre, their cost is not excessive. In feeding beets, split the root lengthwise with a large knife. The fowls will then be able to pick out all of the crisp, fresh food trom the exposed cut surface. These large pieces have the advantage 
over smaller pieces in this respect: The smaller pieces when fed from troughs or dishes will be thrown into the litter and soiled more or less before being consumed by the fowls. Large pieces can not be thrown about and remain clean and fresh until wholly consumed.

Clover, during the early spring, is perhaps one of the cheapest and best foods. It is readily eaten when cut fine in a fodder eutter, and fur-

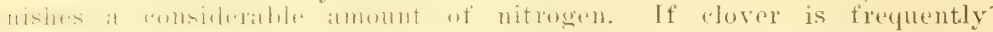
motred, fresh food of this kind may be obtained nearly all summer, partienlarly if the season be a wet one. Should the supply of elover be limited or the season unusually dry, green food may be cheaply and easily

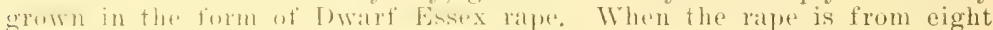
inches to a foot in height, it may be cut and fed. It furnishes a fresh, crisp food that is readily eaten. If cut a few inches from the ground, a second and sometimes a third crop will be produced from one seeding. Alfalfa will also furnish green food. It must, however, be cut frequently, each cutting being made before the stalks become hard or woody.

A good quality of clover hay cut fine and steamed makes an excellent food for laying hens if mixed with soft food.

Cabbages make excellent green food so long as they can be kept fresh and crisp. Kale and beet leaves are equally as good and are readily eaten. Sweet apples are also suitable, and, in fact, almost any crisp, fresh, green lood can be fed with profit. The green food, in many instances, may be cut fine and fed with the soft food, but, as a rule, it is better to feed separately during the midale of the day, in such quantities that the fowls have about all they can eat at one time.

Fresh green bone and meat after leaving the mill should be taken to some convenient place and spread upon the floor, where there is plenty of fresh air circulating and as little sunlight as possible. It can be well loosened by going over it with a common garden rake. After it is well spread out, take fine air slacked lime and sprinkle it thoroughly over the cut bone and meat until it is well covered. Rake it again until the lime adheres well to the meat. Then take corn meal and apply it freely in the same manner you dir the lime, with another good raking. Add as much corn meal as will be necessary to absorb the moisture and grease of the meat. Allow it to remain in this condition for several hours, when it should be gone over again with the rake in order to keep it in a drying condition, and in a short time it will be thoroughly cured and dry enough to keep the entire season without spoiling, providing it is kept dry.

\section{Grit.}

It is necessary that fowls have access to some kind of grit if grain food is fed in any considerable quantities. During the summer months, when they have free access to the yards or runs, it will not be necessary to provide grit, providing the soil is at all gravelly. If, on the other hand, the soil is fime sand or clay, it will be necessary not only to provide grit during the winter months, but throughout the whole year.

Small pieces of crushed stone, flint, or crockery ware will answer the purpose admirably. There are many poultry supply houses which keep constantly on hand crushed granite in various sizes suitable for nearly all kinds of domesticated fowls.

Crushed oyster shells, will supply the necessary material for grinding their food and at the same time furnish lime for the egg shells. Chemical analysis and experiments, together with the reports from many practical poultrymen, show conclusively that the ordinary grain and green food supplied to laying hens do not contain enough lime for the formation of egg shells. It will require several times as much lime as is ordinarily fed if good, strong egg shells are to be produced. Crushed

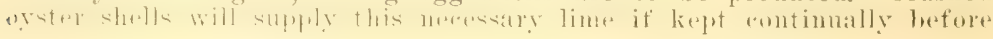


the fowls, trusting to them to eat the amount needed to supply lime rather than mixing the shells with food. The judgment of the fowl can be relied upon in this respect.

If the fowls are fed three times a day they should not be fed all thoy will eat at noon. Make them find every kernel. At night, just before going on the perches, they should have all they will eat up clean. At no time should mature fowls be fed more than they can eat. Keep them active, always on the lookout for another kernel of grain.

A good appetite indicates a healthy hen and no amount of medicine or drugs will improve her. Eggs are made from good food assimilated by a healthy condition, but if sickly and drooping she may be aided by proper treatment. A healthy hen is active and will scrateh and hunt all over the premises for what she likes, her comb and wattles will be red, and her performance on the nest will be to the profit of her owner.

Air slacked lime is fine as road dust and can be easily sifted all over the poultry house by the hand. Buy a barrel of lime, take another barrel and put a bushel of the lime in it, add a little water, enough to make a dry slack and you are ready. Sprinkle everything about the poultry house twice a week. It will prevent disease and banish sour stenches.

\section{FATTENING FOWLS.}

To fatten fowls, confine in coops or pens and feed at regular periods on a fixed diet. When first shut up they should be fasted for about twelve hours, to give an appetite for the new treatment. Feed three times a day at stated times. The food should consist of soft meal, corn meal, pea meal, barley meal or ground oats. Mix to a thin state with skim milk and give in a wooden trough, fastened to the front of the coop or pen. At the end of about a week the food should be made thicker; some beef or mutton fat is added, the quantity of which should be gradually increased. No water is required and grain is not necessary, though some feeders give boiled barley for the last feed in the day. Some flint grit is provided and some boiled nettles two or three times a week. The food must never be given when stale or sour. If a bird appears not to thrive during the process, it should be turned out in an open run without food for twenty-four hours and then replaced in the coop and tried again.

Some chickens fatten much more easily than others, but about three weeks is the usual time for the treatment to continue, before they are ready for the table. After a chicken is fattened it will not remain in the same state, but will go off and become out of health if the same diet is persisted in. It is therefore necessary to calculate the time, if the birds are required for eating at any particular date. No amount of feeding will make an old fowl tender; skillful cooking alone can do this. A cockerel that has been allowed to run with hens will as a rule prove tough and hard.

\section{Raising Ducks}

Duck raising is to be recommended to farmers as a profitable source of revenue; and by careful attention to the work, as knowledge increases, the scope of the industry may be extended. There are numbers of farms in this country today that are devoted exclusively to raising ducks, averaging from 5,000 to 20,000 ducks as an annual output. An idea of the proportions of the business may be had from the fact that as high as three tons of feed are used daily by a single raiser during the busy season. The beginner should start modestly, and increase his plant as his knowledge of the work increases. The average farmer has all the facilities for 
raising a goodly number of ducks, and may with a little outlay add considerably to his income.

It is not at all necessary that ducks should have access to water to be raised suceessfully; they grow and thrive as readily without. There are successful plants where thousands of ducks are raised that have no water save that which is given them as arink. It has been a matter of much dispute which is the better way. Some duck raisers use water and allow their breeders the freedom of it; some allow their growing stock intended for market free access to water until they are eight weeks old, when they are penned and fattened for market. On the other hand, there are raisers who have no water on their farms, excepting walls, who are just as successful and raise as many birds as those who have the water. The only noticeable difference between "upland" and "water" ducks is that the latter are of prettier and cleaner plumage than the former.

\section{Feeding.}

The food of the duck is both vegetable and animal in nature. In the wild state it gathers its food from brooks and marshes, consisting of flag, grasses, small fishes, water insects, ete. When the birds are raised in confinement this diet must, in a measure, be imitated to get the most satisfactory results. The duck has no crop, the food passing directly from the throat to the gizzard, and as a consequence the food must be in a soft mushy state. Too much hard food, such as grain, does not agree with these birds and they ean not thrive on it. While some raisers use a small allowance of grain others do not, and it has not been proved to be of any advantage to feed it. Soft food is their natural diet, together with grasses, vegetables, and animal food. The proper selection of the food is extremely important to secure the rapid growth of the duck, and the ingredients of the food must be such as will afford a well-balanced and substantial ration. As a whole, it may be said that the rations used by the largest duck raisers are essentially the same, differing only in the quantities used in the mixing. Investigations show the real value of the food to be the same for producing rapid growth and early development. The duckling grows twice as rapidly and is a much heavier eater than the chick, and to produce the best results its food must be such as will be easily assimilated.

Pure water is of the greatest importance for ducklings. It is often a good plan to give the water before feeding. Let them learn to find the water fountain as soon as they are placed in the brooder. If they appear stupid, take them one at a time and dip their bills in the water; they will soon learn the way and the first to learn will teach the others. Water to drink should be kept before them all the time, as they will drink and waste a great deal. It is absolutely necessary to their digestion that they have water close at hand when feeding. Unless the duckling has an opportunity to thoroughly rinse its nostrils frequently, clogging of the nostrils may take place to its injury.

(1) From time of hatching to five days old provide the following mixture: Cracker or bread crumbs and corn meal, equal parts by measure; hard boiled eggs, 15 per cent of the total bulk of crackers and meal; sand, 5 per cent of the total of crackers and meal. Mix with water or milk, and feed four times a day.

(2) From five to twenty days old, the following mixture: Wheat bran, two parts by measure; corn meal, one part; rolled oats, 50 per cent of this bulk; beef scraps, 5 per cent; sand, 5 per cent; green food, 10 per cent. Mix with water to a dry erumbly state and feed four times a day.

(3) From twenty to forty-two days old, the following mixture: Wheat bran, two parts by measure; corn meal, one part; beef scraps, 5 per 
cent of this bulk; sand, 5 per cent; green food, 10 per cent. Mix with water to a dry crumbly state and feed four times a day.

(4) From forty-two to seventy days old, the following mixture: Corn meal, two parts by measure; wheat bran, one part; beef scraps, 10 per eent of this bulk; coarse sand or grit, 5 per cent; green food, 10 per cent. Mix with water to a dry crumbly state and feed four times a day.

\section{Management of the Incubator and Brooder}

An incubator is today as much a necessity in the poultry business as poultry. You might just as well try to run an egg farm without bens, or cultivate corn without a cultivator, as to try to raise chickens wichout an incubator. Incubators have been used for thousands of years. In Egypt they are made of mud in the form of a large oven and the heat is kept up by a furnace fire. If one expects to have the early spring ehicken to catch the welcome half dollar he will be compelled to use an incubator. To raise chickens with an incubator is a business. An incubator is not a plaything to be looked at when you see fit. If you wish to hatch chickens with an incubator and be successful you must make up your mind to study and work. You must look after all the details; you must have a suitable place to locate the machine. "Any old place" won't do. You need a room where the temperature will not change too fast. We have found a good dry cellar to be the best place. Access to plenty of fresh air is very important in hatching chickens. The impression that an incubator does not require a great deal of attention is without foundation. This is true of sitting hens. Twenty or thirty hens sitting on eggs require a great deal of looking after and good management, or the production of live chicks will be very disappointing.

Do not commence to operate an incubator until you thoroughly study the instructions that come with the machine. It requires patience, attention, common sense and a certain amount of experience to manage an incubator or anything else successfully. The machine cannot do it all; the operators must do their part. Use common sense and you stand an equal chance with others for success. Do not expect too much at first. If you fail to secure the best results from your incubator or brooder at first, or to produce as many chickens as you should, don't give up in despair; try again. Did you ever think the fault may be in you and not in the machine? It may take a great deal of time and work to get rid of this fault, but keep on and if the fault is yours it will in time give way to success. Those who have raised chicks with old hens know the trials attached; you waste time seeing whether they are in earnest. When a hen will she will, and when she won't she won't. The incubator saves this time, it is willing to set when wanted. A hen is valuable when she is making some returns for her care, therefore she has not time to sit three, six or nine weeks out of a year and spend almost twice that much time looking after her chicks. Nowadays a hen's business is to lay eggs, and when not at that, recuperating for business. $\Lambda$ hen cannot lay all of the time. Nature has arranged a time during moulting when they can rest.

Fully 80 per cent of the eggs are now hatched in incubators. Buy an incubator, don't worry with broody hens. Buy "a good one," use common sense in running it and it will be a souree of continued profit and satisfaction. People think the death of all chicks that die in the shell is caused by the incubator, that they don't do that way when set under an old hen, but they do. The question is often asked, why do chicks die in the shell? No one knows. Let us remember that it is not the hen that hatches the chicks, it is the heat, no matter from what source the heat comes. Cases are on record where chicks have been hatched from the heat of a manure pile. 
Ostriches and reptiles deposit their eggs in the hot sand and leave them there to be hatched by the sun. After an egg has startel to incubate the germ may perish at any stage from lack of strength or any other cause. It is subject to diseases and weakness the same as any other living organism. The principal cause is attributed to the fluctuation of temperature, such as overheating or lack of a suffieient amount. A high temperature causes many chicks to die. This death may not be sudden, but they will die before the hatch is complete. The stronger the vitality of the egg the more apt are chicks to hatch and live. Many operators think they have kept the temperature as near perfect as it is possible, and yet there are conditions which will upset all calculations. Thermometers are not accurate; the thermostat is out of order, the flame of the lamp is subjected to differences in the atmosphere, and is thus permitted to go wild, and the distribution of heat in the egg chamber becomes irregular.

The germs of life will not live if started at too high or too low a temperature. Place two or three thermometers in the same machine and regulate the heat according to the average of the same. If the lamp end of the machine is warmer than the opposite end, lower the lamp end onefourth inch. By so doing you will increase the heat in opposite end of machine one degree. Remember heats travels upward.

Ventilation is also a cause of much trouble, lack of which kills lots of chicks. Follow elosely the instructions which come with the machine in regard to turning, testing and cooling the eggs. Hatches are better and chicks stronger when the eggs are turned by hand. Turning the egg ripens it clear around, and every movement of the egg makes a corresponding movement of the embryo chick. These movements wake the chick up, giving it exercise. The trays must be shifted to equalize the temperature. Change position of the trays from front to back and end to end.

Next comes the cooling of the eggs, which is very important. The egg shell expands in heat or contracts in cold. This expansion and contraction (the result of airing the eggs) breaks the tough fibers of the shell, and when the time comes for the chick to hatch it can hatch. The eggs should be tested the tenth and fifteenth day of the incubation. Only good, fertile eggs should be left in the machine. After the tenth day start with cooling the eggs five minutes and increase the time each day until you have cooled them twenty to thirty minutes, which can be done if the temperature of the room is 70 degrees or above. Cooling and turning as mentioned above gives better hatehes, stronger ehicks and less cripples. Stop turning and cooling the eggs on the evening of the eighteenth, and do not open the incubator again until the chicks are ready to take out and put in the brooder. If temperature and ventilation have been about right the chicks will commence to pip on the nineteenth day, and should all be out at the end of the twenty-first day. No set of rules can be given for running an incubator, as each hateh is a law unto itself. No two are exactly alike. The general principles of management must be thoroughly understood, and the more we know about incubation the better we will be able to adapt the machine to the needs of the developing embryos.

\section{Airing the Eggs.}

Results have taught me that airing the eggs during their incubation makes them hateh better. The plan is adrised by all experienced incubator operators, but very seldom do we see the reasons explained, the answer, or why, is very much like the small boy's "because."

Let us reason it out a little. Let us assume that the chick in the shell is a live thing, needs exercise, a change of condition, a waking up, to make it move, expand and develop its own strength. It does not 
take a great deal of imagination to take these things for granted. We see the sound logic verified in other things than eggs. It is, after all, the natural things tending to develop nature.

Exercising and developing the chick's strength is not all there is to it. This same airing has its influence on the shell; it ripens it. There are, perhaps, things that do not expand or contract with heat or cold, but they are not egg shells. By carefully conducted experiments, I find that eggs perceptibly expand under a temperature of 103 and at 60 again the difference is easily detected with an ordinary machinist's calipers.

These airings, or contractions and expansions, serve to break down the shell's fibres, have a tendeney to weaken the stiffness and to make brittle, etc., hence, when the chick is due to hatch, it can break through and separate the shell without exhausting its feeble efforts.

A popular idea is that the eggs should be cooled down just so much by the thermometer lying on the eggs. Place no dependence on the theory. The real facts are, the thermometer adjusts itself to the temperature of the room more than it does the eggs; the thermometer is misleading. In getting at the question in a logical way, if the eggs are plenty warm and the room comfortable, they can be aired 30 minutes, while if both the eggs and the room are cool the airing should be delayed until the eggs are plenty warm and perhaps five minutes would be long enough.

Airing eggs during incubation should be governed by considerable judgment. I would not advise much airing during the first week of ineubation, a little more the second week and still more the third week. This plan is tempering the work in accordance with the growth of the chick and the needs of the situation, and I believe it copies strongly the natural doings of the setting hen; anyhow it leads to success in the artificial method.

\section{A FEW INCUBATOR DON'TS.}

Don't use poor oil. Don't use a short wick. Don't buy a cheap incubator. Don't forget to test the eggs. Don't slam the incubator door. Don't tinker with the regulator. Don't forget to fill and clean the lamp. Don't heap up the eggs in the incubator. Don't open the incubator door at hatching time. Don't turn and cool the eggs when they begin to pip. Don't run the temperature too high. Don't be in a hurry to take the chicks out of the incubator. Don't try to hatch eggs you would not set under a hen. Don't turn the lamp wick too high, it will make the lamp smoke. Don't fail to clean the incubator after each hatch. Air a day or two before resetting. Don't leave incubator door open when you take the eggs out to cool or turn them. Don't fail to study the directions and follow them carefully.

Those who have used incubators will generally have a preference for one form and make of incubator. I must confess to that failing, but at the same time I know that while there are good makes and bau makes all those makes that have been on the market for several years continuously will hatch well if intelligently operated under proper atmospheric conditions. I believe also that many makes of incubators can be so operated as to hatch all eggs that any hen could hatch, and fully as strong chicks, too. Anyone who has had much experience with sitting hens will readily appreciate the advantage of incubators in place of hens. The apparent advantages from my point of view are:

1. The incubator is always ready. You do not have to wait for it to become broody, nor to waste time and eggs in finding out whether it is broody enough.

2. It never leaves the eggs, nor tramples them, nor refuses to sit where you place it, nor throws any eggs out, nor kills any ehicks when they are hatched. It is absolutely proof against eannibalism. In fact, your eggs are not subject to any one of the caprices that biddy may be addicted to, and they are legion. 
3. The incubator will hateh a large number of chicks, which may be brooded together in large lots, and thus the cost and trouble of rearing is lessenert.

4. Incubator chicks are more tame and tractable than chicks hatehed by hens, and this, with small, nervous breeds, is a valuable consideration.

5. Incubator chicks are not hatched with lice on them, and need never beeome lousy while being brooded, whereas "eternal vigilance is the price of liberty" from lice in most cases where a hen hatches and broods chicks.

6. Finally, I believe that chicks may be reared more rapidly and to better development when there is no hen to interfere.

There seems to be less dissatisfaction arising from the use of incubators as the years roll by. The reason for this is because incubator manufacturers realize that a machine must he mechanically perfect to survive the tremendous competition of these later years.

More incubator hatches are spoiled by the anxiety of the sperator than from any other cause. Get the machine going properly and don't bother it, except to turn the eggs and fill and trim the lamp. If the temperature rums up or down reset the regulator but do not try to bring the temperature back in five minutes.

Almost infinite are the reasons for dead chicks in the shell. The incubator manufacturer is not the responsible party. If the incubator will produce sufficient heat, will permit accurate regulation of heat and will permit a wide adjustment for ventilation, the manufacturer has done his part. The rest of the responsibility rests. with each individual operator and breeder.

Not everyone who has gone into the poultry business will remain in it. Many will not find it to their liking, while others will not have sufficient energy and persistence to learn its details. The poultry business is one of the most stable lines of business in the world to-day. Its products are always in demand in every town and eity in the world. No prejudice of religion or caste stands in its way. Sales are not limited as to locality or season. When use of the incubator becomes known, when farmers generally become acquainted with its management and its advantages, then will the public learn that the supply of poultry products is regular, and then will the use of these products be greatly increased.

So few persons begin using incubators with even a knowledge of the rudimentary principles of artificial hatching and rearing fowls that the greater wonder to me is that as many suceeed as do. If people went headlong into almost any other business they would expect nothing short of failure. However, in this work, they think they can succeed, without experience, guide or study.

The poor incubator is put in all sorts of places from the barn or cowshed to the attic or cellar. It is run in all sorts of weather, temperatures and degrees of humidity. It always gets the blame if the eggs do not hatch or if the chicks die after they are hatcher. After twenty years experience with incubators and broocters I propose telling in as few words as possible a few things that the machine can do and a few of the many things that no machine should be expected to do. It will pay you to spend a little time studying this subject if you contemplate using the inculbator or brooder in raising poultry.

Eggs must be from good, strong stock, fertile and fresh to hatch well. Eggs must not be subject to chills, jarring or other rough usage, impure air, too great heat, too much moisture, nor, as a rule, to continuous heat, to hatch well. The temperature of the room in which a machine is run should vary as little as possible, about sixty degrees Fahrenheit is a good temperature. Hot air machines are more readily heated and cooled down, hot water machines will stand greater variations in ontside temperature, as the egg chamber will be slower to respond to either heat or cold from without. For late hatches it is best to run machines in a cool, dry cellar. 
No machine can make good hatches from poor eggs-those lacking in fertility or high egg quality. No machine can hatch chicks strong enough to live if not properly brooded afterwards. A hen could not do it, and a machine can't do it either. Few people there are who do not have to learn by hard experience that brooding the chicks is the greater seience of the two, and must be mastered before any great degree of success is assured.

There is one secret of success which must be known before any work on an enlarged scale can be entered into with full measure of satisfaction and success - this is a necessity for the use of a good incubator. Those who want early chicks in large numbers are simply compelled to its use. Especially is this the case with the broiler and duck raiser; but almost equally true is it of the grower of fowls for egg machines. The early pullet is the one chief reliance for success with the last, she is a possibility, only through the use of the first-class incubator, she is a necessity to herself, for without her there will be no sitters, and no chance for a continnation of her kind for the next season's work. The incubator is merely an always-reliable "early sitter," which will always continue the line of early pullets. In the enlarged enterprise it is simply a "must have."

\section{Plan for Brooder House}

The proper construction and equipment of a brooker house is one of the most important items on the poultry farm, as the sucess of a poultry plant is largely dependent upon the brooding facilities. The house most popular and profitable is the hip-roofed, single house. This house is seven

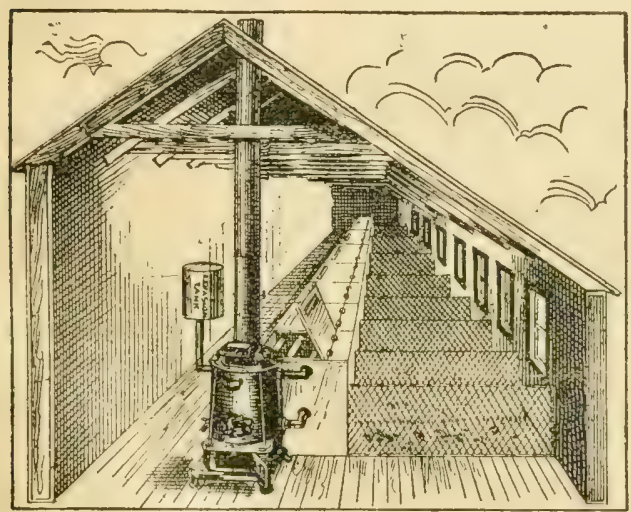

feet high at the back, eight feet at the ridge and five feet at front. We recommend building sixteen feet four inches in width and any length desired. It has a three-foot eight-inch walk along the back, leaving the hover runs twelve feet long, divided off in five foot sections. The cuts and figures here shown are for a twenty-five foot house. In building larger the length only is increased as if a 50 . foot, 75 -foot or a 100 -foot house is desired the bill of material can be multiplied. by two or three or four. To each five feet of hover run there should be a six-light $8 \times 10$ window set in the center of the front of run. The house should face south or a little east of south. These windows should come down within sixteen inches of the floor and should be hinged at the bottom. Do not put more glass in a brooder house front than this, as it makes it too warm in summer, while in winter it frosts up and makes the house too cold. Furthermore, there is nothing to be gained by more glass. It is well to put at least two windows in the back or 'North side, to each twenty-five feet of house. These should be double windows with inner sash hinged at the bottom, the outer sash hinged at the top. In summer the outer sash can be removed. Ample ventilation may be furnished by opening these rear and front windows.

For sills use $4 \times 4$, which go around outside of the house. For the inner 
sills, except that bordering the walls, which is $4 \times 4$, use $2 \times 4$ set ou edge; these alle fomr feet apart at centers. In setting the posts eare should be taken that they are set in a straight line and sawed off on a level. Should the ground be sloping it would do no harm to have one end of the house a little higher than the other, but the end which contains the heater pit positively must be the lowest. Remember that hot water flows up hill and not down, therefore the heater in the high end of the house would give constant trouble.

\section{HEATING.}

The proper heat for chicks is of the greatest importance. We suffer just as much if too warm as we do if too cold. So do the chicks. Too much heat will kill the chicks and so will too much cold. The person who will get up at night to change the heat, when the weather suddenly changes, is the one who will raise his chicks. The other party will lie in bed and wonder why his chicks die off so rapidly. When our chicks are first hatched, we keep the temperature of the hover at 90 degrees, and continue to do so for a week, but keep coaxing our chicks out to an adjoining space, to scratch and exercise, and hustle for their food. At the end of a week we begin to lower the temperature as rapidly as possible, perhaps a half degree or more daily, depending upon their health and strength and teathering. and their general feeling for more warmth.

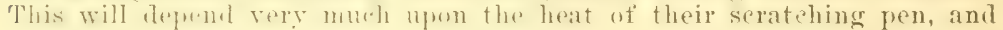
the temperature out doors. If they open their mouths and pant they are too warm; if they scatter they are warm enough; if they crowd up to and over each other they are too cold and must have more heat. A strong, vigorous chick will live if you will let it.

The word "comfort" "best expresses the condition required for the chick's rapid growth. It isn't necessary that the thermometer in a brooder be constantly watched to see that exactly such or such a degree of warmth is maintained. Experienced brooder managers aim to keep a good, strong heat under the hover, so that the youngsters can run in under it to get warm, then ont again for a bit of food or a sip of water, and when cool, another run in under the well-warmed hover keeps the blood circulating and everything moving comfortably.

Get the brooder thoroughly warmed up and running well two or three days before you want to move the chicks into it. The temperature under the hover should be fully ninety degrees for the first few days, then gradually reduced at the rate of about five degrees a week till seventy to seventy-five degrees is reached. The season of the year and the weather conditions have to be considered, a somewhat stronger temperature being maintained in cold, blowy or stormy weather than where sunshine and warmth prevail. As night approaches a greater degree of warmtl should be given invariably. If you find the chicks spread out over the floor under the hover (instead of crowding together) with their heads sticking out through the slits in the curtain, you may feel sure they are comfortable and that the conditions are right.

Regularity establishes best health and habits. As Iong as the chicks scratch they are safe and not overfed. After the chicks commence to feather out they can he fed cracked grain; boiled wheat is one of the best growing feeds. They should have dry bran, charcoal, grit and beef serap before them all of the time. Clean quarters, fresh air, sunlight, shade, sand to wallow in, clean water to drink, green stuff, good, wholesome grains, green cut bone, plenty of grit, and you will raise good, strong chicks. Your success will depend largely on how much thought and study you give them. 


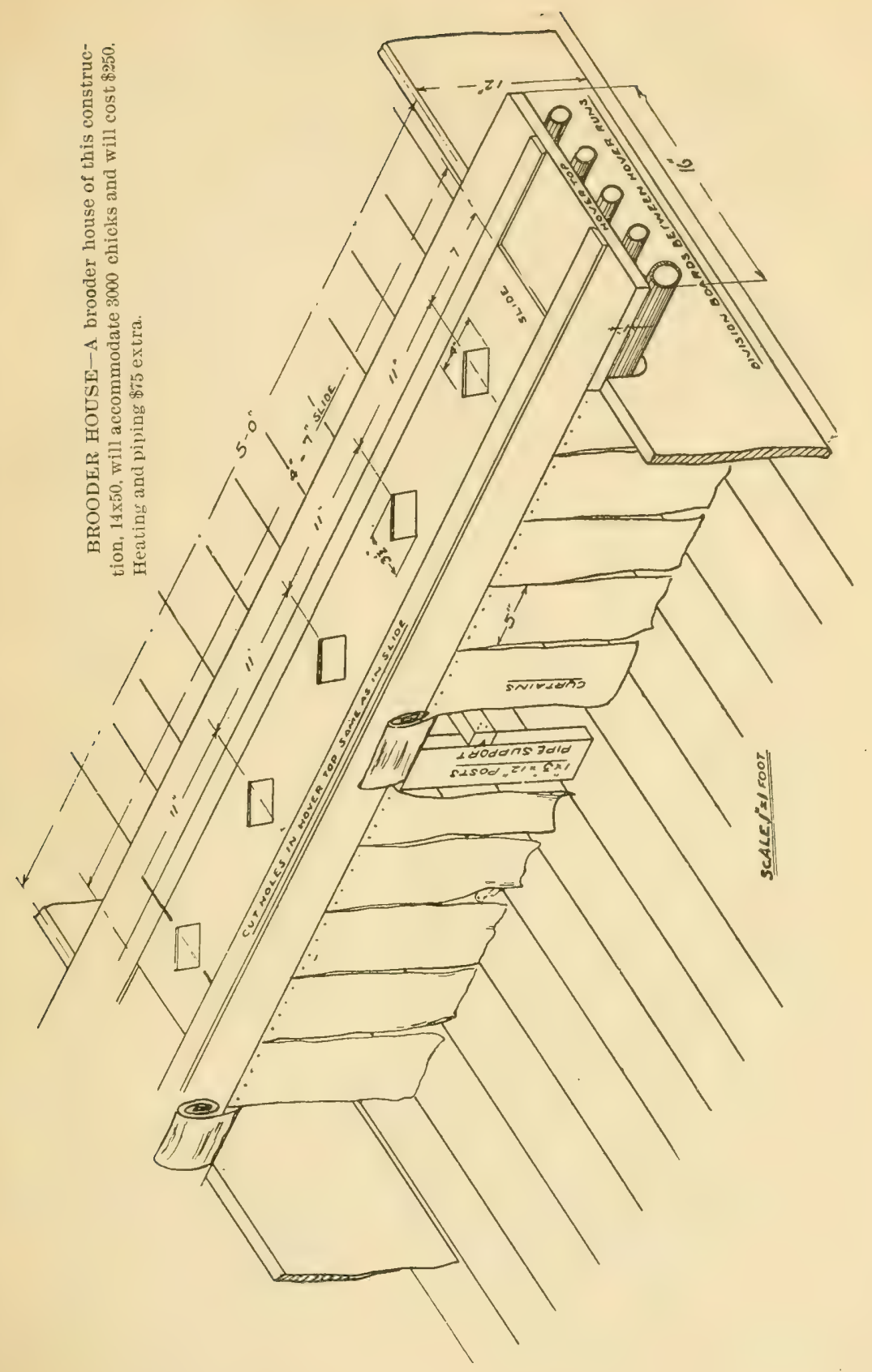


In addition the feed question now becomes important, but if there is one condition more essential than another it is uniform heat in the brooder, and this means not over three degrees variation up or down from the mark. There is a reason for this and perhaps by giving it the reader will understand more fully the importance of observing this rule. The nourishment and growth of the chick are dependent on absorption of nutrition. The nutritive material is first digested and then assimilated or absorbed. These are vital processes, and all vital processes can only proceed at a fixed temperature called the vital temperature. If it falls below this these processes are either checked or cease entirely and instead of physiological ease we have disease.

These processes once checked usually cause death, while it may not follow immediately and the stunted body may linger a long time. Com-

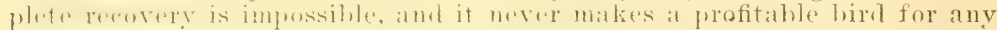
purpose. This miformity of temperature is the first necessity and must be maintained regardless of cost.

The first question to ask yourself is, Do I wish these chicks to live and grow, or struggle and die? If the former, you must provide the best appliances obtainable and use every means known to render them effeetive.

\section{BROODER CHICKS.}

In raising brooder chicks, perhaps the first important thing is to have a handy spot to be used as a cemetery; next a brave spirit. Don't get discouraged when you find the chicks dropping off one, two or half a dozen a day. Don't get hlue. 'There may be some who think there is no need of a "cemetery" or "the blues," and that chickens brought up as they should be will not die. That is true, but how many raise a llock of chickens from the incubator to a marketable age? Such cases are so rare that they serve as a glowing account for the newspapers, where the innocent are cucouraged to go into the poultry business, where will be found plenty of money and an easy occupation. Such glowing accounts also have a tendency to discourage the amateur already in. If we have diseouragements and failures that would paralyze most people, discouraging times, hard work with ehickens when everything seems dark, blot them out and start over again; try and win through the rough school of experience. The tuition often comes high. Our watch word should be, "What man has done man can do." There is much in the past that can be used as object lessons and guides for the future. It requires more of an expert to count the chicks (the same number) when ready for market than it does to count them before they are hatched. There are reasons for this decrease in number, but it does not seem so large until the season is over; then it is too late to mend. By another season the troubles are forgotten and many go through the same experience as before.

I believe that not one-half of the chickens hatched reach a marketable age. Their death is eaused by poor management and a lack of knowledge of the business. Most chickens are given their liberty on the farm where all sorts of dangers are lurking near, such as rainstorms, rats,

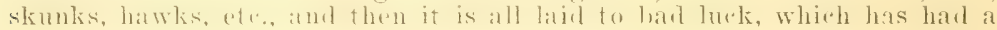
good many things laid to it that never belong there. Each dead chicken represents a fifty cent piece. If every poultry raiser would keep in mind that every dead chicken represents so much loss, so much less cash returns, he would take more pains to prevent the losses. Raising chicks by artificial means is an art, but with the best of appliances it is iully as suceessful as with hens. People have said, what a task it is to look after young chicks. I do not consider it such a task since learning how to use common sense and system about the work. 
Just before leaving the shell the chick draws into the body the whole of the unabsorbed yolk of the egg. This is its food before and after leaving the shell. It must be exactly right, as nature never errs. It is the food nature provided to sustain life until the chick is strong enough to take other food. Chicks should not be fed until 48 hours old. If fed too soon or too much the yolk of the egg which it took into the body before leaving the shell will not be drawn upon; it will remain unabsorbed and in time decompose, causing bowel trouble and death. The greater number of ehicks which die of bowel trouble do so at about a week or ten days of age. If you will open one of the chicks, nine cases out of ten you will find decomposed yolk in the yolk sack. Chicks normally hatehed and given almost any kind of eare will live and seem to thrive for the first week, then the tronble begins. The critical period in the chick's life is the first two weeks. Starting the chicks right is half the battle. When they have arrived at the age of three or four weeks, they have nearly passed the dangers of chickendom. One great danger is overfeeding. The young ehicks require but little food for the first few days of their life. Their digestive organs are not strong, and by overfeeding it overtaxes the digestive system and bowel trouble results. Improperly feeding chicks, especially for the first two weeks, unmakes more would-be poultrymen than any other thing in the whole business. It is the foundation of all diseases. It is essential that chicks should be well born. There is no mystery about feeding chicks. It is easy and only requires common sense. When this is lacking better tackle something else. Chicks die of "too high living." No matter what the feed, be careful to just supply the needs of the chicks. Better keep them just a little hungry than to feed too much.

After the chicks are a. few weeks old they will be able to stand more feed. Failure in brooder chicks is due to the care given them. In most eases it is wretched. The more care you give them the larger the returns. Lice prey upon the chicks if brooders are not kept clean. They should be cleaned every day. When lice and mites are present you feed in vain. "Verily the path of the brooder chick is strewn with thorns" if you do not give them constant eare. As has been truthfully said, "it is one thing to hatch the chicks, but another to raise them.", I don't claim to know it all; far from it; but there are a few things that $I$ have found out through sad experience and that I can properly elaim as my own. I shall endeavor to give a synopsis of the method I have found to be the most successful. The only right way to start is to start.right. The breeding stock must be healthy and vigorous. If this is not the case you had better quit before you start.

The first essential to success in rearing ehickens is plenty of warmth. On the other hand, too much heat must not be supplied lest the ehicks become too tender, like a hot-house plant. This year I have a brooder house equipped with up-to-date machinery. Heretofore I had to improvise ways and means of my own wherewith to accomplish my desire. My experience may be of help to some one situated as I was, on a farm, without suitable poultry buildings. The first year that I hatched chicks with an incubator I had 800 . I put up an old tent, placed a stove in it and my brooders. During the day the chicks were turned out of the brooders in little pens which I had made. After the chicks were old enough to leave the brooders, I put them in boxes in small numbers. One night a storm came up, blew the tent away, and in a pouring rain we carried the chicks to the barns, house, ete., without the loss of one. When you are in the poultry business to not be afraid of storms and heavy rains. Many a time when a storm came up I have run to hen houses and yards, it often storming so I could not get back to the house. When one is at home there is no oceasion for losing chicks by heavy rains. "Where there is a will there is a way."

If the chicks do not get sufficient exercise they will be falling ill with leg weakness, howel diseases and other ills. In cases of this kind something else usually has to bear the blame-the brooder or the feed or 
any of the hundred and one excuses a poultryman can raise, if things go against him, and if they will hide his carelessness and neglect.

Nothing conduces to a steady growth of chicks more than ample shade during the extreme warm season. Shade, if not provided by fruit or other trees, should be supplied by covered runs. Plant sunflowers liberally-they will provide shade and feed, as few things furnish a better feed than the seed from sunflowers.

\section{A CATECHISM.}

When a beginner is losing his chicks and he wants to know why, let him ask himself the following questions: Are his chicks from fresh eggs, laid by healthy, vigorous parents, whose combs were red and rosy? Did he let the eggs in his incubator ever get too hot or too cold? How does he know? Did he examine the thermometer in his incubator daily, both very early and very late, and between times? Did he ever let his chicks get too hot or too cold? How does he know? Did he elean out his brooder daily and put in fresh litter? Did he have more than 25 chicks in one brooder? Are the chicks taught to scratch their food out of the clean litter four times daily? Are their dishes washed clean daily? Is pure water before them all the time in clean vessels? Are the chicks so carefully housed that no enemy can possibly reach and kill them?

The handling of brooder chicks during the summer months has much to do with their health and rapid growth. As a rule they are continued in some brood coop which may be of sufficient dimensions to accommodate them, but by their rapid growth they. soon overerowd it and consequently fail to obtain the proper rest and freedom they require. They also become overheated by reason of the high temperature, caused by warm weather and the heat from their bodies, which unfits them for the sudden chill of the morning on being released from this pent-up prison. Owing to other demands on the breeder's time, or from sheer negelct, they are allowed to continue in these quarters, often through the entire summer, and is it surprising that many of them fail in making rapid growth, or are subjects for roup, diarrbea and leg weakness? More than all this, such coops are often neglected and filth accumulates in them until it is one, two, three and even four inches deep; possibly while in such a comlition a heary rain sets in and the chicks on emerging from such quarters are besmeared and bedaubed with their own filth until it would be difficult, often, to distinguish the breed whence they sprang. This is no idle or extreme statement; in fact, it is of frequent oceurrence to find it unexaggerated on the farm and even in breeder's yards, who make pretentions as good breeders.

To gain the best and most rapid growth the young chicks on being removed from the brood hen should be taught to go on perches provided especially for the purpose and thus prevent crowding, and where cleanliness and good ventilation can be had at all times.

\section{GROWING CHICKS.}

Much has been written on growing chicks. Probably many have written on almost the same lines but with different wording. Some beginners have been able to grasp the writer's meaning-others have not. There is only one right way. By attending to the many small things that many think unimportant. We have seen experienced poultry raisers feeding well, housing well and yet neglecting watering -in our mind one of the most important of them all. From the beginning the baby chick should have clean, fresh water before it at all times. They drink many times during the day-the first thing in the morning and the last at night. In the fall, 
winter and early spring water should be slightly warmed to take the ehill off. In the late spring and summer the water generally used is not too cold. As soon as possible get the chicks on the ground that they may obtain natural green food which they crave. Feed fine cracked grain, wheat, oats, millet, barley the first eight weeks with good meat scraps every day after they are ten to fifteen days old. Use judgment in the feeding of meat, as excessive use of it sometimes causes weak-legged chicks. At eight weeks the chicks are ready for a mash once a day, using bran, shorts, a little corn meal, the meat scraps being fed in the mash three to four times a week. Cooked potatoes, etc, are good if used now and then for a change. We do not believe in heavy corn feeding to growing stock unless foreing for broilers or market. Neither do we believe in having meat scraps before the chicks all the time, for when they are hungry one can see them going for the scraps in the hopper to take the place of grain they should eat. Keep them a little hungry at all times. This induces them to keep active in search of food, making them exercise, which is essential to promote strong growth. Even on a good free range they do not get bugs or worms enough, and the meat should be fed as stated above. Never neglect the grit and charcoal. While nice chicks have been raised without it, it is better to be on the safe side and have it before them at all times. See that they are supplied with shade. The growing chick needs shade as well as sunshine. Do not keep above fifty in one house, and if possible give them all the run they desire. We have grown June-hatched chicks that made good winter layers and proved valuable birds in the breeding yards. But the beginner seldom has the same success, for the simple reason that during the five or six months they have a check-sometimes two or three. Chicks once checked can never regain what they have lost, be it either through poor feed, chilling, crowding, overfeeding, ete. We do not believe in forcing maturity. But by a steady healthy growth fowls will prove earlier layers, more steady and longer-lived as to egg production. Separate the male birds as soon as possible that the pullets may have the range or yards to themselves. Keep them contented. A happy, contented chick is a growing one. Keep the house elean. It need not be cleaned every day. Use judgment in the management of your fowls. If brooder chicks you will not be troubled with lice if every precaution has been used. If hen raised use one quart kerosene to one ounce of carbolic acid for the little red louse. This is also a good disinfectant. Purchase good, clean feed. It pays in the end. At the end of the fifth month the fowls can be yarded in their permanent quarters that they may become accustomed to their new home. In clean, comfortable houses, fed with good, clean feed, the fowls are happy and contented and prove profitable. Attend to the many small details. The small ones count, and poultry raising will prove a source of income never realized by those who give their fowls indifferent eare.

\section{Poultry Diseases and Insect Pests}

In order to assist poultry growers, the cause, symptoms, and treatment of some of the most common poultry troubles are given very briefly below:

\section{Roup.}

This is one of the most common disease in poultry. It is caused by a bacillus. The disease germs are most likely to attack fowls that are housed in quarters where there is filth, foul air, and cold drafts. It manifests itself by hoarse breathing, swelling about the eyes, and discharge at the nostrils which dries and clogs the air passages so that the 
fowl must open the beak in order to breathe. Slaughter and burying deeply is the best treatment, to be followed by thoroughly disinfeeting the quarters, and the feeding and drinking troughs so as to destroy any germs that may remain.

If the fowls are worth the trouble, the following treatment, when adopted in the earlier stages, will usually prove effectual: Dissolve two ounces of permanganate of potash in six and one-half pints of water. Completely-submerge the fowl's head in this solution, and hold it there as long as the bird can endure it without choking to death. This will cause it to sneeze, thus forcing the solution through the nostrils when it comes in contact with the diseased parts. Repeat two or three times, morning and evening. Next dilute some of the same solution with four times as much water and give the fowls to drink, allowing no other water. Do not mistake a cold for roup.

\section{LICE AND RED MITES.}

Either of these is sufficient to destroy whole brooder flocks. Lice present one of the dangers to the raising of small chicks with hens. The hen-hatched chick, the hen-mothered chick, is in constart danger of having lice make its life miserable, if indeed they do not end it. You cannot hope to raise any ehicks in brooders infested with red-mites, nor chicks housed at night with the hen, where mites are plentiful. Lice and redmites give you all the symptoms of all diseases. Whenever you have sick chicks look first for vermin. It will be time to think of other causes of disease when you have cleaned ont the lice tribe.

No matter how free from lice your birds were last year, no matter how thoroughly you got rid of them this spring, you must keep in mind and watch for lice. You may have overlooked a few in your killing process, and the few lice of April may become a hundred thousand in June. Lice are not so hard to get rid of as are the mites. Lice live on the birds, while mites spend their resting hours in cracks of nest boxes and walls. ihey are out of reach much of the time, coming out for food only at night unless they have been kept from food by the method of the poultryman. Some of the worst cases of "cholera" I ever was called to advise upon, were due solely to the work of red-mites.

Until the chicks are feathered you should look at a few every day with the thought of lice. Examine carefully the heads of the chicks. Take time for this, do it carefully, or you will overlook lice many times. Whenever you find the large head lice, grease the heads of the chicks with olive oil or lard. Broorter chicks seldom need to have this done more than once, but hen-raised chicks may need it every week.

Red mites can be fought by using one of the liquid lice killers now advertised, painting the inside of the brooder on a warm day when the chicks can be shut out for several hours. This liquid killer will injure chicks if shut in with it for any length of time.

\section{THE GAPE DISEASE OF CHICKENS.}

This common and destructive disease of chickens is due to the presence in the windpipe of the gapeworm, known to scientists as Syngamus trachealis. These worms obstruct the passage of air to and from the lungs, and thus occasion the characteristic. gasping movements of the suffering chicks. This disease has been carefully studied by the Kentucky Station. It was found that "the commonly recommended practice of introducing into the trachea a partly stripped feather, or a bluegrass top, and by a twisting motion dislodging anl removing the worms does not seem to be practicable for very young chicks. The trachea is so small and so easily injured that it is impossible to dislodge and remove 
all of the tworms by such means. Chicks generally recover without treatment when they are attacked after they are half grown, and henee fowls that might from their size be treated successfully with a feather do not require treatment of any sort. It is the very young chicks that suffer most, and the only remedial treatment in their ease that seems to be successful is rubbing the neek from time to time with lard or vaseline, thoroughly mixed with a little turpentine (three parts of the lard or vaseline to one part of turpentine.) This treatment should begin before the disease makes its appearance. It will not help a chick in the last stages of the disease. Pure turpentine will very quickly kill a chick when rubbed on the neck over the trachea.

Chickens contract the disease when allowed to run on soil which has become infested with the gapeworm or when fed earthworms. Keeping chicks on a plank floor for several weeks after they hatch will prevent the gapes. It is probable that the same result would be obtained by simply elevating an earthen floor above the surrounding level, so that it would not retain moisture. It must be remembered, though, that after the disease is established in a brood it will be conveyed from one to another through the medium of food and drink, and in sueh ease a plank floor would not alone save it. In ease the disease should be introduced by ehicks which had contracted it elsewhere, the proper treatment would be to isolate atfected individuals as soon as discovered and medicate the drinking water of the rest.

It has been claimed that hens may be infested with the gapeworm without showing any evidence of the fact, and may thus be the means of transmitting the disease to the chicks. If this be true, it becomes important to see that the brood hen is free from the disease before the chicks are hatched.

\section{Chicken Cholera.}

This is an exceedingly fatal contagious disease, which is widely distributed over this country, and eauses annual losses, especially in the central and southern sections of the country.

The first symptom of the disease is, in the majority of cases, a yellow coloration of that part of the excrement which is usually white, quickly followed by violent diarrhea and rise of temperature. Other common accompanying symptoms are drooping of the wings, stupor, lessened appetite, and excessive thirst. Since the disease is due to a specific germ, it can only be introduced into a flock by direct importation of this germ, generally by fowls from infected premises. As soon as the symptoms of the disease are observed "the fowls should be separated as much as possible, and given restricted quarters, where they may be observed anil where disinfectants can be freely used. As soon as the peculiar diarrhe is noticed with any of the fowls, the birds of that lot should be changed to fresh ground and the sick ones killed. The infected excrement should be carefully scraped up and burned, and the inclosure in which it has been thoroughly disinfected with a one-half per cent solution of suphuric acid or a one per cent solution of carbolic acid, which may be applied with an ordinary watering pot. Dead birds should be burned or deeply buried at a distance from the grounds frequented by the fowls.

"The germs of the disease are taken into the system only by the mouth, and for this reason the watering troughs and feeding places must be kept thoroughly free from them by frequent disinfection with one of the solutions mentioned."

"Treatment of sick birds is not to be recommended under any circumstances. The malady runs its course, as a rule, in one, two, or three days, and it can only be checked with great difficulty.',

Learn to recognize and stop diseases in the early stage. Don't wait until the fowl is dead. The medicines mentioned (sulphuric acid, carbolic acid) are poison. Use earthen dishes for medicine. If possible 
separate every sick fowl from the well, unless your fowls are expensive, kill instead of doctor. Burn or bury the carcasses to avoid spreading the disease; an ounce of prevention is worth a pound of cure. Also give the fowls plenty of pure fresh water, seald and disinfect all drinking vessels; always keep the houses sweet and clean and there will be no cause of diseases. Sulphuric acid is my panacea of all ills, it eats up the poison in the system, give it in the drinking water once a week, one teaspoonful to two quarts of water. I use the commercial sulphuric acid, it is a great preventative of cholera.

\section{Cholera.}

If any of you write to me and say: "My chicks are dying with cholera. What shall I do?" My answer would be "No cholera in your case! Just diarrhea from some other cause." Why do I say this? Because cholera, the real thing, is very, very rare, and violent diarrhea from simple causes is very common. I have never seen so-called cholera in chicks that proved to be the real disease. If you will handle your chicks along common sense lines you will have no occasion to ask for help for "eholera!"

\section{CHICKEN-POX OR SORE HEAD.}

This disease at times causes serious losses, especially amony young stock. It chiefly affects the head and comb, appearing as an eruption of yellow nodules or pimples, varying in size from the size of a pin-head to as large as a pea.

In many cases the disease does not seem to affect the general health of the fowl; but if the disease extends the bird becomes emaciated, the plumage rough, and in some cases death results.

The eyes are sometimes closed by the pimples, and if not released the bird is unable to see and will die of starvation. This is a contagious disease of a fungoins nature and is therefore more troublesome in damp weather.

To prevent it keep the houses dry and clean. If it appears remove affected birds and thoroughly disinfect the house. To eure, soften the scabs with warm water and remove them, rubbing carbonated vaseline into the sore or touching the part several times with bluestone.

\section{DOUGLAS MIXTURE.}

Douglas Mixture is made thus: Take of Sulphate of Iron (common copperas,) 8 ounces; Sulphuric acid, 1/2 fluid ounce. Put into a bottle or jug one gallon of water; into this sulphate of iron. As soon as the iron is dissolved add the acid, and when it is clear the "mixture" is ready for nise.

In hot weather, or when the flock is small, less may be prepared at once; but the above proportions should be observed. The "mixture" or tonic should be given in the drinking water every other day. A gill for every twenty-five head is not too much. And when there is infection it must be used every day; but where there is no disease not so often, or in smaller quantities, if it be used every day.

This preparation, simple as it is, is one of the best tonics for poultry known. It is alterative as well as tonic, and possesses, beside, antiseptic properties which make it a remedy as well as a tonic.

\section{CROP BOUND.}

Occasioned by careless feeding with hard grain or pieces of tough meat, bone, or other substance too large for the bird to swallow, causing the erop to be so distended and swelled as to close the outlet to the stomach. 
Warm water poured down the throat, and the crop gently kneated or worked for an hour, if necessary, until becomes soft, holding the bill open and the head down. Then give a tablespoonful of castor oil and feed sparingly for several days to prevent a permanent distention. If this is not effective an incision about an inch long should be made at the top of the crop, first removing some of the feathers, and care being taken not to open any of the large blood vessels. The contents of the crop should then be removed and the outlet examined to see that it is not stopped up. The incision may be closed by making three or four stitches with silk or horsehair in the inner skin, and the same in the outer. Be careful not to sew the two skins together, as it is almost certainly fatal. Feed on soft or sopped bread, and allow no water for twenty-four hours after the operation.

\section{SCALY LEGS.}

This is caused by a small insect that burrows underneath the seale on the legs. It eauses rough and unsightly bunches, and being contagious it should be promptly attended to. Take the affected fowls and dip their feet and legs up to the feathers in a can containing kerosene oil, and keep them in it long enough for the oil to penetrate beneath the seabs. When the attack is slight one application is usually sufficient, but in bad cases sometimes it takes two or three treatments. Remember to paint the roosts with kerosene or some other good insecticide.

\section{APOPLEXY}

The nature of this disease is an overflow of blood to the brain, whereby one or more vessels may be ruptured. The victims are the fat and indolent in habit, or those of a more active and excitable temperment, that have been fed on an overstimulating and heating diet.

It is generally the plumpest and apparently healthiest bird that suffers, and, as already said, the overfed and those denied proper exercise; hut eggbound hens are liable to it, the exertion used by them to expel the egg forcing the blood to the head in quantity and force greater than the distributive vessels can receive.

Symptoms.-The preliminary symptoms are giddiness and staggering; in the real attack the head falls and spasmodic action of the limbs is seen; when the disease attacks the laying-hen she will frequently be found dead on her nest, the attack being produced as explained above.

Treatment.- It is rare that any remedial measure is of use, for unless the attack is witnessed or immediately discovered the bird will either be dead or have recovered without help, aceording to the severity of the attack. The prompt measures likely to do good are opening the vein of the neck or one under the wing, which must be done by a longitudinal slit, not a cross cut, which latter would sever the walls of the blood-vessels so that they would not reunite. The after treatment consists in keeping on a light diet with plenty of green food, and at first a place of exercise away from the annoyance and excitement of the other hens. It is also well to give a teaspoonful of eastor oil.

\section{BRONCHITIS.}

This is really an extension of a common cold to the deeper seated air vessels, or breathing apparatus, or, as we should say speaking of ourselves, the cold has settled on the chest.

Symptoms. - These are a rattling in the throat caused by the presence of accumulated mucous, and this the fowl tries to force out, an effort analogous to our cough. 


\section{CATARRH, OR COMMON COLD.}

Causes.-Exposure to damp and to cold east and northerly winds and draughty roosting-houses.

Symptoms.-A discharge from the nostrils, at first watery and gradually increasing, and thicker as the disease proceeds, the eyes are more or less bleared and the fowl presents a generally moping appearance.

\section{Bumble-Foot.}

Symptoms.-A swelling on the bottom of the foot, which extends to the uppermost side. It is usually caused by a fowl jumping off a high roost on to a hard floor.

Treatment.-Lance the swelling and squeeze out all the pus or matter. Then poultice with linseed meal, renewing the poultice every morning.

\section{PREVENTION OF DISEASE AMONG SMALL CHICKS.}

In fact, a sick chick is seldom worth saving. These apparently cured chicks stand exposure very badly and usually die before mid-winter of some fowl ailment.

If all chicks seriously ill would die quickly it would save much cost and reduce the number of birds that produce weak chicks the following spring. There is no way to get sturdy stock unless these sick chicks are kept out of future breeding problems. I wish to consider the causes of illness in young ehicks that they may be avoided rather than cured. The man who knows the dangers in the way of raising chicks is more likely to get suceess in this branch of poultry keeping.

What are some of the ailments of young chicks? What is the most common symptom in sick chicks? First, and most often seen is:

\section{Diarrhea.}

Diarrhea may come from variations in temperature in the brooder, from exposure to damp winds, from damp floors, from improper feeding, from absence of grit, from poison, from cholera and tuberculosis.

In brooder chicks usually it is due to one of two things; too low a temperature at night or bar methorls of feeding. In hen-raised chicks, diarrhea is often produced as the result of a too active hen, because she leads her flock into wet grass or is too busy with her seratching to mother the chicks when needed. The method of feeding ehicks with hens, the old way, is apt to produce bowel trouble.

\section{Variations in Temperature.}

A brooder that varies in temperature when least expected, or that cannot be depended on to hold heat through the night, that will not keep warm enough during the cold snaps to satisfy the chicks, will so chill the chicks as to cause the appearance of looseness of the bowels. Watchfulness may overcome some of these dangers, but you eannot always be on hand when needed. A good brooder is harder to find than a good incubator, yet the brooder question does not get half the attention it deserves.

To avoid bowel disease because of brooder conditions, you need a brooder that is dry, one that maintains the degree of heat the chicks need, that can be warmed enough to absolutely prevent crowding at night. Most brooders are run at too low a temperature. With a good "mother" to hover the chicks, the temperature at the level of the chicks hearls shomld he high enongh to anse the chicks to sprearl out until their heads are near the fringe of the " mother." If the chicks persist in erowaing around the central source of heat you may know that the heat is not sufficient. 
Increase the lamp flame until you find the chicks spread out over the brooder floor away from the center. Let the temperature run so low that the chicks must erowd to keep warm, and the massing and sweating will be followed by serious disease. There is much less danger from too much heat in the mother than from too low a temperature.

To be sure, there must be a surrounding space of cooler air where the chicks ean move out to, or this will not work. If your brooder is so made that there is no such arrangement for the chick's comfort you have yet to know the pleasures of a good brooder.

A brooder that will only hold its heat in usual weather, that has no reserve flame to meet the sudden drops in temperature, is a constant eause of bowel trouble in the chicks it is supposed to house.

\section{Wrong Feeding.}

The old method of raising chicks on mashes has much to answer for in the causation of diarrhea. The farmer's way is to mix up equal parts of bran and meal with water, or sour milk, and feed to hens and chicks alike. Too many real poultrymen follow the same method. It works well in many cases, but is always open to abuse and is not to be recommended.

The danger of the wet mash is from fermentation. In warm weather this begins soon after mixing and if not fed at once may be far advanced before the birds have any chance to get it into their erops. Even if it is in fairly good condition when swallowed, there is danger of spoiling after it gets into the erop. Fermentation irritates erop, gizzard and intestines, and the prominent symptom that first appears is the diarrhea under consideration.

If a mash must be fed to summer chicks let it be mixed with cold water, so that fermentation may be delayed as long as possible. The best way, nature's way, is giving all food dry. Then the ehicks cannot "bolt" the feed, mixes it with its own moisture that helps digestion, and the food when swallowed is free from fermentation. It is one of the results of the dry food movement that bowel diseases have become rare in such fed flocks.

Too large a proportion of bran in the mash will irritate the digestive system and produce a looseness of bowels. Unhulled oats are too hard to digest by the chick at any age and make trouble for the intestines.

Grit is necessary to the work of digestion in the chick. If not allowed access to grit, the gizzard cannot do its work, digestion suffers and the softened grain passes into the bowels improperly prepared for absorption. Without grit the gizzard often becomes impacted, the erop fills to its limit, and the chick dies with a looseness of the bowels.

Over-feeding or over-crowding, with whole grain, especially with cracked corn, leads to a condition of digestion that is often accompanied by diarrhea.

\section{Exposure to Damp Winds.}

This occurs to all chicks that are not looked out for by the owner. It is second nature for the mother hen to drag her chicks into wet grass, out into rain storms, and to brood the chicks in the open air rather than to get under cover of the coop. Not one hen in fifty seems to care about rain or cold in her duties toward the chicks. If a cold rain sets in she is as likely as not to pick out a low spot in the grass where the water will settle and soak her chicks.

I have seen hens persist in mothering their chicks in a fence corner when a heavy shower was coming, rather than get them under cover. I have seen hens that had been driven to shelter with their chicks, come 
out into the storm if opportunity were afforded. If you would avoid bowel "colds," as indicated by diarrhea in young chicks after exposure to wet, look well to the flock with hen or in brooder.

\section{Damp Floors or Wet Soil.}

Floors laid directly on wet earth, or coops without bottoms in damp localities, are sources of danger to growing chicks. The little chicks are easily chilled, the newly hatehed chicks especially subject to diarrhea from dampness under them. It is the hen raised chick that is in danger from this cause. Brooders are usually dry-unless the roof leaks-and not places where we need to consider dampness. Coops need a board .toor, with an air space underneath, well littered with dry earth.

Experience has taught me that sunlight is very beneficial to fowls in winter. In my coops I always arrange that the low winter sun shall sweep the entire floor and the roosting places every sunny day. This is the best germ-destroyer known. At the same tme it imparts vitality to the fowls to be able to sit in the sun.

It is said that the ablest scientist is unable to explain scientifically just how a plant grows-what there is in the sunlight that produces growth. The same applies to the growth of animals. But there is absolutely no question that the two prime necessities for growth in both the animal and vegetable kingdoms are sunlight and oxygen.

These are very simple things and everybody knows them; yet I will venture the assertion that not one fancier out of ten (professionals excepted), fully appreciates the value of fresh air and sunshine in poultry keeping. It cost me a good deal to learn these simple elementary facts, and I guess the rest of us that really know, have had similar experience. There are lots of us that don't know it yet.

\section{FEATHER PLUCKING AND EGG EATING.}

A great source of annoyance in the poultry yard is the habit the birds sometimes acquire of plucking the feathers out of one another and eating them. Sometimes the cock bird may be seen holding his head down and standing quietly while the hens pluck the feathers from his head till it becomes bare and often streaming with blood; or in other instances the hens will be noticed picking feathers from each other until they are almost naked. Whether the fowls are intended for the show pen, Ior table purposes, or for egg production, feather eating is a most unpleasant practice to contend with. One bird will learn this trick from another, so that, if it is allowed to go on all the yard will speedily acquire it. Cure is nearly hopeless when it has gone far.

As a rule, feather eaters are more often found in small confined spaces than when the birds bave a large grass run. Various reasons are given to account for this troublesome habit. Over-feeding, or a diet of too stimulant nature, insufficiency of animal food, an inadequate supply of sulphurous food, thirst, want of occupation-all these, and many others, are among the supposed causes. Where the poultry in small yards have been fed with too stimulating a diet the blood becomes overheated and irritation ensues; consequently the bird pecks itself to procure relief, and the practice travels to the other fowls. Want of sulphur is a very usual cause of this bad habit, for sulphur enters largely into the composition of feathers. Fowls, when they have a free range, obtain a quantity of sulphur from weeds and other vegetable food, particularly from the seeds of plants, also from beetles and other insects, which they find in their wanderings. But poultry in confinement are debarred from this. Another likely inducement to feather eating is want of occupation. When cooped up in close quarters, the birds have little to do after they have had their meals; they sit huddled up elose together and for amusement 
they peck at one another's plumage until they acquire a taste for feathers. Directly this disease is noticed the offender should bo removed from the others and fed on a cooling diet, with a good allowance of green food. The heads of the birds that have been ill-treated should be well washed, any broken quills extracted, and the bare places rubbed with carbolic disinfecting soap. When there is feather eating, it is well to give the fowls some sulphur, about a teaspoontinl in the soft food to every three fowls, twice a week. Sulphur has a laxative effect on the skin and bowels so it should not be given in cold or wet weather. A plan to check this unisance, which is sometimes adopted with satisfactory results, is to place a daily supply of broken up bones in the run. To give employment to the birds, some loose straw should be scattered on the ground and a handful of small grain thrown into it; this will induce them to scratch and search for the grain. If none of these suggested remedies are of any avail, it is better to kill the culprits, ior to keep feather eating fowls is worse than useless.

\section{Egg Eating.}

A remedy that is largely adopted in this country, and which is found to answer better than any other, is to give the hens a supply of eggs or egg shells for a few days. Infertile eggs that have been sat upon by broody hens or that have been removed from the incubator will answer the purpose; or egg shells obtained from confectioners or other business houses where eggs are largely used. The shells must be given as whole as possible, not broken, and the birds must be allowed to surfeit themselves with them. After several days of this the fowls will not touch eggs again, and the cure will be completed. But there must be a large and continuous supply while it lasts, so that the eggs or shells are lying about the run all the time. To use a nest with a false bottom is another way of preventing egg eating, so that the eggs when laid disappear down an inclined board into an underneath receptacle, out of reach of the thief.

\section{Notes by the Way}

Be patient and do your work well.

Helter-skelter methods work destruetion.

Drawbacks are often blessings in disguise.

Lazy hens, like lazy men, are not money-makers.

System and regularity are the keynotes of success.

Mongrelism in stock, and fogyism in ideas, are on par.

Success is due more to good management than to anything else.

Quick sales make poultry profitable. Waiting for a market is a risk.

A pint of kerosene in a gallon of whitewash makes a very good in. secticide.

It is not uncommon to find that the worst looking hen in the flock is the best layer.

Mistakes are object lessons. They show why the fallure. To the wise they are important.

From a scientific standpoint or that of quick, vigorous growth, the brooder beats the old hen about six to one, and chicks are infinitely less trouble and the loss is also less.

Patience is a strong link in the chain of success in poultry raising. A very strong link indeed. Lost patience, lost poultry profits, is about the quickest way to express it. 
As a rule, successful poultry raisers possess an exceedingly large amount of patience; and if this were not true, few of them would ever rise to that plane called suceess.

Standard-bred poultry is the best for any purpose because the standard requires that they be started right. They are bred for results as chicks are fed for growth. That is the only way to get hens that will lay well and pay well.

Do not forget the green food for those brooder ehicks. It is absolutely essential. So is grit and chareoal in their daily foot. Do not feed too much of the latter. Put one tablespoonful in the food of one huntred chicks.

Did you ever stop to think what a wonderful piece of mechanism a hen is? What a tremendous strain there is on that frail looking thing we call a hen? Shouldn't we give them the best care and attention? And if we do this, how grateful they are and how hard they try to tell us of it.

There is a greater incentive for the poultry breeder to work earnestly now than ever before. Now that the pure bred bird has taken its rightful place as the best for market purposes, and thousands of new reeruits have entered the ranks of poultrymen, it meins more work, more trade, more money for those already established.

A great many people go into the chicken business with zeal and fire enongh to burn mountains to ashes. But how long does it last? Every time.I see a neglected flock of poultry I feel like having a heart-to-heart talk with the person in charge and tell them to do one of two things. Get in love with the business or get ont of it.

Why do some farmers endorse the mongrel hen? Simply because she is cheap. Nature has no regard for money values, one way or another. If mongrel blood were higher in price than pure blood no one would harbor a mongrel hen. When once obtained, the cost is no more to maintain pure blood than mongrel blood, and the results are much better.

Early molting may be encouraged by withholding heavy feeding about the first of August, and feeding very lightly for a few days. If hens are laying at that period, the light feerling will throw them off, and this will give a chance to the birds to molt. Upon resuming normal feeding, liberal allowances of grain, mash and beef seraps may be furnisher to promote feather and muscle growth. The right kind of feeding should put the hens in condition to begin laying again well by the cool September days.

When selecting the young pullets, bear in mind that any lack of vigor in them while they are small is evidence that they will not be hatrly when folly matureil. IInthenss is everything with at flock, for if any of the old or young stock cannot pass through the warmer season of the year with perfect freedom from disease, they will not prove profitable as layers next winter. The getting of eggs from a flock during cold weather depends on the selection and mangement of the pullets in the summer and fall.

I An ont believe in the thousand hen firm for the heginner and always disconrage it when it comes up before me. Howerer, I do believe that it is a good thing to work up to the thousand hen farm, but not all in one year or in two years. This is as much as one man should undertake to handle in this country. Farther south more may be taken care of with good results. Are you raising poultry with a view of making money out of it? If so you cannot neglect it for some other part of the farm work or the office. It is work that must be done on time and done right.

The woman who finds herself possessed for the first time with a flock of poultry will soon learn that she may spend an afternoon working with her hirds, and low just as murh amosed as if she sprent her time "shopping," nor will she be nearly as tired as if she were walking 
around on the hard sidewalks. Instead of being out of pocket, for most every woman will buy things that she does not need if she chance to see them, she will find that she has added to the possibilities for gain. To be out in the open air. and sunshine is to see more real life than does the woman who are always in the house. Personally, there are oftentimes when the duties of my house compel that I stay in all day, and when those days come I always feel as if there was just one day lost out of my life; lost with nothing to show for its loss.

\section{VENTILATE THE POULTRY HOUSE.}

This must be done in some way during the winter; as it is well known that a close, tight house is a disease breeder. The best ventilator is a square light-box going straight up through the roof and reaching to one foot of the floor. Fit a frame in one window and cover it with canvas. Use this in place of the sash in day time and at night when the weather is not too cold.

\section{HOUSES MUST BE KEPT DRY.}

And how to keep them dry is the next problem, as the first time the thermometer drops below zero the inside of the houses will be covered with a white frost. We have found the best way to remedy this is to build a loft two or three feet above the roosts and cover with about six inches of straw or hay. This adds greatly to the warmth of the house and absorbs the moisture. Loft should not have tight floor; just: enough boards to keep litter from falling down, and this litter should be removed in summer. It makes the houses too warm and a harbor for lice and mites.

\section{CLEANLINESS.}

You have no doubt heard of the man who took a bath once a year whether he needed it or not. Do not clean your hen house this way. Clean it often. It is worth the trouble just to see the fowls enjoy it. When I clean the dropping boards I cover them with ashes. This answers several purposes. The fowls enjoy picking the charcoal from it while it is clean. It helps to remove the next lot of droppings, keeps the boards sweet and clean and helps keep lice away. Be sure there is no fire in the ashes.

The best breed is the one kept by the best breeder, but this varies in many neighborhoods and among certain classes of people. We are inclined to believe the best stock is always kept by the man who gives his stock the best care.

\section{WHY CHICKS DIE IN THE SHELL.}

There are many causes of chicks dying in the shell. The chief causes are, too much ventilation, an uneven distribution of heat in the egg chamber, too much moisture. Overheating the eggs has been the cause of many poor hatches. After eggs have been incubated a week they will stand a temperature of 107 for a few lours; and from the fifteenth to the twenty-first day I have known machines to get up to 110 for a short time and still the eggs hatch well. It is not necessary to have the temperature at 103 all the time; any variation of temperature from 101 to 104 will produce good results. Eggs from sickly, inbred hens, or from birds in poor condition or confinement may start, but as they haven't sufficient vitality they die in all stages of incubation, in the ineubator or under the hen. 


\section{POULTRY NOT SUCH AN EASY ROAD TO WEALTH.}

A great many who have failed to make a success in life will start in the poultry business thinking that they can easily crown their efforts with suceess and wealth. They could not make a greater mistake. As a rule, any one that cannot make a comfortable living at anything else, cannot do so at this. Sound business principles must be applied, along with plenty of hard work to insure a paying business.

Unless broilers are the poultry product you aim to turn off, don't sell a single early hatched pullet off the place. You are selling the producer of the golden egg when you do it.

Experience has proven beyond a doubt that fowls confined in pens or small yards do just as woll as those in large yards or on free range-in fertility of eggs, in the number procured and in the health of the fowls. The requirements are clean quarters, but few fowls in a pen, fresh water, oyster shells and, of course, proper management all the way through. So if you have a small place, don't be discouraged, but go ahead.

The month of September usually finds the breeder of poultry with a surplus of young stock on hand. The correct policy in such cases is to advertise early in the season, and sell all that are sufficiently matured. A bird sold at $\$ 2.00$ in October is more profitable than a $\$ 3$ or $\$ 4$ bird in January or later.

There are all kinds of drawbacks and disappointments in the poultry business, and all kinds of money also; a man must conquer the former before he gets the latter.

\section{THE BEST.}

We all like the best that exists, whether it be horse, house or poultry. We desire to own something a little better than our neighbors. We try to possess poultry appliances that will give us most certain profits.

While we desire all these good things, do we put into practice the efforts we know must be made to obtain them? In the buying of a brooder do we try to find that one that will best take through the "hover" age the flock of chicks committed to it? Too often we try to find the cheap brooder that will hold the largest number of ehicks. The man who offers an incubator for three dollars less than his competitoran incubator perhaps good for only half the life of the higher priced one -is very likely to get our order.

The grain man who shows us musty wheat at fifteen cents per one hundred pounds eheaper than the best article too often is told to ship us the poor article.

We write to five men for prices on a hundred eggs, and does not the cheap offer get our order? Or, we wish to buy a breeding pen of ten birds and ask quotations of several poultrymen. Do we let quality count? Too often we order the pen that can be had for the smaller number of dollars.

The best, usually, is cheaper in the end. It may cost more at the start, but commonly there is more satisfaction in a good article as we use it, as well as in the larger profit that follows.

The brooder that costs twelve dollars is not always better than the five dollar article, but of two unknown articles the higher priced one is safer to buy.

Do not try to see how little money you can put into the many purchases that must be made by poultrymen, but always endeavor to get full money value for all you buy. Better put a few more dollars into a good male bird this summer rather than try to save half the cost of a first-class bird. Quality counts, quality pays and quality costs a little more than the common article. Do not hold back when you find what you want. If you need it, it is worth the price asked. Strive to do your best in getting those things you need in your poultry work and before long 
you will be selling quality birds at the long prices that such birds command. Follow this into all the lines of your work.

However imperfect your system of bookkeeping may be, yet use it the best you can. Don't be afraid to jot down your losses as well as your gains. The greatest teacher is sometimes our greatest failure. Do not neglect doing a thing, beeause it is little. Keep your eyes open for new ideas, Give your birds full credit for what they do, same as for what they do'not do.

The principal trouble with nine of out of ten men that start in the chicken business is that they take it up as a side issue. Thry liave failed at everything else they have undertaken and expect to recuperate their previous losses in the poultry business. Others are broken down in health-doctors recommend some out-door employment. They take to chickens just as though that did not require work or being out in all kinds of weather. When it comes right down to it, the old hen is expected to square all old seores. Any other business, dry goods, groceries, etc., would prove a failure if conducted on the same ideas. A little good horse sense is just as essential to a successful poultry business as it is to any other buiness. When this is lacking better tackle something else.

\section{BIRDS THAT PAY.}

Paying birds are a delight to the eye. You like to show them to your friends, and linger in your description of what they are and what they have done for you.

Paying birds never make up a large part of your flock when you sell the cream of the chicks every year. Money-making flocks are made up of the best you raise-always letting the second quality go to market.

This class of birds-because they pay-receive thought and attention from you. You gladly take good care of them; you are willing to properly mate and feed them; you look for fresh blood to improve your flock.

What is necessary to own birds that pay? It takes more than money to do this. You can buy birds that can pay, but it is another thing to have them pay you after you own them. Not only must you have the right kind of hen, but you must use time and thought in caring for her to make her of the "paying kind."

Some hens are not worth their keep. Others produce enough to cover the cost of their handling. The hens that pay are those that more than meet the expense of money and time necessary to make them worth while. Three classes of hens, and the last is the one we all desire, and the one that we can have if willing to pay the cost.

The paying hen is usually hatehed from a paying strain. The paying hen that comes out of a flock of good-for-nothing birds is seldom met and is not worth hunting for. It takes time-it takes money-it takes born hen-sense-to produce a flock of paying hens. It takes a very little neglect to send this flock back to the class of non-paying birds.

Paying birds live in houses free from vermin and supplied with pure air and water. They get food that is needed to bring the profit to the proper point. Cheap food-because it is cheap-never helper to produce the paying hen and kept her running to the nest. Hens that pay can be yours if you are willing to do your part. Hens that more than pay-splendid profits-are what the world is asking for, is looking for, is demanding. Are you going to be among the breeders who will fill the orders for this kind of birds? 


\section{HELPS TO BEGINNERS.}

One of the objections to feeding sloppy food is that it too often makes conditions which invite disease.

Sooner or later we must learm the lesson of patience in the poultry yard, and if we do not we will soon be out of the business from a suecessful point of view.

Strictly first-class eggs always demand a premium and stale eggs should never be placed upon the market by the producer. Eggs are always a cash product, they are ready for the market the minute they are laid.

There is absolutely no excuse for selling young chickens from the farm as thin as some people do. The amount of corn that will make a pound of hog will also make a pound of chicken that is always easily worth two pounds of hog.

An up-to-date business man studies the market. He finds out what the people want and he produces it as near to the demand as it is possible for him to do. He gets the trade. Is not that a good object lesson for the poulterer?

Crowding two hundred hens into the space that ought to accommodate one hundred will crowd out all the health, comfort, vigor, flesh, temper and eggs of your entire flock. Overcrowling is bad for any stock and particularly bad for the feathered stock.

No one will gainsay the statement that there are some enterprising farm wives and daughters who are making more clear money every year from the intelligent care of a tlock of pure bred birds, and sometimes mongrels, than the husband and father from his general farm work.

Breed for eggs. This can be done, though many poultrymen act as though they do not believe it. Selection has given us the race horse, the big milker, the 200-egg hen. Know your best layers, get males from 200-egg hens, mate these to your best record hens, get more eggs from less bircts.

There is a rift in the clouds. The entire road of poultrydom is not covered with dead and dying chickens. If there is a dark side to the work there is also a light side. If by times you find yourself swimming down stream, remember there will come times when you will muster all the courage you have and row up stream.

It's pretty hard for the poultryman to take a summer vacation, in fact, it should be his busy time as with the hot weather comes the lice and mites in all manner of kinds, that must be rigidly combated. The wise ones that begin the early nse of lice killers, insect powders and whitewash are the ones that can spend a day fishing.

One reason why men or women fail in the poultry business is from lack of experience. It is amazing to see how jauntily men assume they can rum a poultry plant. And yet the poultry business requires as long an apprenticeship as any other. Even the veteran is constantly up against problems that tax all his resources to the utmost.

If snceess in the poultry business cane easier than in any other, the movement towards it would he so great that in a short time there would he no profit in it for any one. The fact that there is still good money in poultry keeping for those who know how, shows us that there are difficulties to be overeome sufficient to discourage the majority.

Still breeding seasons have many disappointments for most of us, and we ean only profit by them by gaining some point of knowledge that may be of benefit in our future efforts. We must profit by failure as well as from success. The knowledge of experience is often dearly gained, but it is valuable, and should be used to good advantage in ou work.

There is no better place in the year's work for poultry to increase the profits than during the winter months. The average keeper of hens 
will never do mueh better at present and it's up to our ruiders to reap the harvest. A little more efiort, better rations, bred to lay birds, morlern housing and feeding methods, will inerease the number of eggs the next three months.

What most always attracts people to the poultry business is the fact that one can start into it with so little capital. A little shack in the back yard, a few fowls picked up here and there, and the business is begun. Many a person has started in this way who in the end has become a prom. inent figure in poultrydom. It is the tenth person who succeeds. You may be that person.

The value of chareoal must not be underestimated. It is of much help in keeping fowls in health and preventing looseness. Ficed it powdered in the food two or three times-a week: Chickens for market will fatten faster if fed charcoal. Chareoal is not a medicine, strictly speaking. It is an absorbent and as such takes up the poisonous gases in the system and carries them off.

There is no royal road to success with poultry, because every man or woman in order to be successful, must start at the bottom, no matter on how small a scale. Among a certain class of people, failure is the rule and success the exeeption; not because a failure is necessary or success a matter of good luck, but some feel above the small details, and figuratively, try to run before they ean walk.

Comfort for the fowls is symonymous with profit; every day I come nearer to believing that this is strictly true. In winter, in summer, in spring the case is the same-the comfortable bird is the one that is giving the profit, and the most profitable thing the owner of the fowls can do is to go over very earefully the conditions which cause discomfort to the flocks and to use every effort to overcome these sources of loss.

The droppings board saves a lot of filth from acenmulating in the scratching material. Through the winter the birds spend more than half their time on the roost and just so much of the droppings are caught on the board. Do not do it! Have it high enough to give all the floor space for litter, unless you see fit to have a nest box or two under it. It is a movement backward when you give up the use of the droppings board.

The good business man pushes business; he never lets the buisiness push him. It should be the same with the poultry farmer. Poultry and eggs are staple crops. There is a constant demand. The good poultryman not only aims to continually produce a good supply but he endeavors to have that supply of the very best. To secure the best prices the quality should be of the finest. That word "choice" in the market report means a great deal.

The longer you make the breeding of poultry an intelligent study the more you will realize how little you knew at a time in your early experience when you thought you knew about all there was to learn. The fellow who ridicules "fooling away time with chickens" is related to the man who sits around the stove at the grocery and tells his listeners how to run the country and settle the great economic questions of the day. The "fool killer" still has plenty of work to do.

The poultry business ealls for a large share of good common sense. Beginners so often do not stop to think; they do not reason. When in doubt is when good common sense comes in. Supposing a rather difficult problem presents itself and there does not seem to be any way to solve it, how easy it is to stop and carefully think over the matter. Reason with yourself-use good common sense in your reasoning-and ten chances to one you will not be the wisest one, but it will answer until you have become acquainted with something better.

"Double mating" is the system of using two yards, one for producing pullets and the other cockerels. For instance, the pullets of the first 
year may be superior show birds and the cockerels not. so desirable, and vice versa with the second. It is practical with only a few breeds, and is forced upon the breeders by standard requirements to produce stated eolors on males and females for the show room. Breeders who sell eggs do not sell them from double matings unless requested by the customer, but mate their birds as "breeding pens," so as to get the best results.

The little chicks need green food as soon as they got out of the down age. If you let them out on the grass the problem is solved. If not, then you must feed them lettuce, cabbage, beets, potatoes, etc. Do not attempt to grow chickens on grain and meat without some green food. Cut clover will help out in the matter, but real green, live food is needed aiso. Short cut clover is extra good to cover the floors of the brooders. The chicks eat mueh of it, and it makes good scratching material to induce exercise. Put it in two inches deep and see the chicks make it fly. I use barrels of waste from the hay mow for brooder purposes.

\section{Caponizing}

\section{What are Capons?}

Capons are aptly termed the "Finest ehicken meat in the World," for there is nothing growing feathers their equal or superior. A Capon is neither rooster nor hen-it is nothing else than a Capon. After removing the testicles from the cockerel, its nature becomes entirely changed. They take on a more rapid growth, are more tame, awkward in carriage and always exceedingly lazy, take on a very heavy and beautiful plumage, the comb and wattles cease to grow, the spurs do not develop as in the cockerel; and being east off by both rooster and hen soon show a fonduess for the society of little chicks. To these they will act as mother, covering them with their heavy plumage at night or leading them about during the day. In France this is extensively practiced, the Capon taking the place of the mother in rearing chicks, while the mother unfettered by the cares of her feathered family, becomes a layer only. France is the foremost nation on the globe for bringing much out of little. That they universally practice caponizing is a proof of the large and successful results to be derived from this operation. The Rural New Yorker says:

"The flesh of Capons is decidedly sweeter and of finer flavor than that of cocks. They gain from two to four pounds in weight, while the cost of feeding is no more. If the farmer could once get a taste of Capon, there would be a great reduction in the number of roosters on his place. After Capons have once been introduced into a market, there will be a great demand for them. Any large breed will make fine Capons. I do not see that the birds suffer any pain after the first incision. They lie motionless unless you touch their heads. To show how little people in general know about caponizing, I can relate a fact that came under my observation. At a poultry farm where I was visiting, a lady called and examined some Capons. When told what they were, she said they were splendid birds, and asked the proprietor to be sure and send her a setting of their eggs. It made considerable laughter after her departure."

\section{Best Time to Caponize.}

Fowls hatehed any time of the year make fine Capons; no ill results follow the operation at any time in the year. The bird should be from two to three months old (not over six months) and weigh not less than a pound to a pound and a half. The size is equally as important as the 
age. April, May, June, August, September and October are the months generally taken for eaponizing, for the reason that spring ehickens arrive at proper age and weight during these months, also because cockerels caponized then arrive at the proper age and weight for market during the months of November, December, January, February, March, April and May, at which times there is the greatest demand for them in the cities and highest prices secured

With the aid of the incubator, chickens can be hatehed during any season of the year, and will be ready for caponizing at the age of two months. In this way caponizing need not be confined to the above months, but may be performed at any season of the year. If performed in extremely cold weather, the bird should not be unduly exposed until the cut is healed.

That capons are in our markets at certain seasons only is beeause the demand is so far in excess of the supply. The time should and soon will be when capons may be obtained the year around.

All cockerels not needed for breeding purposes should be caponized after reaching the age of two months. Do not try the operation on too young ehicks, as their organs are then so small and undeveloped that you may either kill or cause a slip. The age already given is the proper time.

\section{Caponizing.}

There is always a pre-eminent object in departing from the ordinary, and caponizing has this object. The wise farmer looking to assured future profit, sees far more weight in the steer than in the bull. Castration makes the wonderful increase, and in just the same proportion does this apply to the cock and Capon. In poultry-raising (as in all other enterprises), the most successful results from certain lines are aimed at and it is over the threshold of this highly important point that the Capon has stepped, opening up certainties never before dreamed of by the most sanguine. "What shall we do with our cockerels?"' has ever been a perplexing question to the poultry-raiser, as, in a great many settings hatched, the male predominates. Chasing about the yard, worrying the hens, continually spoiling for a fight, and eutting all kinds of capers in general, the cockerel loses his flesh almost as rapidly as gained, displays $a$ voracious appetite, and in the end proves the cost of keeping to be far more than the price he brings in the market. This is very discouraging to the poultry-raiser, and after a careful figuring of accounts he considers the "game hardly worth the candle."

In caponizing, all these troubles are swept away-the erstwhile fighting cockerel becomes as docile as a chick. Instead of chasing about the yard he keeps his own company and spends each day in quict living. Without the drawback of physical exertion the flesh rapidly increases, the bones add weight to weight, and where under the old way a farmer would kill an ordinary looking cockerel of but little weight, he now dresses for market a bird rivaling the turkey in size and weight, whose flesh in flavor is superior to that of the spring broiler and as tender and juicy. Caponizing solves the problem of disposing of a large number of cockerels to the dealer.

Caponize the chicks and you have at once laid the foundation for a handsome profit in a short time to come. Ontside of the cardinal points of profit, the simplicity of the operation (when proper instruments are used) recommends itself to everyone. A boy ten years old can readily perform the operation, and everyone can soon become an expert.

\section{Profit in Capons.}

To the poultry-raiser we would say we know of no source of profit bringing larger returns for the outlay than raising Capons, the profit in a great majority of cases being over 100 per cent. The question of assured profit is an all-convineing argument in any line and pre-eminently 
so to the poultrymen whose losses are added to from various unlooked for sources. As an illustration: Ordinary dressed poultry in the market will bring from ten to fifteen eents per pound. Capons readily sell at from twenty to thirty cents per pound. When we take into consideration that their cost is no more-even if as much-than the cockerel we readily see the enormous profits derived from caponizing. Not many years ago the practice of caponizing was very little known in the United States. Today it is extensively practiced among poultry-raisers throughout the country, a growth convincing in itself of the great profits derived therefrom. We have given this matter of profit close attention for a long period and find the results in all cases highly satisfactory. It is now an established fact that equally as fine Capons can be raised in the North, West or South as in New Jersey. They ean be successfully grown anywhere, New Jersey being the pioneer state in which Capons were raised in this country, and owing to the fame attached to the bird this has given that state an enviable prominence to outside poultrymen. Now, nearly every state sends its Capons to market. The live poultryman is not slow as to his best interests.

\section{Large Demands for Capons.}

The better a good article becomes known the greater the demand, and Capons are no exeeption to this rule. It seems impossible to meet this demand. As the practice of eaponizing grows and as the birds come to market in greater numbers, in greater proportion the demand increases. In February and March it is hard to find a Capon in the market. This should not be, particularly when it is possible to have them any time in the year, and, when the supply falls far short just at the time when it would seem that other poultry could take the place of them, this conclusively shows what a field is open to the Capon-raiser. February and March is the season of the year when most Capons are placed on the market, and yet it is hard to find them there. The reasun is quite obvious - they are caught up at once at large prices. Ordinary chicken meat has no show with the Capon. The publie is fast learning this fact, and where a Capon is to be had, no other fowl will suffice. This eauses all far-seeing poultry-raisers to put on their thinking caps, with the result that they at once begin to eater to this demand, increasing their income 100 per cent thereby. The field is open to everyone. You can do it! Have you tried?

\section{Directions for Caponizing.}

From twenty-four to thirty hours before performing the operation, select such cockerels as you intend to caponize (these should be from two to four months ol(l), confining them in a clean and airy coop or room without either food or water. The best time to confine them is at early

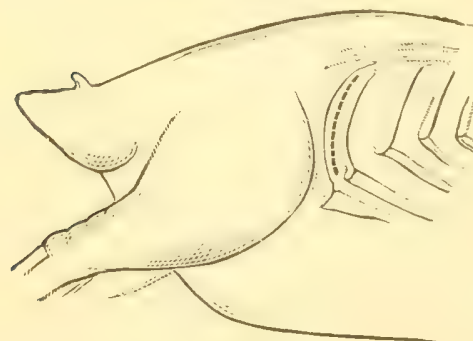

Dotted Lines Show Where Incision Should be Made Between First and second Ribs morning, as their long fast will then end about noon of the following day, at which time the operation is best performed. Should the day be eloudy or wet do not eaponize them, but let the operation go until you have a bright and fair day. It is necessary that you have all light possible in the matter. If it be a cloudy day, and you decide not to caponize, the birds may be given a little water and food if necessary, but it is very desirable to have their intestines quite empty, this allowing their testicles to be more readily 


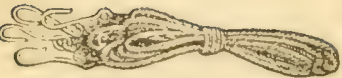

Figure 1. Cords for Holding Fowl. seren, besictes griving the operator much more room in which to perform his work. Lay the bird on the operating table (this table is fully described elsewhere in the book) on its left side. Wrap the cord (Figure 1) twice around the bird's legs above the knees. In making one wrap only there is danger of the birds kicking themselves ont of the loop. Hook the other cord once around both his wings elose to the body. To the opposite end of these cords attach a half brick or some equal weight, letting them hang over the sides of the table. This holds the bird securely. Have all your instruments in readiness that you may work quickly. Thread the Canula (Figure 5) with a strong and loose horse-hair or fine steel wire (we think wire the best), letting the wire form a loop at the curved end and well out at the other end. Now, after slightly wetting the spot, proceed to turn down the feathers from the upper part of the

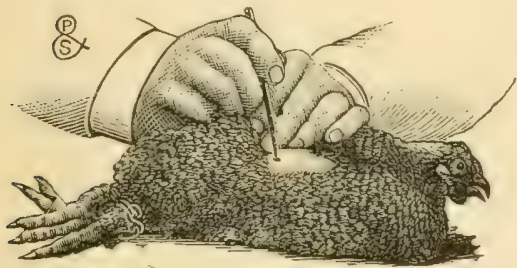

G.P.PILLING \& SON,PHILA

Making Incision. last two ribs and just in front of the thigh joint. Pull the flesh on the side down toward the hip, and when the operation is finishedthe cut between the ribs will be antirely closed by the skin going back to its place. While holding the flesh back with the left hand, with the right hand take the knife (Figure 2) and insert it (cutting edge away from you) between the last two ribs, eutting first down and then up a little ways, following the direction of the

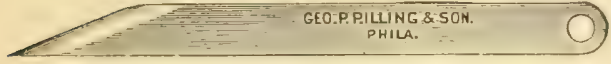

Figure 2, Knife for Making Cut. ribs, making the cut not over one inch long. Cut deep enough to go through the skin and ribs, being very careful not to go so deep as to cut intestines. There is little danger of doing this, however, if they are empty, as they will be from the bird's long fast. The danger of cutting the intestines is when they are full, as in this state they press against the ribs. Should the eut bleed, stop a moment, let the blood clot on the thin skin covering the bowels, and then

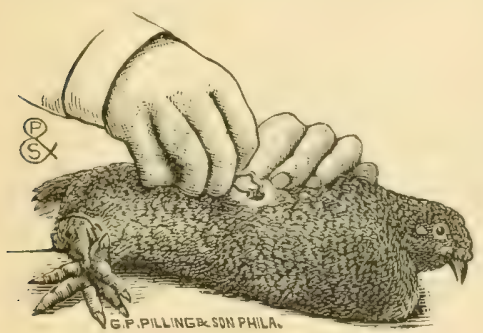

Inserting Spreader. remove it with Curved Spoon Forceps. See Figure 1.

Now take the Improved Spring Spreader (Figure 3), press it between the thumb and finger until the ends come together, inserting the ends in the incisiun with the spring end toward the bird's feet (see operating table).

The spreader is now in place, but opening may not be quite large enough. It is best to increase length of opening to such a size as to allow canula (or if twistiug scoop is used) to enter freely. Do not cut too near the backbone.

Upon looking into the Figure 5. Caponizing Probe. cut a thin tissue-like skin will be seen just under the ribs and enclosing the bowels. Take tho sharp hook (Figure 4) and pick the tissue open so that you may get into the bird with the instruments. The breaking of this skin does not cause the least pain to the bird. One of the testicles will now be brought plainly 


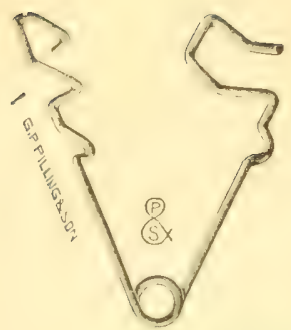

Figure 3. Improved Spring Spreader

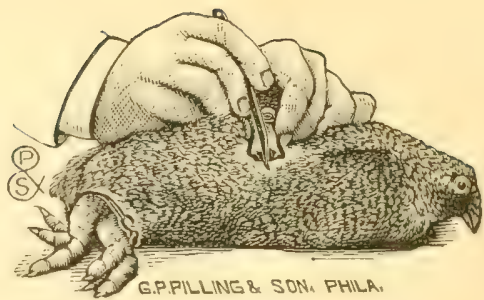

Enlarging Opeuing.

to view lying close up to the back of the fowl. Sometimes both testicles are in sight, but this is not generally the case, as the other one lies beyond and more on the other side of the bird, the intestines preventing it from being seen from this opening. The testicle brought to view is enveloped in a film. This should be brought away with the testicle. Some people in caponizing tear the skin open and then take the testicle out. The danger in so doing is that if this skin is left there is danger of causing a "Slip.",

Now comes the only dangerous part of the whole operation-getting

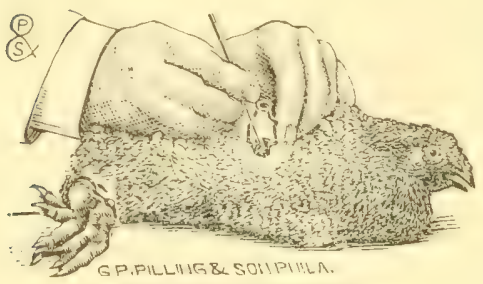

lemuving 'hin 'Tissueskin. hold of and removing the testicles. But with a steady hand and plenty of light not one bird in a hundred should be lost. Attached to the testicle and lying back of it is one of the principle arteries of the fowl, and this, if ruptured, is sure to cause death. It is here that our improved Canula (Figure 5) proves of the greatest advantage. The hair (or wire) being small and very fine is easily slipped between the testicle and artery without injury to either, a clear, clean cut made. Take the Canula in the right hand and adjust the hair (or wire) in it so Figure t. Shary Mook to Open Film-like Skin. that a loop, about one-half inch long, will extend from small end of tube, leaving the two ends of wire extending far enough out of the open end to secure a good hold. Insert the end of tube that has the loop on it very carefully and slip the loop over both ends of the testicle and entirely around it, hold end of tube close down to the testicle. When the testicle is entirely encircled by the loop, take both ends of wire (or horse-hair) which comes out of the other end of tube with thumb and first finger, holding it tight, and draw up on it carefully but firmly, being particularly careful to have loop around testicle. Keep end of tube

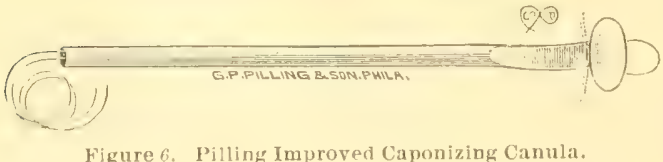
very close to testicle all the time. If drawing up on the wire does not at once cut testicle, slightly turn from one side to the other (but not entirely around), then the testicle will come off. After removing it, carefully examine inside of bird to see that no piece is left in and also to see that no foreign substance, such as feathers, etc., has gotten in. If there has it is necessary to remove them, for, if allowed 
to remain, they are liable to cause inflammation. Sometimes a feather or part of the testicle may drop among the bowels; if this oceurs, move the bowels around with probe (Figure 6) until the object is found, then remove with Forceps. When the operation is performed remove the Spreader at once and the skin will very soon slip back over the eut and heal in a short time. Never sew

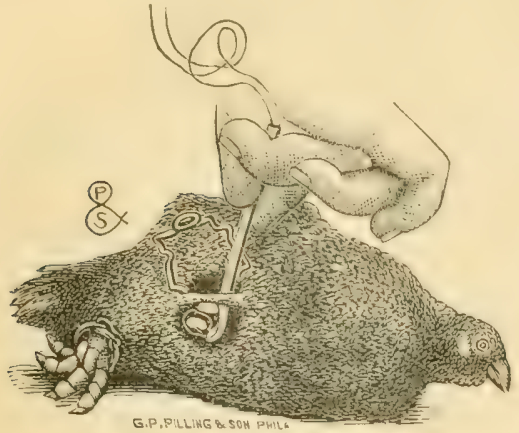

Canula Ready to Remove 'T'esticle. the eut, as it will heal just the same as any other small flesh wound.

The bird ean now be turned over on its right side, cut made and testicle removed in exactly the same manner as just describer for the left side.

Both testicles may be taken out with the one incision, but to the learner we would say this is attended with more difficulty than the two incisions. The other testicle being situated so far over on the other side there is more difficulty in reaching it, besides danger in piercing artery running back of first testicle. To an experienced party there is no danger in removing both testicles from one incision, but to those who have not that degree of confidence given by practice we would recommend the two cuts. The bird recovers just as quickly as though one cut was made and the operation is performed equally as quick, if not quicker. If both testicles are removed from one cut, the lower must always be taken out first, for if the top one is first removed, the small amount of blood that may $f^{-1}$ low will cover the lower one, keeping it from view.

\section{Directions for Using the Pilling-Farmer Caponizing Set.}

After the incision has been made on the left side by

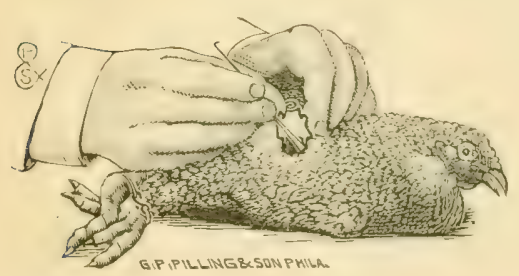

Inserting the 'T'wisting Scoop. the same method as deseribed for the use of the "Philadelphia Set,' and the testicle exposed, the slotted scoop is inserted in the opening, allowing the lower testicle to slip into the scoop so that the spermatic cord slides down to the bottom of the slot; then simply twist the scoop, which will separate the testicle from the cord. The beginner should be very careful to see that the testicle does not slip out of the scoop; this can be easily accomplished by using the probe in the left hand to hold the testicle in or to keep the bowels from being caught in Combined Knife-Forceps.

the scoop. The other testicle may then be removed in the same manner. The reason the lower testicle is first taken out is because it is the hardest to extract; if the upper or right testicle was removed first it might perhaps allow the blood to rum on the lower testicle, thereby making it somewhat difficult to extract. 
The suceess of an operation will be helped if, after caponizing, the incision and other parts are washed with a weak solution of

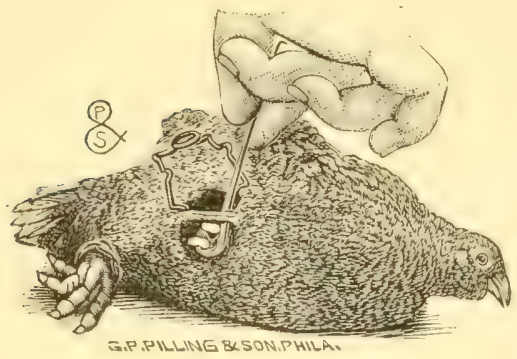

Twisting Seoop Ready to Remove 'Testicle

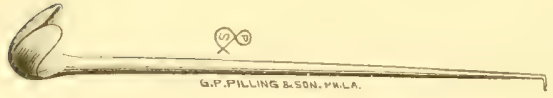

Pilling-Farmer Twisting Scoop. earbolic acid. Use a metal basin, clear water and a very small amount of carbolic acid. It will also be helpful to have several small pieces of sponge about the size of an acorn, so that in case of unusual bleeding the blood can be absorbed by the sponges.

\section{CAUTION.}

Be very careful to avoid tearing the large artery, for if this is torn or ruptured the fowl will probably bleed to death in a few moments. If reasonable eare is used, this tearing of the artery will not oecur.

1 The lower hole in the above cut has been made in order to show how the Twisting Scoop slips the wire over the Testicle. Of course this lower hole is really not in the fowl. It is merely to show how the instrument is used.

\section{Operating Table.}

There are numerous styles of tables on which to caponize, but experience in this matter places our choice between two only.

The top of an ordinary barrel (see illustration) meets all requirements as a table, admits of the bird being easily secured, brings the birt to the proper height with the operator, in brief, makes as good a table as can be desired. It costs nothing; there is always an empty barrel lying around, or one that can be easily emptied.

For those, therefore, who do not propose caponizing on an exiensive scale, we would recommend the top of a barrel. Whichever method is

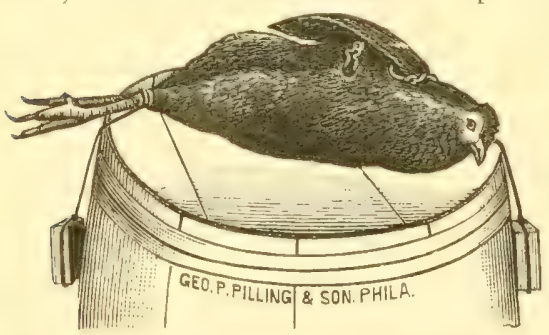

Table No. 1. The above, photographed and engraved from life, illustrates method of holding. Fowl ready for Caponizing used, make it a point to have plenty of sunlight and the table so situated that the light will strike squarely on the fowl. You cannot have too much light during the operation.

The second illustration shows how a good caponizing board (or table) can be constructed hy the use of our Improved Staple A to slide over the wings of the bird. The staple has two fenders about one inch from the points to prevent forcing the bird's wings too close together, as would be the case without them. The eross-bar on staple allows you to use the upper part for a handle. This will be found very convenient during caponizing. One point of staple is longer than the other. This enables it to enter the board much easier. By cutting six or seven holes in the board it will take any size bird. $\mathbf{B}$ is the strap loop with a pin across the top to pre- 


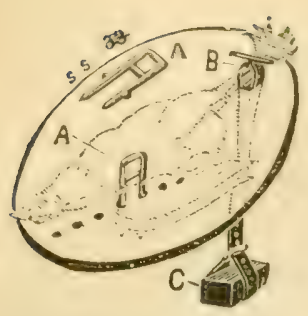

Table No. 2. Can easily and cheaply be made: is suit able for those who intend able for those who intend

vent strap from falling through the board when not in use. $\mathbf{C}$ is the weight (at other end of strap) for keeping feet down.

This staple we send by mail on receipt of price, 'I'en Cents.

This table is very good for those who propose caponizing on a large scale. The entire construction (as shown in illustration) is very simple and easily made.

All Poultry-Raisers Should Caponize.

Every poultry-raiser has a useless number of cockerels rumning about his place. We say useless so far as any certain degree of profit is concerned. often (simply owine to their number) these cockerels are killed for the home table-this offers one solution of their reduction. This is quite proper; but when we stop for a moment and think that the poor little cockerel just killed, scarcely tipping the beam at three or four pounds, and representing 25 per cent more in feed and care than his worth-when we think of it that this same bird caponized would cost no more (if as much), would have more than doubled his weight and engendered a fat, juicy and tender flesh, it is an unanswerable argument upheld by the bird himself that all poultry-raisers cannot afford to do otherwise than caponize, and this argument is just as convineing for the table as for the market.

Caponizing makes fine birds from common stock; makes birds twice as large as, and double the weight of, ordinary fowls with the same amount of food, and turns the otherwise useless number of cockerels into a large source of profit.

\section{Feeding Capons.}

The question is often asked: "How are Capons to be fed?" The answer is easily given. After caponizing, give the bird all he will eat of soft feed, and let him have plenty of water. Caponized fowls begin to eat almost immediately after the operation is performed, and no one would think for a moment that a radical change had been made in their nature. Now leave the bird to himself, as for the time being he is his own doctor. It is well to look him over two or three days after the operation, as in breathing the air sometimes gets in under the skin, causing "wind puff," or a slight swelling, in other words. Simply prick through the skin at the sides with a sharp needle, gently pressing at the same time, when the air will be expelled and the Capon relieved. Within ten days from the operation it would be difficult to find where the incisions were made. A day or so after eaponizing the bird should be allowed to run at large, treating him just the same as any growing poultry would be treated.

\section{Caponizing is Not Cruel.}

A large number of persons hesitate in caponizing, feeling it to be cruel to the bird. To these we wish to bring our experience in this matter proving to the contrary. This is a greatly mistaken notion, and the operation bestows an unlimited amount of kindness on the bird, even if there were no other considerations or return. The writer has seen cockerels fly at one another time and again, tearing flesh and feathers with beak and cutting with spurs. Before the combatants could be separated there has been a disfigured comb, probably a blinded eye and a generally cut-up bird. This is the essence of cruelty.

After caponizing, the habits of the bird (as already noted) are entirely changed. Their disposition is quiet and peaceable, habits mild and tend- 
ing to a solitary life and perfectly contented wherever situated. They no longer chase about the farm spoiling for a fight and running off flesh as fast as put on. They no longer arouse the whole neighborhood from morning until night by their incessant erowing, but, on the contrary, become models of good dispositions, leading a quiet life that will surely bring large returns to the raiser. An operation that does away with so much inborn evil cannot be considered eruel.

With the proper instruments and eare this term should not be known. But so many beginners allow themselves to be hoodwinked by unserupulous traffickers in cheap and common so-called caponizing sets that it seems impossible to avoid this result.

\section{"Slips."}

A "Slip"' is neither Capon nor cockerel. He is much inferior to the former and a great deal worse than the latter. The "Slip" is caused by not entirely removing the testicles. The smallest fraction left in the bird will grow again with no benefit to himself, but rather a great trouble, as he incessantly chases the hens, and, while not a fighter himself, becomes the cause of numerons broils.

Either our Improved Caponizing Canula or Pilling Twisting Scoop, properly used, make the "Slip" an impossible factor.

\section{Points for the Learner.}

Our first advice would be "Keep cool and make haste slowly." If you are rather too tender-hearted, read the directions over carefully and then try your hand on a dead fowl. All surgeons do this in the first place, and probably it would be as well for you to follow their example. Have plenty of light. It is impossible to properly perform the operation unless you have this. Do not get nervous, you are not giving the bird one-half as much pain as you are giving yourself uneasiness. Have your instruments all in readiness, secure the bird properly, make the incision, insert the spreaders, pick open the film-like skin covering the bowels and go on in the operation with your thought entirely on it and not on the bird. After your first performance of caponizing you will be surprised at its simplicity, and, instead of heing a learner, will find that you have gained the lesson. Be very particular to see that your instruments are first-class, as the market is already being flooded with a cheap and worthless lot of caponizing instruments. It surely must be that such unscrupulous dealers are blind to the fact that they cannot sell a second set in the same locality, else they are satisfied to make all they can out of the first deal. Always keep your instruments in perfeet order. Before using the knife see that the edge is sharp, and that the other tools are as they should be. After beginning the operation of caponizing there should be nothing to hinder you from going right ahead. Use plenty of good common sense. This is an indispensable quality on any point. After caponizing once (or probably twice) you are a learner no longer, but master of the situation. There is no reason why everyone who reads this work should not be able to eaponize properly. To this end we have made it simple as possible, and yet at the same time sufficiently explicit and exhaustive.

The pre-eminent question asked by the learner is: "How long does it take to caponize a bird?" We would reiterate our first advic: "Make haste slowly." The first operation may take from fifteen to twenty minutes, but take your time, go slowly, but act quickly, note every point, keeping your thoughts intently on the work. The first operation is your instruction. After a little practice a bird ean be caponized in two minutes with the Philadelphia Caponizing Set or Pilling-Farmer Set. 


\section{Killing and Dressing Capons for Market.}

The Capon should be allowed to grow until at least one year old. By this time they are a beautiful bird and will have attained an imposing size. Some keep them even longer than a year. While this is optional with the raiser, yet we would not advocate killing them under one year old if they are being raised for market.

There is a great difference between the dressing of Capons and an ordinary fowl. Some writers enlarge in a very gilt-edge manner on this process. We shall endeavor to place the operation before you, shorn of all unnecessary adornment as to useless words. When the Capons are ready for market, select such as you propose killing and confino them. Keep them without food or water for about twenty-four hours before killing, that their crops may be entirely emptied. Now get ready your place for killing and dressing the fowl (if you have conveniences in the chicken-house this will do quite as well, or the woodshed, or any cool outhouse) and drive two heavy nails or wooden pins, about one foot or less apart, in an overhead beam. Make two nooses of strong string, each noose long enough to hold each of the legs and have the Capon hang low enough to pluck with ease. Have a weight of two or two and one-half pounds attached to a hook, and when the bird is killed, fasten this hook in his lower bill after you hang him up for plucking. The weight holds the bird in position while picking and renders the operation much more easy.

Next procure a table to dress the fowl upon, and make a frame on the saine principle as a small box without the ends and cover. In this you lay the Capon, back down, to remove intestines.

When everything is in readiness, take your Capon and suspend him by the two legs from the nooses. Catch hold of his head and with your French Poultry Killing Knife cut rein at back of throat through the mouth. Never ent this from the outside. Immediately upon cutting vein, run point of knife through roof of

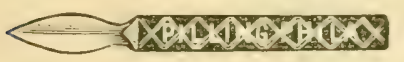

French Poultry Killing Knife. the mouth clear into the brain. "This operation causes what is termed "dropping the feathers," making them come off very easily. Soon as the knife enters brain the bird loses all sense of feeling. Begin plucking at once.

Now, the style of dressing. The feathers are left on the wings up to second joint, the head and hackle feathers, also on legs half way up to drumsticks, all the tail feathers, including those a little way up the back and the long feathers on hips close to tail. These feathers add greatly to the appearance of the bird when dressed and are also a ready marker from other fowls in markets. Never cut the head off, as this is a distinguishing feature $o_{1}$ the bird. A Capon may readily be identified among a thousand cockerels, as the comb and wattles of the latter ceased to grow immediately after caponizing was performed. Wash head and moith well with cold water, being eareful to remove all blood. A Capon should not be torn in plucking. There is no danger of this happening if proper care be taken. Now, take weight from the bird's mouth, and place him back downwards in the box frame already described. Cut carefully around the vent and pull out the intestines. These will be found covered with fat, which, as they are pulled out, should be pushed back. When the end of the intestines is reached, run your fingers up in the bird and break it off, leaving everything else in. As may be expected, the fat will be found very heavy around the opening, and, if slightly turned outward, will soon become hard, which will give a very rich appearance to this portion of the bird. Let the birds hang in a clean, cool place until thoroughly cold. F'or packing, use a new box of the required size, lined with white paper (any good, clean paper will do), pack the birds in solid, back up, being careful not to bruise them. Your 
birds are then ready for market. With a bird not torn and the feathers properly left on you have a fowl which for inviting and "taking" appearance it is impossible to equal.

\section{Breeds}

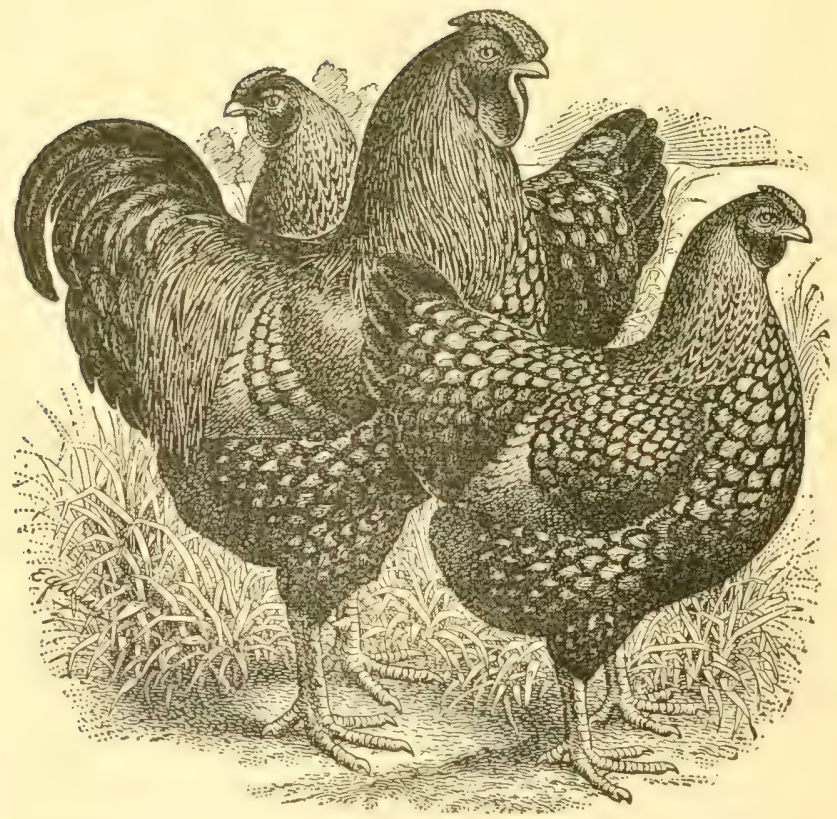

GOLDEN WYANDOTTES - THE BEAUTY BREED.

Headed by eockerel that scores 93 and mated with hens that score from 91 to 93 . Well mated and ought to product winners. Price $\$ 2.00$ per sitting of 15 , ex matings. Eggsfrom free range utility stock, $\$ 1$ per 15, $\$ 2$ per $30, \$ 3$ ver 50 , \$5per $100, \$ 10$ per 200 . 


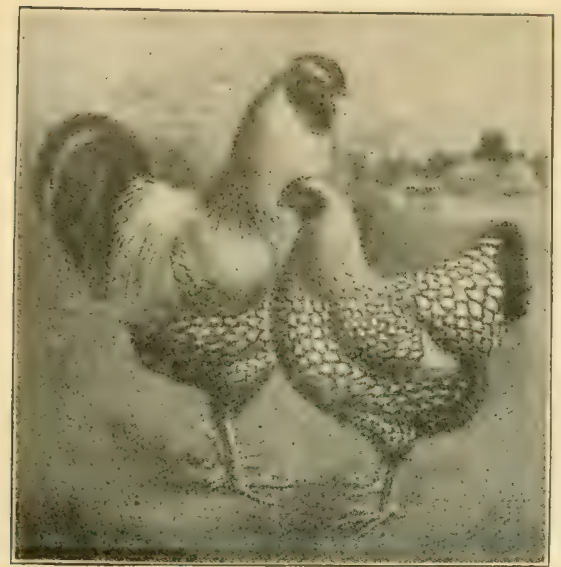

Silber Laced Wyandottes
DOTTES.

Headed by a cockerel that seores $921 / 2$ and mated with pullets that range from 90 to 93 . Price $\$ 2$ per sitting of 15 , exhibition matings. Eggs from free range utility stock, $\$ 1$ per 15, $\$ 2$ per $30, \$ 3$ per $50, \$ 5$ per 100 , $\$ 10$ per 200 .

\section{BARRED PLYMOUTH}

\section{ROCKS.}

Headed by cocks and cockerels that score from 90 to 94 and mated with hens and pullets that score 90 to 93. Eggs from exhibition matings, $\$ 9$ per $100, \$ 2$ per $15, \$ 3.50$ per $30, \$ 6$ per 50 . Eggs from free range utility stock, $\$ 1$ per $15, \$ 2$ per $30, \$ 3$ per $50, \$ 5$ per 100 , \$10 per 200.

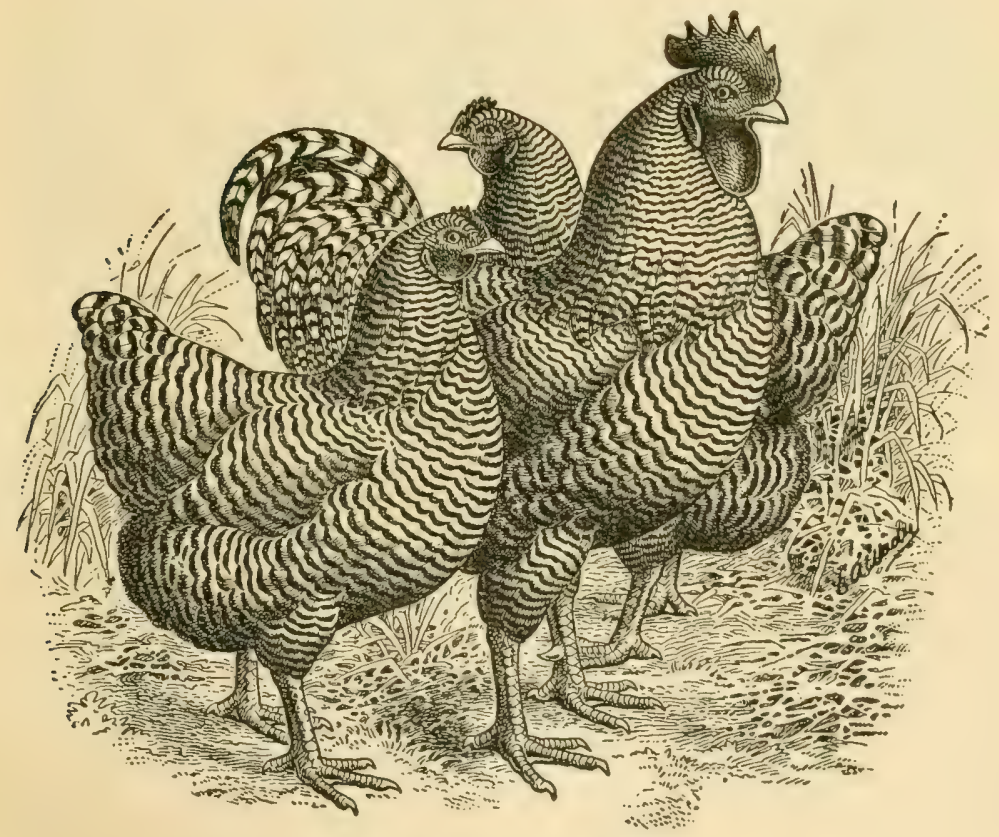

Barred Plymouth Rocks 


\section{BLACK IANGSHANS.}

Langshans were originally imported from China and are today one of the most popular breeds in the Orient. No variety of fowls ever gained popularity faster since their importation. The Langshans are large, stylish birds, with full, broad breasts, small wings and erect, small combs, their bright red wattles, ear lobes and combs glowing against their glossy black feathers, form a striking contrast.

The Langshans being as yet a comparatively new breed, command a large sale and it will pay to breed them. They are good layers, better than the average large fowls. Early hatehed pullets will begin laying ir early winter and continue laying throughout the whole winter and will lay reasonably well all spring and summer.

Price, chicks from general utility stock, $\$ 1.50$ per doz., $\$ 10$ per 100 . Exhibition stock, $\$ 18$ per $100, \$ 3$ per doz.

\section{BUFF LEGHORNS.}

Buff Leghorns are a comparatively new breed and are fast growing in popularity. They are very hardy, easily raised, quick to mature and great

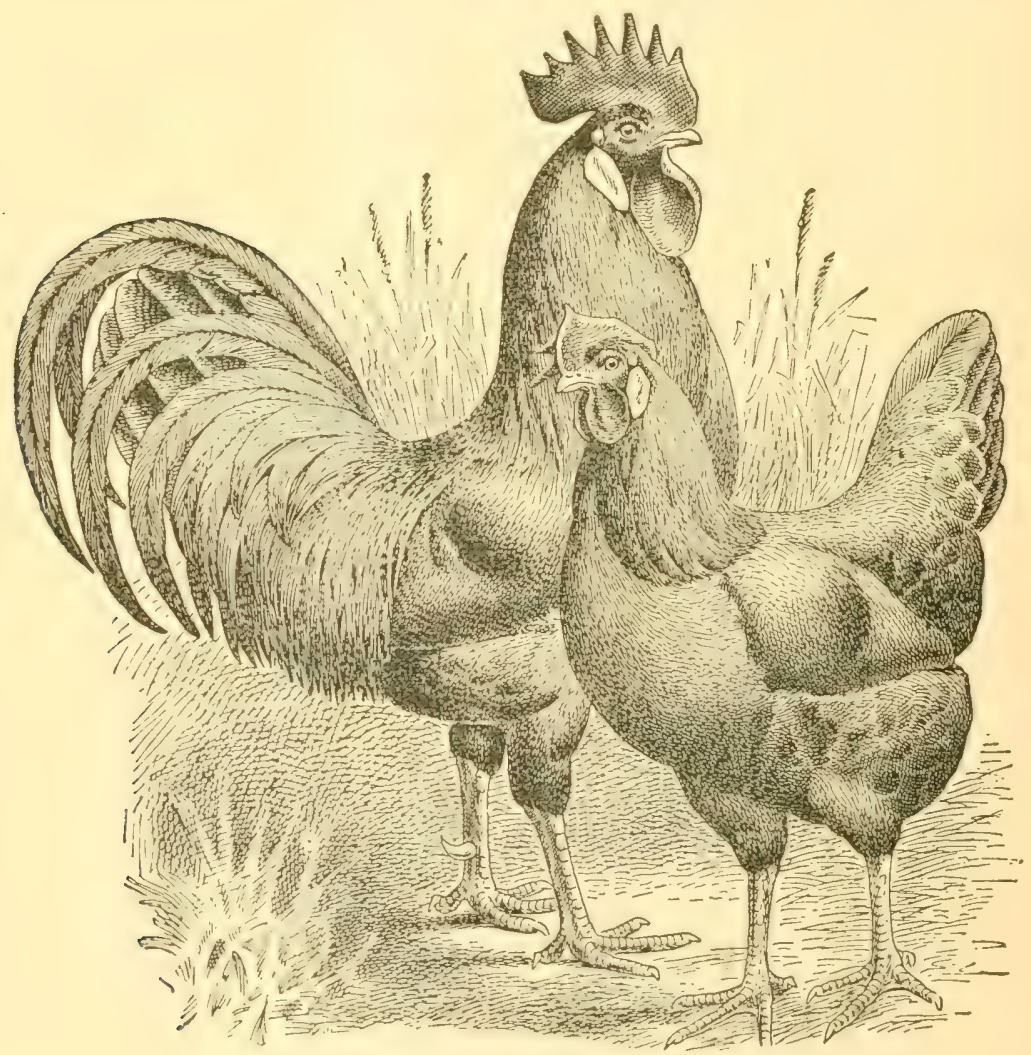

\section{Buff Leghorns}


rustlers. They belong to the Mediterrancan family, and in general eharaeteristies are the same as other varieties of Leghorns. They are of a rich buff color, a good table fowl, combs, wattles and face a bright red, creany white earlobes, beak and legs a rich yellow. They are very stylish and have a beautiful buff color, which makes a handsome appearanee. They are great layers when allowed to run. Our stock is of the best strains to be found in this country and I am sure no other breeder has better.

Headed by cockerels that score 93 and mated with hens that score from 91 to 93 , well mated and ought to produce wimners. Price $\$ 2$ per sitting of 15 , ex matings. Eggs from free range utility stock, $\$ 1$ per 15, $\$ 2$ per 30 , $\$ 3$ per $50, \$ 5$ per $100, \$ 10$ per 200 .

\section{PRICE OF STOCK.}

This varies according to the time of year I receive the order. Special prices are made in November to reduce the stock for winter.

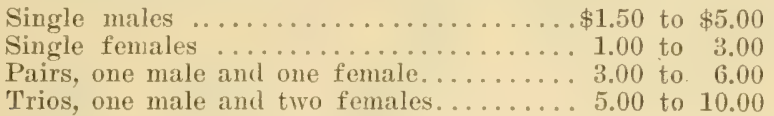

My prices may seem high, yet they are very low when the quality of stock is considered. In buying eggs for hatehing it is not the eggs you are paying for, but the stock they are expected to produce. In laying the foundation for a flock it pays to start right, as it costs but a little more to raise good thoroughbreds than scrubs. Inferior fowls as breeders are ciear at any price. A few dollars spent for good stock at the outset will come back to you over and over again in the long rum. When you are buying of me a pen consists of 1 male and 10 females, $\$ 22.00$

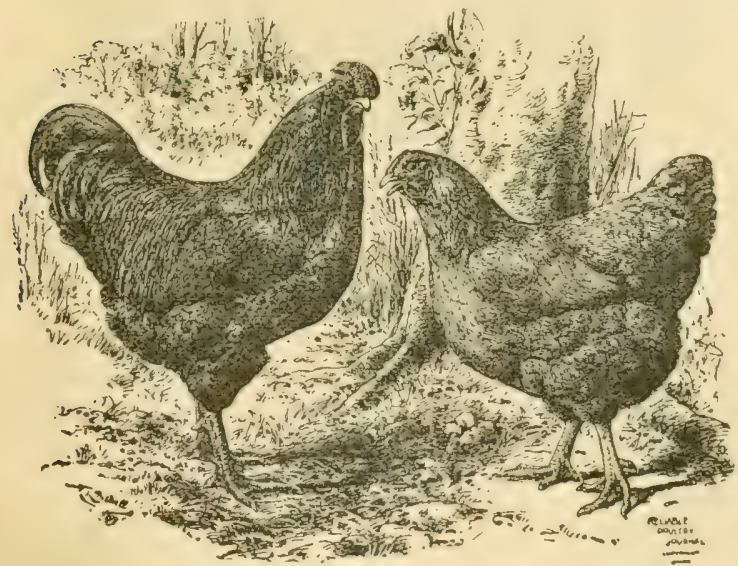

Buff Wyandottes
BUFF

WYANDOTTES.

Headed by cockerels that seore 93 and mated with hens that score from 91 to 93 , well mated and ought to prod uce winner's. Price, $\$ 2$ per sitting of 15 , ex. matings. $\quad \mathrm{E} g \mathrm{~g} \mathrm{~s}$ from free range utility stock $\$ 1$ per $15, \$ 2$ jer $30, \$ 3$ per $50, \$ 5$ yer 100 , $\$ 10$ per 200 . 


\section{IMAMMOTH IMPERIAL PEKIN DUCKS.}

The Best Duck Raised.

The Pekin variety, above all others, seems to meet the market want best. They are the most popular, as well as the most profitable duck we have in this country. They are very large, creamy white, laying from 100 to 150 eggs each season. They are, as a rule, very easy to raise, mature

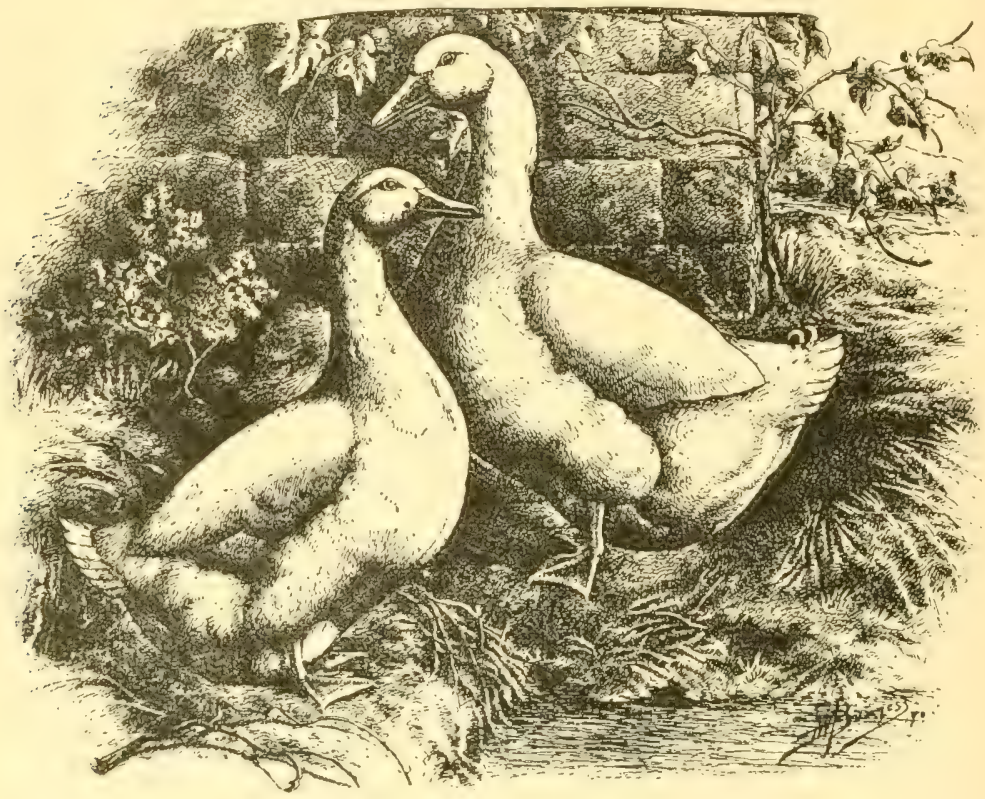

Mammoth Imperial Pekin Ducks

quickly, and are the leading variety for market; do not require water except for drinking. Pekin ducks are, as a rule, very healthy, not being subject to many of the diseases that ponltry are heir to. The demand for Pekins was never so large as during the past year; thus proving their popularity, and that people realize that there is money in duck eulture. We have taken great pains in selecting our breeders and have been trying to improve them by increasing depth of keel and forepart of bodies; our breedings birds are, as a whole, very deep bodied. This type of ducks will be the plumpest and most attractive when dressed. When mating breeding ducks in November and December, you should provide a drake for every five ducks; later in the season a drake may have six or seven ducks.

Prices, single birds $\$ 3$, pairs $\$ 5$, trios $\$ 7$; pen, 1 male and 4 females, $\$ 10$. Eggs, $\$ 1.50$ per $11, \$ 2.50$ per $22, \$ 4$ per $50, \$ 7$ per 100 . 
In many ways this machine is easily our most popular incubator. It is large enough to take in 264 hen eggs or 220 turkey or duck eggs without crowding. Our safety appliances make this style as nearly automatic as

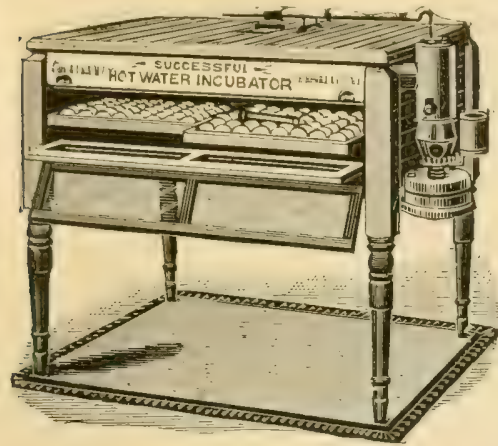
it is possible for an incubator to be. There is really nothing to do except keep the lamp cared for and the water tank filled.

The tubular form of water tank used in our hot water machines is far superior to the flat tank system. They are made of 14-ounce copper, and with reasonable care will last a lifetime. The heating tube is of brazed copper, making it as durable as if one solid piece.

There is no soldering to melt and cause leaks. The system of ventilation is all that could be desired, and the egg chamber is furnished with a constant supply of warm fresh air.

Each machine is supplied with a patent safety lamp, patent wafer thermostat regulator, drying nursery for chicks, thermometer, extra egg trays and egg tester. You can make no mistake in ordering this machine for your own use. A complete direction book accompanies each machine.

The Successful Incubators are the most economical in consumption of fuel, and no other incubator is so completely automatic in its action as to recpuire no oversight except filling the lamp and turning and airing the eggs. Price No. 4, \$28.00.

\section{LIGHTNING LICE KILLING MACHINE.}

This popular machine does the work in an hour that it takes a day to do by hand. It is a great invention for poultrymen, saving both time and insect powder. By using this machine and our insect powder there is no need

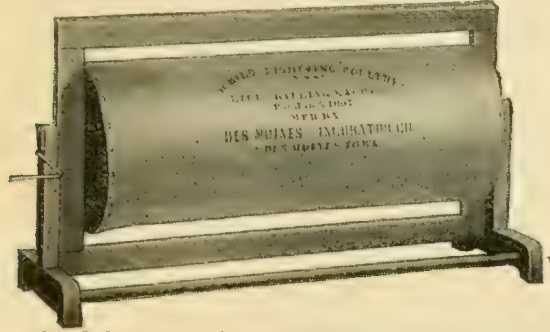
of your chicks having lice. The Lice Killing Machine will kill all the body lice on your fowls or chicks by simply placing them into the machine together with a small quantity of powder scattered over them. By turning the crank slowly for a few times the work is done. Do the same with your lousy fowls. It is no work to clean 1,000 fowls with this machine, as all the work required is emptying and filling with poultry. There is no waste of powder or any filth connected with it.

This machine will kill lice from poultry, pigeons, turkeys, geese, ducks, cage birds, or anything that wears feathers. A one-half pound can powder goes free with every machine that we ship.

The No. 1 is made for cleaning cage birds, little chicks and mother hens. This size will hold three to five brood chickens at a time.

No. 2 standard size, used by poultrymen in general, is for all sizes of chicks and fowls. This size will hold 100 chicks or twelve fowls at a time.

No. 3 , the turkey size, is used to elean fowls of any size, but is made for turkeys and geese. 
Prices, with sizes and weights are as follows:

\begin{tabular}{l|ll|ll|ll|r}
1 & $91 / 2$ & inches & 28 & inches & 10 & pounds & $\$ 2.50$ \\
2 & 12 & inches & $291 / 2$ inches & 15 & pounds & 3.00 \\
3 & 20 & inches & $291 / 2$ inches & 20 & pounds & 4.00
\end{tabular}

\section{SPRAI'T'S PATENT POULTRY FOOD.}

\section{The Cheapest and Best on the Market.}

It is neither a medicine nor a condiment, but a specially prepared food, containing all ingrenlients neessary to develop and l,ring chicks to the highest state of perfection. It is thoronghly cooked and easily digested.

To rear successfully and bring chicks to the highest state of perfection, they must have, during their early days, a cooked food, and must not be overfed on grain. They require a food composed of cereals, meat, vegetalbles, home, and shell in julleins mombination. Such is suratt's Patent Poultry Food. There is nothing like it for young chicks. Ion will rear nine wat of exery ten hatrhesh, if you use this foul and kere the ehicks free from lice.

Directions:-Three parts meal, one part water, mixed up crumbly moist; not too dry, but not slopiny.

Price:-5-pound hag, 50 cents; 10-pound bag, $\$ 1.00$; 25-pound bag, $\$ 2.00 ; 100$-pound "bag $\$ 6.00$.

The directions for feeding this meal are very simple because it is a well balanced ration which has been thoroughly cooked, and therefore, is easily digested. After the chickens are hatched, let them remain in the brooder undisturbed, or under the hen for about twenty-four to thirtysix hours, and then as a first meal give them a little of the chick food, slightly moistened, not so as to make it sloppy but with just sufficient water to make it crumbly moist. A dozen or more chicks will only require about a teaspoonful or two at each meal because they eat very little for the first day or two.

There are as many different ways of rearing young chicks as there are for rearing infants, but I advise five meals a day and believe that it is best to feed the Spratt's Chick Meal for the first meal and then give them mixed grain for the next, such as finely cracked wheat with a little millet, canary seed, cracked corn, or something of that kind, for the third meal give Spratt's, the fourth the mixed grain, and the fifth Spratt's.

There are a great many breeders who think that chicks should be reared entirely upon dry food. If you believe in this theory, feed Spratt's Chick Meal perfectly dry, only be careful that very little is given at a time because it swells so much when moisture is applied and after it reaches the crop in the dry form.

Spratt's Chick Meal is a food in the true sense of the word. It is a condiment, medicine, or spice. It is beyond doubt the best food ever invented and will rear larger, finer and hetter chicks than any other. Besides this, it ureatly reshees the pereentage of mortality in the flock, and diarrhest and bowel tromble is almost muknown and unheral of where the birls are regularly and properly fed on this food if the temperature of the brooder is what it should be and cleanliness is observed. When I say cleanliness, I allude as much to lice as anything else.

Spratt's Patent Poultry Food No. 3 which is for the adult forl, materially increases egg production and produces eggs at a season of the year when they are very scarce. Besides this, it increases the percentage of fertility and it gives you stronger and healthier chickens.

If there is any further information that you require on the subject, I shall be pleased to have you write direct if you wish to do so, and you will be at any time welcome to the benefit of my experience.

Mrs: B. F. Wilcoxon, Agent. 
A cheap and effective remedy for all kinds of poultry vermin, lice on horses, cattle, swine, or plants, fleas on dogs, ticks on shcep, moths, bedbugs, roaches, etc.

6 ounce package postpaid 50 cents; 15 ounce package postpaid $\$ 1.00$.

\section{LICE PAINT.}

A Safe and Sure Liquid for Killing all Insects Affecting Poultry or Stock.

Lice Paint is a liquid lice destroyer especially prepared for killing insect parasites of poultry. It is also useful for killing lice, mites and ticks affecting horses, cattle, sheep and hogs. It is safe and easy to use, and at the same time stronger than any other lice killer, as it is not diluted with cheap adulterations which would impair its effectiveness. It does the work and does it economically.

How to Use It. To free fowls from lice, thoroughly paint or spray the roosts and droopings boards in the poultry houses oceupied by the fowls to be treated. The fumes rising from the paint kill the mites and lice on the fowls while the birds roost at night. The fumes of the lice paint, while fatal to parasites, are not injurious to fowls.

1-quart cans, each, 35 cents; 2-quart cans, each-60-cents; 1 -gallon cans, each \$100.
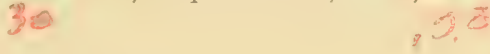

\section{ROUP CURE.}

Will cure all discharge of the nostrils, rattling of the throat, swelled head, colds, or any of the various symptoms of roup which fowls are subect to, it is put in the drinking water and the fowls take their own medicine. One 50-cent package makes 25 or 30 gallons of medicine.

Price, 50 cents and one dollar per bottle, postpaid.

\section{POULTRY INVIGORATOR AND EGG PRODUCER.}

NO EXPERIMENT, has been thoroughly tried and tested. Prepared especially for me by a registered ehemist. Condition powder for old and young stock. No filling, aids in the moulting season. Keeps hens healthy by preventing disease; it is stronger than the condition powders you are now using. But one rounded tablespoonful is given in the mash to 30 hens. Used daily it costs about one cent per month per hen. It not only keeps the fowls in good condition but will increase the egg yield to a remarkable extent if used aceording to directions. 2 -pound package 50 cents; 5 pounds, $\$ 1.00$.

\section{A FAT PRODUCER.}

It greatly aids in producing fat. If you want to fatten birds for the market, you can not afford to be without this; no bogus material, this is prepared by a state chemist.

2-pound package 50 cents; 5 pounds $\$ 1.00$.

\section{MY NEW METHOD FOR PRESERVING ŁGGS.}

If you have an egg or fancy poultry farm, pack your surplus eggs out of breeuing season. You cannot afford to be without it. Pack your eggs and profit by the high prices during the winter. Don't wait until eggs 
get cheap to begin business, but put up some eggs as soon as possible, if only a few dozen, to show you what you can do. Don't be afraid to invest your surplus money in eggs. Don't put it off because eggs are high, try it and if you try once you're started then and will be sure to make money. Some people say "I would try it only it takes two or three dollars. What if it does? Don't expect to make money without any investment. You can't raise a crop without sowing seed and that costs money. A few dollars invested in starting in the egg business will make you more than one or two hundred dollars in seed for a farm crop. You can pack eggs from time to time, in jars, kegs, barrels, ete, and place in cellar, cave or shady place. Eggs preserved in this way may be kept two years if necessary, absolutely fresh.

Prices.

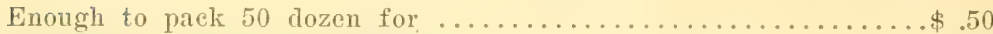

Enomeh to park lou dozen for . . . . . . . . . . . . . . . .

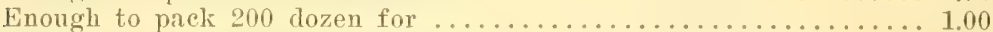

Enough to park fou doren for .........................

Enough preservative to pack 50 dozen by mail, postpaid......... .50

On all other orders over this by express at purchaser's expense. My New Method is sold direct only. 


\section{THE PHILADELPHIA CAPONIZING SET}

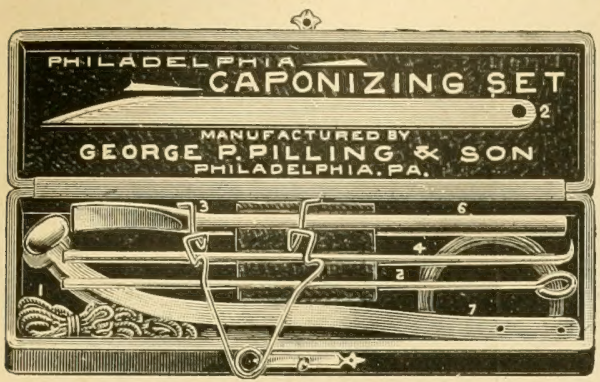

\section{PRICE}

Complete with

instructions ......\$2.50

Complete with in-

structions, in Velvet

lined case, as per

Engraving........ 2.75

\section{Squab French Killing Knife}

Same style as Poultry Knife, but size for squabs. Sent on receipt of price 50 cents.

\section{Pilling Angular Poultry Killer}

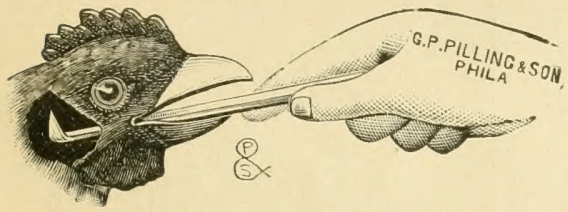

The use of this knife is so simple that the most inexperienced can do the work of an expert in killing poultry. By simply turning the wrist the jugular vein and spinal cord are cut, thereby bleeding the fowl, allowing the feathers to be removed without using water. 50 cents net, postpaid.
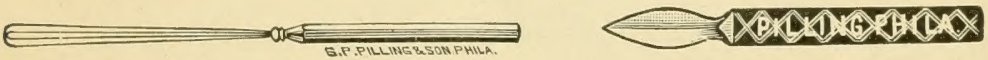

PHILADELPHIA GAPE WORM EXTRACTOR POSTPAID, 25e EACH

$$
\text { French Poultry Killing Knife }
$$

The Pilling Farmer Caponizing Set
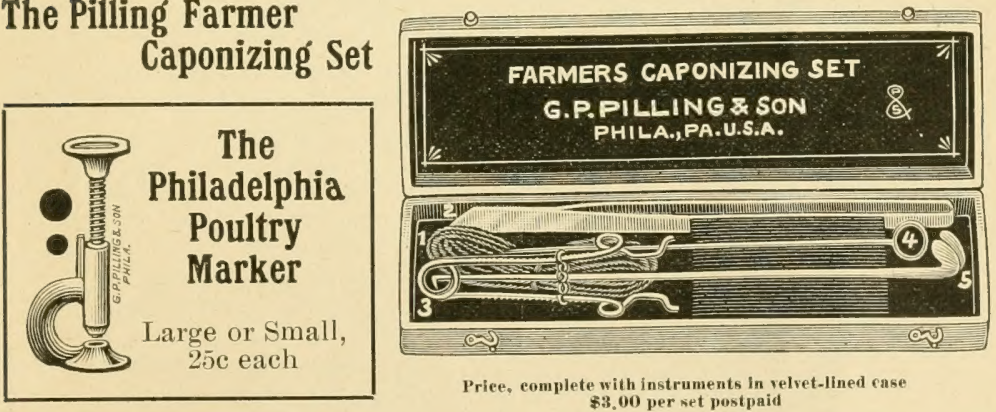

MRS. B. F. WILCOX0N, Fort Des Moines, Iowa, Agent. 
A

Air, Let in the Fresh..... . 22

Airing Ineubator Eggs.... 36

Apoplexy, Treatment for.. 49

$\mathrm{B}$

Breed, Keeping one..... 8

Bone, Green For Poultry . . 30

Bran, Feeding ......... 31

Brooder, Management of.. 35

Breeding Stock, Prices of. . 73

Bronchitis .......... 49

Birds that Pay ....... 57

Beginners, Helps to..... 58

Breeds ............. 70

C

Characteristies of Poultry$\operatorname{man} \ldots \ldots \ldots \ldots \ldots 4$

Culling ............ 11

Cooping ........... 21

Chickens, Winter ....... 25

Chickens, Summer ...... 27

Chickens, Food and Care. 30

Comfort of Fowls ...... 30

Chicks, Growing ........ 44

Cholera ............ 47-8

Cleanliness .......... 55

Caponizing, Directions for. $62-5$

Caponizing not Cruel .... 67

\section{D}

Ducks, Mammouth Imperial Pekin ........... 74

Douglas Mixture ........ 48

Diarrhea ............ 50

Directions for Caponizing. 62 $\mathrm{E}$

Eggs, Airing ........ 36

Egg-eating ......... 52-3

Egg Producer .......... 77

Egg Preserver, new ..... 77

$$
\text { F }
$$

Flock, How to Improve... 8

Fall Care of Poultry.... 24

Food and Care ......... 30

Fowls, Comfort of ..... 30

Fattening Fowls ........ 33

Feather rlucking ......... 53

$$
\text { G }
$$

Green Food ........... 31

Gapes ............ 46

\section{$\mathrm{H}$}

Hens, Keeping $1000 \ldots \ldots .15$

Houses, Cheap ......... 16

Houses and Yards ....... 18

Helps to Beginners ..... 58

Insect Pests .......... 45

Incubator Don'ts ....... 37

Improve Flock, How to... 8
K

Killing and dressing Cap-

ons ...............

Line Breeding ....... 11

Lice and Mites ....... 46

Lice Paint ........... 77

Langshans, Blac ....... 72

Leghorns, Buff ....... 72

Lice Killing Machine.... 75

MI

Moulting, Process of...... 28

Mites-Red-and Lice.... 46

Mrs. B. F. Wilcoxon's

"New Remedies.", . 77

$\mathrm{N}$

Notes by the Way....... 53

New Remedies, Mrs. B. F. Wileoxon's ....... 77 $\mathrm{P}$

Poultry Talks to Farmer.. 5

Poultryman's Opportunity. 7

Poultry, Green Bone for.. 30

Plan for Brooder House. . 39

Poultry Invigorator...... 77

Profits in Capons ....... 61

Points for the earner.....6.68

Plymouth Rocks, Barred.. 71

Price of Breeding Stock.. 73 Q

Quarters Ior Young Stock. 22 $\mathrm{R}$

Roup ............45-77

Remedies, Mrs. B. F. Wilcoxon's ......... 77

$$
\mathrm{S}
$$

Summer Care of Poultry. 24

Shade and Water....... 27

Sore Head or uncken Fox. 48

Stoek, Price of Breeding. . . 73

Scaley Legs .......... 49

$$
\mathrm{T}
$$

Temperature, Variations in 50

Time, Best to Caponize.. '60

Table, Operating $\ldots \ldots \ldots \quad 66$

U

Utility, Pure Breeds for.. 9

Uniformity of Heat...... 42 $\mathrm{V}$

Variety, Keeping One .... \&

variations in Temperature 50 W

Women as Poultry Keepers 6

Winter Chickens ....... 25

Water and Shade ....... 27

$\mathrm{Y}$

Yards, Cheap Houses and. . 16

Yards and Houses....... 18

Young Stock, Quarters for 22 


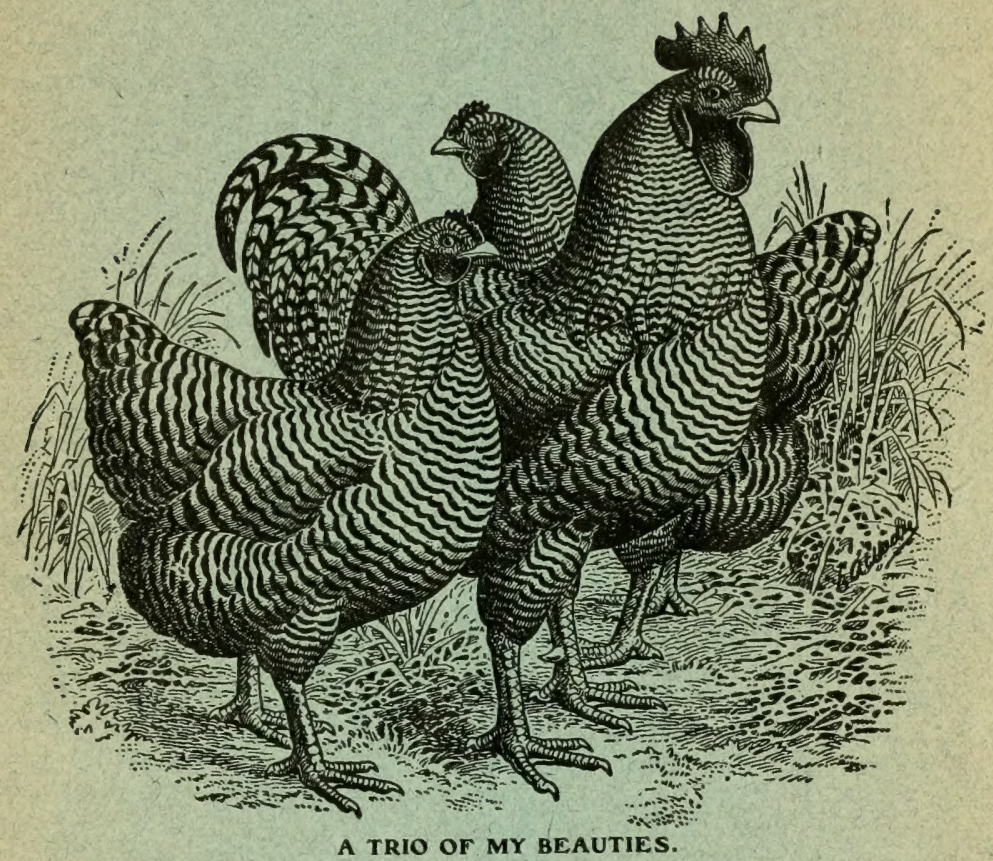

This is what you will get

If you order birds of

\section{Ft. Des Moines Poultry Farm.}




\section{LIBRARY OF CONGRESS}

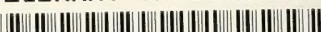

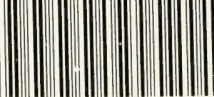

00028496400 